Concepção e implementação de um modelo de coordenação para uma plataforma de visualização exploratória 
SERVIÇO DE PÓS-GRADUAÇÃO DO ICMC-USP

Data de Depósito:

Assinatura:

\title{
Concepção e implementação de um modelo de coordenação para uma plataforma de visualização exploratória ${ }^{1}$
}

\author{
Vilson Moreno
}

Orientadora: Profa. Dra. Maria Cristina Ferreira de Oliveira

Dissertação apresentada ao Instituto de Ciências Matemáticas e de Computação - ICMC-USP, como parte dos requisitos para obtenção do título de Mestre em Ciências de Computação e Matemática Computacional.

\section{USP - São Carlos \\ Março/2005}

\footnotetext{
${ }^{1}$ Este trabalho conta com o apoio financeiro da Fapesp.
} 


\section{Agradecimentos}

Primeiramente, gostaria de agradecer à minha mãe, Neusa, que sempre esteve ao meu lado durante essa caminhada. Ao meu pai, Vilson, pelo apoio dado nos momentos em que mais precisei.

Á todos os meus amigos, estejam onde estiverem. Vocês sabem que são as coisas que mais prezo nessa vida.

À minha orientadora, Cristina, por tudo o que tem feito fez nesses dois anos para que esse trabalho se concretizasse. Obrigado pela sua dedicação e paciência.

Aos meus professores por tudo o que vocês me ensinaram. Agradecimentos especiais ao Eraldo Marinho que sempre me apoiou e me incentivou a continuar os estudos na carreira acadêmica.

Á USP pela oportunidade.

Ao CNPq e a FAPESP pelo apoio financeiro. 


\section{Sumário}

AGRADECIMENTOS ............................................................................................ I

SUMÁRIO ............................................................................................................. II

LISTA DE FIGURAS ......................................................................................IV

RESUMO ...................................................................................................... VI

ABSTRACT ................................................................................................... VII

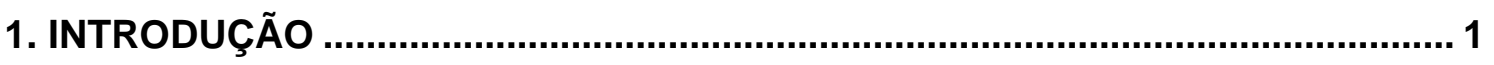

2. VISUALIZAÇÃO E COORDENAÇÃO .................................................................. 3

2.1 Técnicas de Visualização ..............................................................................................................................................3

2.2 Múltiplas Visualizações ..................................................................................................................................................

2.3 Coordenação

2.4 Sistemas de Visualização e Coordenação .....................................................................................................10

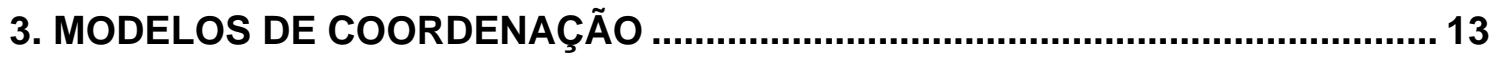

$3.1 \mathrm{O}$ modelo proposto por North....................................................................................................................13

3.2 O modelo proposto por Boukhelifa ............................................................................................................................18

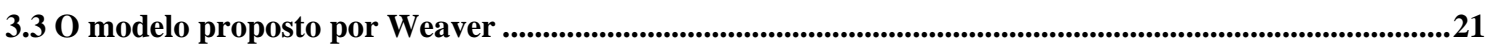

3.4 Considerações Sobre os Modelos.........................................................................................................................26

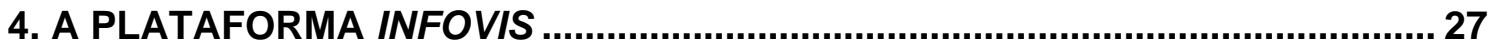

4.1 Características - Versão Original_..............................................................................................................................27

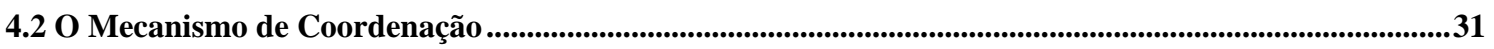


5. O MODELO DE COORDENAÇÃO

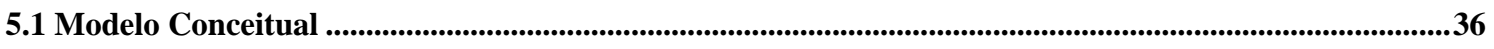

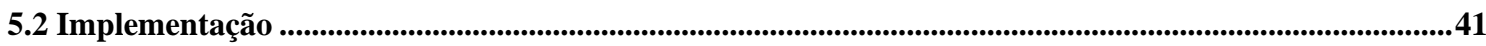

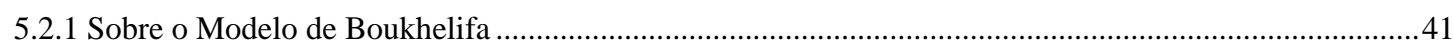

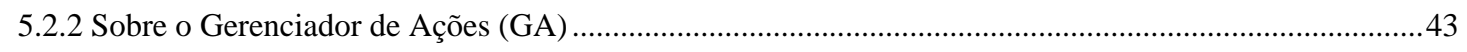

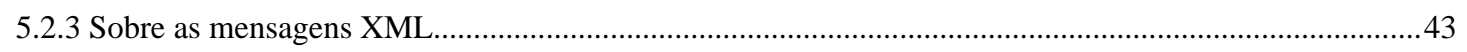

5.2.4 Sobre a definição dos Componentes Funcionais ....................................................................................45

5.2.5 Sobre a definição de novos tipos de coordenação ................................................................................48

6. CENÁRIOS DE USO................................................................................... 49

6.1 Interface com o Usuário e Definição de Coordenações..........................................................................49

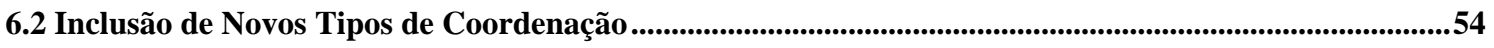

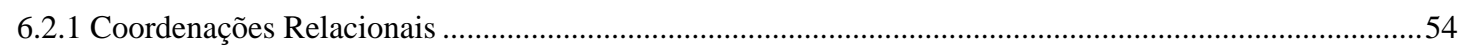

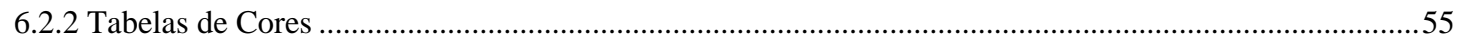

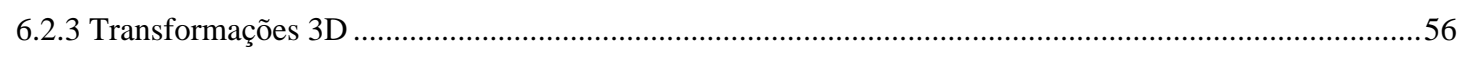

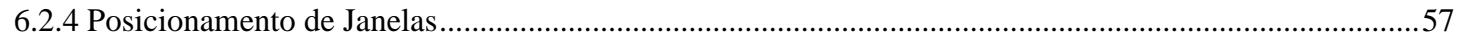

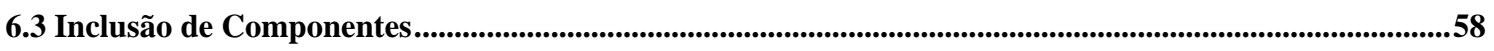

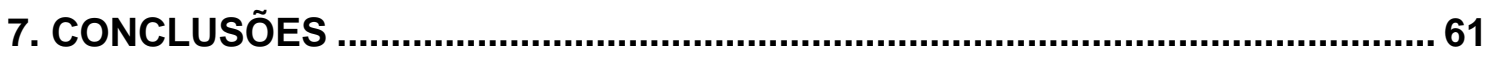

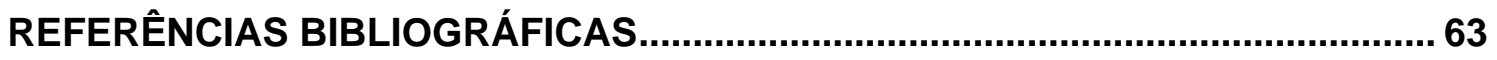

ANEXO A - CÓDIGO EXEMPLO DE COMPONENTE FUNCIONAL ......................66 


\section{Lista de Figuras}

Figura 2.1 Técnica de Coordenadas Paralelas. As linhas vermelhas representam os registros selecionados pelo usuário. Gerada no XmdvTool [War 1994].

Figura 2.2 Técnica de Matriz de Gráficos de Dispersão com a mesma seleção da Figura 2.1. Gerada no XmdvTool [War 1994].

Figura 2.3 Exemplo de utilização da técnica Treemap. A região em amarelo apresenta a seleção atual do usuário. Gerada no Snap [Nor 2002a].

Figura 2.4 Exemplo de aplicativo que utiliza múltiplas visualizações, destacando as coordenações.

Figura 3.1 Modelo conceitual do Snap e analogia com o modelo relacional. Adaptado de [Nor 2000a]

Figura 3.2 Exemplo de aplicação para exploração de estruturas de arquivos com três visualizações coordenadas, utilizando o Snap [Nor 1999].

Figura 3.3 Esquema de coordenação referente a aplicação para exploração de arquivos 16

Figura 3.4 Camadas da arquitetura do Snap. Adaptado de [Nor 2002]...

Figura 3.5 Modelo conceitual proposto por Boukhelifa [Bou 2003].

Figura 3.6 Fluxo de dados em uma aplicação com quatro visualizações coordenadas e suas respectivas funções de tradução.

Figura 3.7 Modelo de coordenação direta por Weaver [Wea 2004].

Figura 3.8 Modelo de coordenação indireta usando consultas coordenadas proposto por Weaver [Wea 2004].

Figura 3.9 Aplicação desenvolvida no sistema Improvise, destacando os seis mecanismos de coordenação utilizados [Wea 2004]..

Figura 3.10 Esquema de coordenação envolvendo controles [Wea 2004].................................. 25

Figura 3.11 Esquema de coordenação de navegação (scrolling) sincronizada [Wea 2004].......... 25

Figura 4.1 Visão geral da arquitetura do InfoVis [Shi 2004]................................................... 29

Figura 4.2 Exemplo de uso da plataforma InfoVis apresentado sua interface principal e duas visualizações coordenadas.

Figura 4.3 Interface do Gerenciador de Dados exibindo as tabelas presentes no Banco de Dados e suas chaves.

Figura 4.4 Interface para definição das manual das chaves primária e estrangeira. 34 
Figura 5.1 Esquema de ativação das ações em um OC

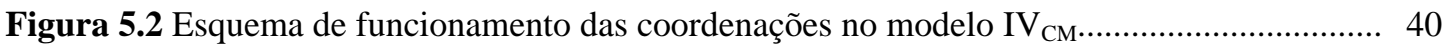

Figura 5.3 Área de interface do GA indicando três OCs ativados........................................... 43

Figura 5.4 XML Schema das mensagens trocadas pelos componentes................................. 44

Figura 5.5 Exemplos de mensagens XML utilizando como parâmetros chaves de identificação (a) e atributos de uma tabela de cores (b) ........................................................................ 45

Figura 6.1 Interface principal do InfoVis ilustrando os componentes gerenciadores (GD: Gerenciador de Dados, GC: Gerenciador de Componentes, GA: Gerenciador de Ações e GH: Gerenciador de Históricos.

Figura 6.2 Interface para escolha das ações coordenadas.............................................. 51

Figura 6.3 Interface de um OC contendo duas ações acionadoras e duas ações acionadas.......... 52

Figura 6.4 Interface para definição de chaves primárias e estrangeiras..................................... 53

Figura 6.5 Esquema de coordenação utilizando chaves estrangeiras apresentando também a relação entre as tabelas......

Figura 6.6 Exemplo de mensagens XML para coordenacoes utilizando transformações 3D (a) e para coordenações envolvendo reposicionamento de janelas (b)

Figura 6.7 Exemplo de uso da platafortma com o componente Treeminer. 


\section{Resumo}

Técnicas de Visualização Exploratória acopladas a estratégias de interação podem ser muito úteis para apoiar processos de descoberta de conhecimento a partir de dados. Múltiplas visualizações de um mesmo conjunto de dados permitem observá-lo sob várias perspectivas, bem como explorar os pontos fortes e minimizar o efeito dos pontos fracos de técnicas específicas. Nesse contexto, é interessante que as múltiplas visualizações estejam coordenadas de forma que ações de interação executadas pelo usuário sobre uma delas possam ser propagadas para as demais durante as etapas exploratórias. Um aspecto complexo do projeto de ferramentas de visualização é justamente como acoplar representações visuais e controles interativos de maneira flexível. Esse projeto de mestrado abordou a concepção e implementação de um modelo de coordenação de ações capaz de tratar a coordenação entre múltiplas visualizações de forma genérica e flexível. Para isso, foram estudados alguns modelos de coordenação descritos na literatura e utilizados em Sistemas de Visualização de uso geral. O modelo proposto foi implementado no InfoVis, uma plataforma de software extensível que incorpora múltiplas técnicas de visualização exploratória, em desenvolvimento no ICMC-USP. 


\begin{abstract}
Exploratory Visualization techniques in association with interaction techniques provide useful tools to support knowledge discovery processes from raw data. Multiple visualizations of the same data set allows users to observe the data from multiple perspectives, so as to make the most of the strengths of each technique, while minimizing their weaknesses. In this context, in exploratory processes it is interesting to coordinate the multiple visualizations, so that user interaction actions on one visualization are reflected in the remaining ones, thus reducing the cognitive load on the user. A complex aspect in the project of visualization tools is how to connect visual representations and interactive controls in a flexible way. This work approaches the conception and implementation of a coordination model capable of handling multiple visualizations in a generic and flexible manner. In order to accomplish this, some coordination models described in recent works in the literature and used in multi-purpose Visualization Systems were studied. The proposed model was implemented in InfoVis, an extensible software framework that incorporates multiple exploratory visualization techniques under development at the ICMC-USP.
\end{abstract}




\section{Introdução}

Com o objetivo de tornar os processos de análise e descoberta de informações a partir de dados mais eficientes, é importante inserir o ser humano no processo de exploração, combinado a flexibilidade, criatividade e conhecimento geral dos seres humanos com a grande capacidade de processamento e armazenamento dos computadores atuais. A idéia básica da visualização exploratória (Visual Data Exploration - VDE) é apresentar os dados em algum formato visual, proporcionando ao ser humano uma melhor percepção dos dados e dos fenômenos que eles representam, de modo a obter conclusões rapidamente e manipular diretamente os dados [Kei 2002]. Técnicas de visualização permitem aos usuários uma exploração interativa dos dados, na busca por características importantes como tendências, padrões e exceções. O suporte visual pode resultar em uma exploração rápida, com melhores resultados e com grau maior de confiança em relação a processos automatizados.

A visualização é uma linha de pesquisa que foi apresentada pela primeira vez em um relatório para a fundação de pesquisa norte-americana NSF em 1987 [McC 1987]. A sua definição, segundo Card, Mackinlay e Shneiderman [Car 1999], consiste no uso de representações de dados visuais interativas e auxiliadas pelo computador para ampliar a cognição. A visualização é, usualmente, categorizada como Visualização Científica, cujas técnicas manipulam conjuntos de dados que possuem uma representação espacial inerente; ou como Visualização de Informação, cujas técnicas manipulam conjuntos de dados abstratos cuja representação espacial não é inerente, mas sim atribuída no processo de mapeamento visual.

Os princípios básicos do processo de VDE podem ser resumidos pelo chamado Information Visualization Mantra [Shn 1996], que consiste em três passos básicos: apresentar primeiramente uma visão geral dos dados, filtrar e focalizar os dados de maior interesse, e fornecer detalhes adicionais sob demanda do usuário. Pode-se observar que, em todas etapas, a interação se faz necessária, tanto para navegar pela visão geral com a finalidade de focalizar os dados mais relevantes, como para escolher os elementos de interesse para obter um maior nível de detalhe sobre os mesmos. Algumas dessas interações podem operar sobre múltiplas visualizações, cada uma podendo revelar diferentes aspectos dos dados e diminuindo a sobrecarga cognitiva associada a uma única visualização mais complexa.

A coordenação entre múltiplas visualizações é um recurso poderoso para apoiar a interação do usuário durante um processo de exploração visual. Por exemplo, o ato de selecionar um grupo de elementos em uma visualização, se coordenado com a seleção e realce dos 
elementos correspondentes em outra pode revelar novas relações, como distribuição, agrupamento ou subordinação entre esses itens, que de outra forma poderiam permanecer ocultas [Bou 2003]. O estabelecimento de um modelo que defina como ocorrem essas coordenações é importante para formalizar a troca de informações entre as visualizações, dessa maneira especificando o que pode ser coordenado e como.

O objetivo deste projeto de mestrado consistiu em propor um modelo de coordenação, com base no estudo de modelos já existentes, e incorporá-lo à plataforma de Visualização de Informação InfoVis, em desenvolvimento no ICMC. O InfoVis tem por objetivo proporcionar uma plataforma genérica, flexível e extensível que ofereça diversas técnicas de visualização, que possam ser configuradas pelo usuário em ambientes personalizados de exploração visual (Processos FAPESP 2001/07566-2 e 2004/09888-5). O mecanismo de coordenação implementado na versão atual [Shi 2004] é bastante restrito e ad hoc, pois não é apoiado por um modelo de coordenação subjacente.

Esta dissertação está organizada da seguinte maneira: no Capítulo 2 são apresentados alguns conceitos básicos associados ao uso de múltiplas visualizações: como e quando utilizálas, no que consiste a coordenação, e os possíveis níveis de flexibilidade em sistemas de visualização, em termos de técnicas de visualização e de estratégias de coordenação. Alguns sistemas de visualização são discutidos para ilustrar o surgimento e a evolução de modelos específicos para tratar a questão da coordenação. Três desses modelos de coordenação são estudados em detalhes no Capítulo 3. O Capítulo 4 apresenta a plataforma InfoVis, cujo arcabouço básico é resultante de uma tese de doutorado desenvolvida no ICMC [Shi 2004]. Serão apresentados suas características principais, seu estágio atual de desenvolvimento e as restrições do mecanismo de coordenação original, ressaltando a necessidade de um modelo mais genérico para tratar a coordenação entre técnicas na plataforma. Nesse mesmo Capítulo destacaremos outras alterações feitas à plataforma relativas ao acesso aos dados e aos componentes funcionais.

$\mathrm{O}$ modelo de coordenação $\mathrm{IV}_{\mathrm{CM}}$ é apresentado no Capítulo 5, ilustrando sua base conceitual, características principais, e detalhes de alguns aspectos de sua implementação. No Capítulo 6, são encontrados alguns exemplos que ilustram o funcionamento da plataforma e procuram avaliar o modelo de coordenação com respeito a interface de uso, a flexibilidade em se definir novas coordenações e a facilidade de inclusão de novos componentes. Por fim, as conclusões deste trabalho são apresentadas no Capítulo 7. 


\section{Visualização e Coordenação}

Neste capítulo, primeiramente são apresentadas, a título de ilustração, algumas técnicas de visualização de uso geral: Coordenadas Paralelas, Gráficos de Dispersão e TreeMaps. Deve-se ressaltar que não se trata de uma revisão sobre técnicas de visualização, sendo que as técnicas são utilizadas para fundamentar a discussão sobre o uso de múltiplas visualizações e sobre a questão do tratamento da coordenação. Para uma revisão sobre técnicas e suas classificações, diversas referências estão disponíveis [Kei 1996] [Car 1999] [Shn 1996] [Oli 2003] [Shi 2004].

Em seguida, é discutido o uso de múltiplas visualizações, e são apresentadas algumas diretrizes que esclarecem as vantagens e desvantagens de seu uso e, portanto, direcionando quando e como utilizá-las. Na discussão dessas diretrizes fica evidente a necessidade de coordenar o uso simultâneo de múltiplas visualizações para facilitar o entendimento pelo usuário e ampliar as possibilidades de uso. Em seguida, são expostos alguns exemplos básicos de coordenação entre múltiplas visualizações.

Ainda neste capítulo são introduzidos alguns sistemas de visualização conhecidos e uma classificação quanto a sua flexibilidade no tratamento de dados, visualizações e coordenações. Os sistemas mais flexíveis introduzem o conceito de modelo de coordenação, que será o objeto de estudo do Capítulo 3.

\subsection{Técnicas de Visualização}

Card, McKinlay e Shneiderman [Car 1999] afirmam que a Visualização de Informação se insere no processo de Cristalização do Conhecimento, que é uma tarefa na qual deve-se coletar informações, dar a essas informações algum sentido por meio de uma representação, e apresentá-las em alguma forma de comunicação ou ação. Para isso, o usuário necessita de um conjunto de dados e de um esquema de representação. As técnicas de visualização podem apoiar a aquisição de informações relevantes e ajudar a encontrar um esquema adequado para representação desses dados em busca do conhecimento.

Existe, atualmente, uma ampla diversidade de técnicas de visualização de informação, variando desde técnicas de uso geral até técnicas voltadas para domínios e tarefas específicas. A título de ilustração, são discutidas duas técnicas de uso geral bastante populares para a 
exploração de dados multidimensionais: Coordenadas Paralelas e Gráficos de Dispersão (scatterplots).

A técnica conhecida como Coordenadas Paralelas [Ins 1990] associa os atributos dos dados a eixos (em geral verticais) paralelos igualmente espaçados, sendo que cada elemento de dado é visualmente representado como uma poli-linha conectando pontos nos eixos que representam o valor do registro no atributo correspondente ao eixo. Um exemplo pode ser visto na Figura 2.1, na qual é visualizado um conjunto de dados bastante conhecido (IRIS) que contém dados sobre um tipo de flor e possui quatro atributos que caracterizam três espécies distintas da flor: comprimento da sépala (sepal_length), largura da sépala (sepal_width), comprimento da pétala (petal_length) e largura da pétala (petal_width). A área em azul representa uma seleção (brushing) multidimensional feita pelo usuário, na qual apenas os registros cujos atributos estejam dentro dos limites estabelecidos pela seleção são destacados na visualização.

Essa técnica tem a vantagem de permitir a exibição de muitos atributos simultaneamente, e facilita a localização de agrupamentos de registros com o mesmo comportamento (clusters). A maior desvantagem é a sobrecarga visual que ocorre quando visualizamos conjuntos de dados com milhares de registros ou mais, devido ao fato das linhas se sobreporem dificultando a identificação do comportamento dos registros. Outro problema decorrente desta técnica é a dificuldade de identificar relações entre os atributos plotados em eixos distantes entre si.

Algumas técnicas de interação podem ajudar a contornar essas deficiências. O usuário poderia, por exemplo, interagir com esta visualização selecionado $n$ elementos (linhas) para um maior destaque, reorganizando eixos, invertendo a ordem de distribuição em cada eixo (ascendente ou descendente) para facilitar a identificação de correlações positivas e negativas, retirando atributos (eixos) para diminuir a sobrecarga, entre outras possibilidades.

Outra ferramenta bastante utilizada em análise de dados é o Gráfico de Dispersão que projeta dados multidimensionais em um espaço cartesiano bidimensional. Dois atributos quaisquer podem ser escolhidos para serem representados nos eixos da visualização e outros atributos podem ser mapeados em outras propriedades visuais dos elementos plotados, como cor, tamanho e forma. Para contornar a limitação no número de atributos que podem ser exibidos simultaneamente, pode-se utilizar uma matriz de gráficos de dispersão, na qual cada célula exibe uma visualização de dois atributos dos dados. Deste modo, várias visualizações são geradas, cada uma exibindo as relações entre cada par de atributos. 


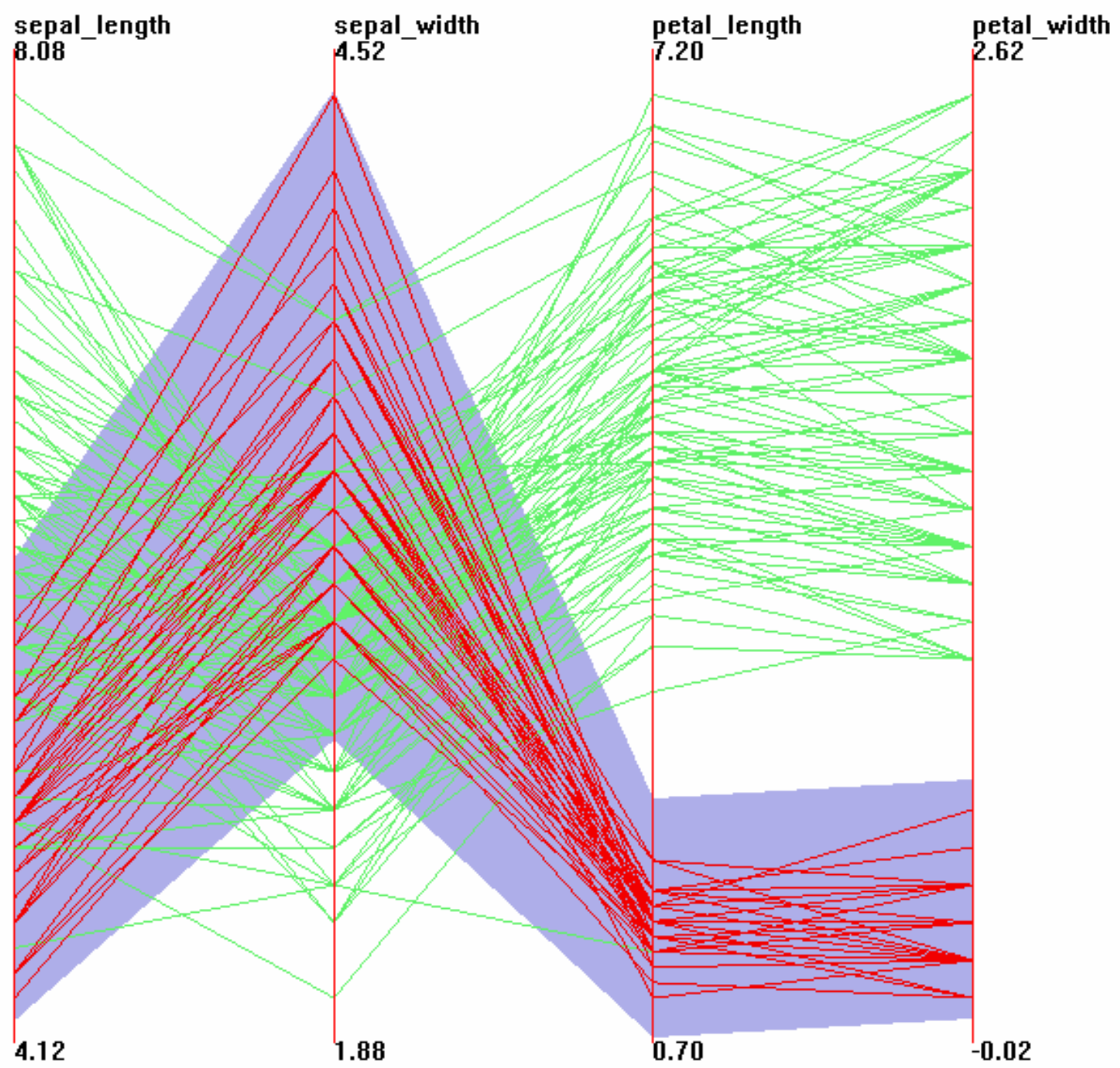

Figura 2.1 Técnica Coordenadas Paralelas. As linhas vermelhas representam os registros selecionados pelo usuário. Gerada no XmdvTool [War 1994].

A Figura 2.2 ilustra esta técnica utilizando o mesmo conjunto de dados do exemplo anterior, e a mesma região de seleção indicada em azul. As duas visualizações foram coordenadas pelo mecanismo de seleção ligada (brushing-and-linking), o qual compartilha uma seleção realizada em uma visualização com as outras visualizações associadas de maneira que a seleção efetuada em uma se reflita na outra. O Gráfico de Dispersão é uma ferramenta de fácil interpretação e que permite a visualização de um grande número de registros. A sua maior desvantagem é o número limitado de atributos exibidos simultaneamente e a dificuldade de detectar relações envolvendo mais de dois atributos. 


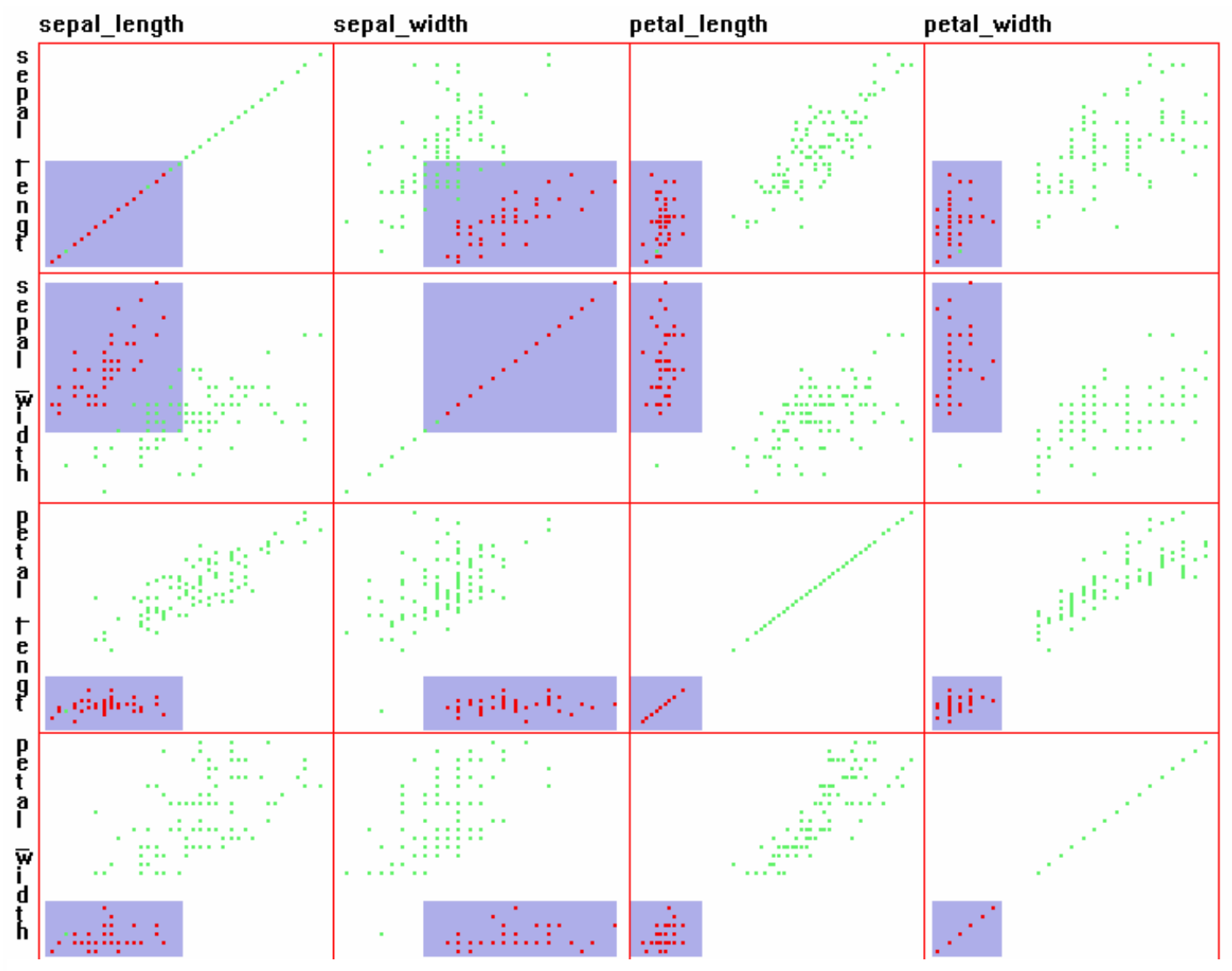

Figura 2.2 Técnica de Matriz de Gráficos de Dispersão com a mesma seleção da Figura 2.1. Gerada no XmdvTool [War 1994].

O TreeMap [Shn 1992] é uma técnica de visualização proposta inicialmente para representar dados hierárquicos, e que funciona por preenchimento de regiões. A é mapeada em uma hierarquia de regiões retangulares, que são subdivididas recursivamente, e atributos dos dados pode ser codificados no tamanho e cor das regiões. O atributo visual "tamanho", por exemplo, é especialmente útil para representar variáveis que podem ser decompostas hierarquicamente, podendo ser usado de modo que os nós da hierarquia que contenham informações mais importantes sejam representados por regiões maiores do que os de menor importância. Isto permite aos usuários comparar os tamanhos dos nós e das sub árvores, ajudando a mostrar padrões hierárquicos incomuns [Alm 2003].

Na Figura 2.3 temos um exemplo de uso desta técnica, gerado utilizando a implementação disponível no ambiente Snap [Nor2002a] O exemplo apresenta dados sobre os estados norteamericanos, e está subdividido por regiões geográficas. O espaço ocupado por cada retângulo representa a população absoluta de cada estado, e a cor de preenchimento representa a taxa de desemprego (regiões mais claras possuem taxa de desemprego maior). 


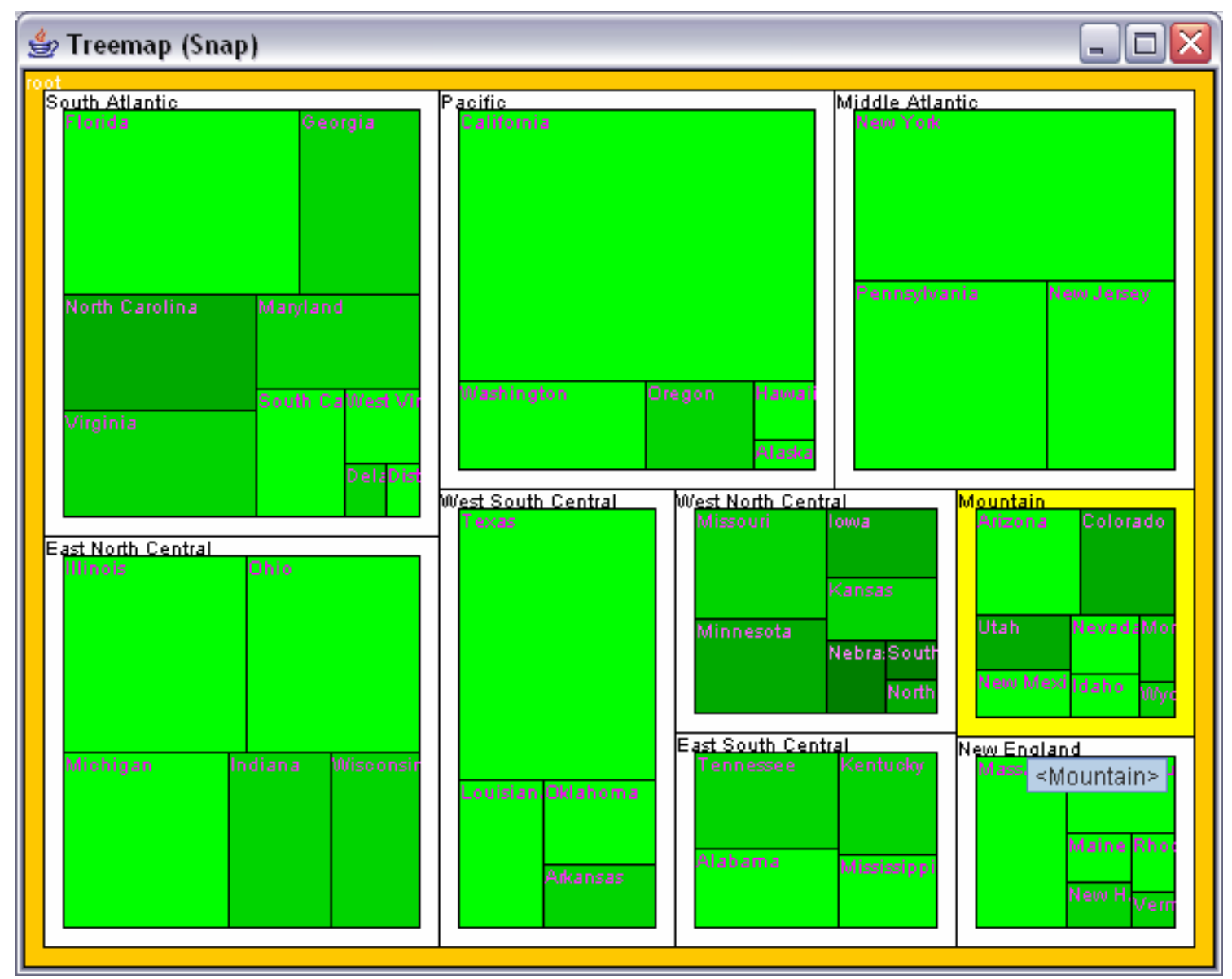

Figura 2.3 Exemplo de utilização da técnica Treemap. A região com borda em amarelo apresenta a seleção atual do usuário. Gerada no Snap [Nor 2002a].

\subsection{Múltiplas Visualizações}

Múltiplas visualizações distintas podem ajudar os usuários a perceber diferentes aspectos dos dados e podem ser utilizadas para facilitar a sua interpretação. Um exemplo comum de aplicação que utiliza múltiplas visualizações é o Microsoft Windows Explorer (Figura 2.4), em que várias janelas auxiliam o usuário a organizar os arquivos e pastas do seu sistema de arquivos. Na região à esquerda temos uma visão em árvore das pastas do sistema. A seleção de uma pasta carrega na janela a direita uma lista com todos os arquivos dessa pasta. Novamente, a seleção de um arquivo pelo usuário mostra os detalhes relativos ao arquivo selecionado na área central da visualização. 


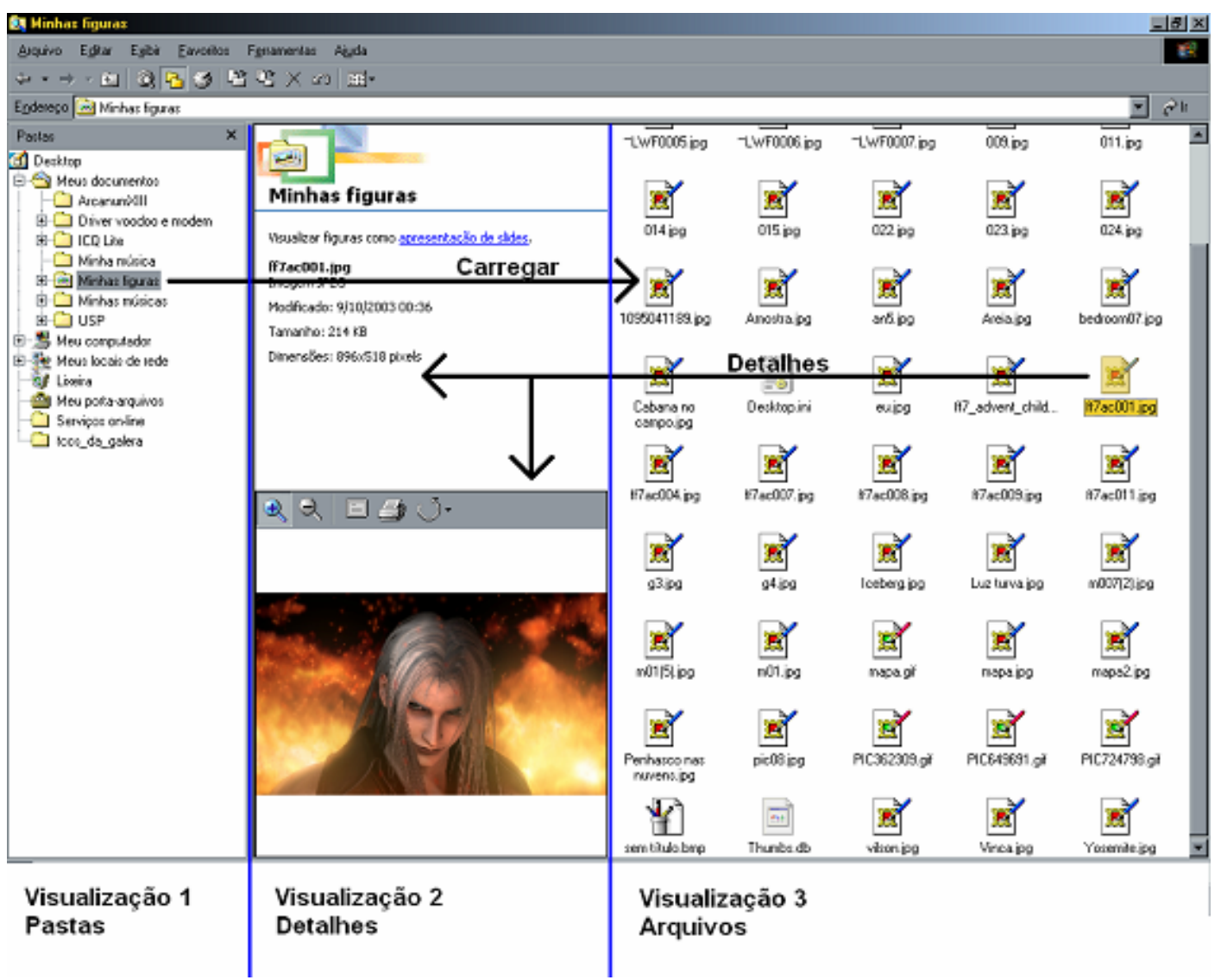

Figura 2.4 Exemplo de aplicativo que utiliza múltiplas visualizações, destacando as coordenações.

Duas visualizações podem ser diferenciadas pelos dados sendo exibidos, pelos atributos mapeados, ou pela representação visual utilizada. No caso de estarmos visualizando dados diferentes, estes podem ser subconjuntos ou tabelas de um conjunto de dados global, dados agregados, como somas e médias, ou mesmo dados que tenham alguma relação entre si, a ser verificada. A maior vantagem obtida com o uso de múltiplas visualizações dos mesmos dados, ou de dados complementares, é a minimização da sobrecarga cognitiva associada a uma única visualização complexa. Entretanto, alguns usos de múltiplas visualizações podem aumentar essa sobrecarga, por exemplo, devido ao esforço necessário para o usuário se adaptar a contextos diferentes. Deve-se, também, considerar o aumento dos requisitos sobre o sistema de visualização, como o tempo de processamento e espaço na tela.

Segundo Baldonado [Bal 2000], há três questões importantes a serem observadas quando desejamos utilizar múltiplas visualizações. Primeiramente, devemos identificar quais visualizações devem ser utilizadas para uma determinada tarefa. Depois, devemos definir como essas visualizações serão apresentadas, se seqüencialmente ou simultaneamente, e que espaço cada uma ocupará na tela. Finalmente, devemos considerar quais mecanismos de 
interação se encontram disponíveis individualmente e verificar a possibilidade de coordenar esses mecanismos entre as diferentes visualizações.

A seguir, são apresentadas as oito diretrizes gerais identificadas por Baldonado [Bal 2000] para o uso de múltiplas visualizações. As primeiras quatro diretrizes dizem respeito à seleção das visualizações:

- Regra da Diversidade: Use múltiplas visualizações quando houver uma grande diversidade de atributos, modelos, perfis de usuários, níveis de abstração ou gêneros.

- Regra da Complementaridade: Use múltiplas visualizações quando correlações ou disparidades forem ressaltadas.

- Regra da Decomposição: Particione dados complexos em múltiplas visualizações para criar ambientes gerenciáveis e promover maior entendimento sobre a interação dos dados entre as diferentes dimensões.

- Regra da parcimônia: Utilize múltiplas visualizações o mínimo possível, principalmente quando uma visualização simples provê um bom contexto para análise dos dados.

As outras quatro diretrizes abordam a apresentação e a coordenação das visualizações:

- Regra da Otimização do Uso dos Recursos de Tempo/Espaço: Balanceie os custos em tempo e espaço de apresentar múltiplas visualizações com os seus benefícios.

- Regra da Evidência: Use artifícios perceptíveis para tornar relações entre as visualizações mais aparentes para o usuário.

- Regra da Consistência: Faça as interfaces e os estados das múltiplas visualizações consistentes.

- Regra do Gerenciamento da Atenção. Use técnicas para focalizar a atenção do usuário na visualização certa e no momento certo.

\subsection{Coordenação}

Segundo as diretrizes de Baldonado discutidas na seção anterior, é importante tornar aparentes as relações entre múltiplas visualizações e manter a sua consistência. Para isso podemos usar a coordenação com o propósito de propagar as interações realizadas pelo usuário para todas as visualizações relacionadas. Podemos coordenar o conteúdo apresentado, a forma de 
apresentação e o comportamento das visualizações. Entre as coordenações mais comuns estão:

- Seleção ligada (linking-and-brushing). $\mathrm{O}$ ato de selecionar e destacar determinados objetos de uma visualização (ilustrado na Seção 2.2) faz com que os mesmos objetos ou objetos relacionados em outra visualização também sejam selecionados ou destacados.

- Navegação compartilhada: $\mathrm{O}$ ato de alterar a região visualizada em uma visualização é refletido em outras visualizações, que passam a exibir a mesma região ou a centralizar o objeto em foco.

- Detalhes sob demanda: Utiliza-se uma visualização para apresentar uma visão geral sobre o conjunto de dados e uma outra visualização para exibir detalhes relativos a um objeto específico selecionado na primeira.

- Carregamento sob demanda: Coordena uma ação efetuada em uma visualização geral dos dados, na qual a seleção de um elemento faz com que os elementos relacionados a ele sejam carregados em uma outra visualização.

Além dessas coordenações focadas nos objetos que representam elementos de dados, podemos coordenar outros aspectos da visualização, como o mapeamento de cores e parâmetros como o nível de detalhe, ou posicionamento de câmera em um ambiente 3D. Um exemplo de uma coordenação desse tipo seria a sua utilização para extender o conceito de seleção ligada para alterar permanentemente a aparência de um conjunto de itens, alterando sua forma. Esse tipo de coordenação será tratado mais detalhadamente no Capítulo 3.

\subsection{Sistemas de Visualização e Coordenação}

Existem atualmente diversos Sistemas de Visualização de propósito geral que reúnem diversas técnicas de visualização em uma mesma plataforma e que incorporam mecanismos de interação e de coordenação. Um sistema bastante conhecido é o XmdvTool ${ }^{2}$ [War 1994], um aplicativo de domínio público disponível em diversas plataformas computacionais, e que implementa diversas técnicas bastante conhecidas. O XmdvTool possui um mecanismo de coordenação simples que permite compartilhar a seleção de elementos entre múltiplas visualizações (linking-and-brushing), como foi ilustrado na Seção 2.2.

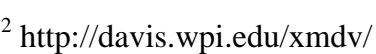


O IVEE/Spotfire ${ }^{3}$ [Ahl 1995] é um sistema comercial que oferece várias técnicas de visualização em conjunto com diversas técnicas de interação, e que também incorpora mecanismos de coordenação entre múltiplas visualizações. Em ambos os sistemas, o universo de coordenações possíveis e é fixo, não havendo flexibilidade para o usuário definir suas coordenações.

North e Shneiderman [Nor 2000] classificam os sistemas de visualização quanto a sua flexibilidade no tratamento de:

- Dados: possibilidade de o usuário definir diferentes conjuntos de dados para serem carregados no sistema.

- Técnicas de Visualização: possibilidade de o usuário definir quais técnicas de visualização serão utilizadas.

- Coordenações: possibilidade de o usuário definir diferentes coordenações entre diferentes visualizações.

São definidos três níveis de flexibilidade no tratamento destes elementos. Sistemas no Nível 0 não oferecem ao usuário flexibilidade alguma no tratamento de dados, técnicas ou coordenações. Um exemplo é o já citado Windows Explorer, que utiliza sempre as mesmas técnicas (mapeamentos visuais), coordenadas do mesmo modo, e o mesmo conjunto de dados, no caso, a estrutura de arquivos do sistema computacional do usuário.

Muitas ferramentas de visualização têm Nível de flexibilidade 1, o que caracteriza flexibilidade na escolha dos dados a serem visualizados, mas não na escolha das técnicas disponíveis. Por exemplo, uma ferramenta de visualização que implementa apenas a técnica Coordenadas Paralelas, na qual o usuário pode selecionar e carregar o conjunto de dados visualizado.

Grande parte dos sistemas de visualização de propósito geral se enquadra no Nível 2 de flexibilidade. Esses sistemas implementam várias técnicas de visualização, as quais podem ser selecionadas e utilizadas em um conjunto de dados especificado pelo usuário. Os sistemas citados acima (XmdvTool e Spotfire) são exemplos de sistemas enquadrados nesse nível.

Os sistemas no Nível 3 seriam os que fornecem flexibilidade ao usuário na definição dos mecanismos de coordenação, bem como na seleção dos dados e do conjunto técnicas disponíveis. Para isso, tais sistemas devem prover um modelo que suporte a definição e a execução dessas coordenações. No próximo capítulo serão apresentados três modelos de

\footnotetext{
3 'www.ive.-com
} 
coordenação presentes em sistemas desse tipo: o modelo proposto por Chris North utilizado no Snap Together Visualization, o modelo proposto por Nadia Boukhelifa em uso no Cviews, e o modelo proposto por Chris Weaver e implementado no sistema DEVise/Improvise.

Outra característica importante de alguns sistemas de Nível 3, como o Snap, é a extensibilidade quanto às técnicas de visualização disponíveis. Em um sistema extensível, além da possibilidade do usuário definir as técnicas de visualização que irá utilizar em sua análise, existe a possibilidade de se acrescentar novas técnicas ao sistema. Para isso, o sistema deve possuir um protocolo de comunicação simples que possa ser utilizado para adaptar uma nova técnica de visualização a fim de que esta técnica possa ser integrada ao ambiente e utilizada em conjunto com as outras já existentes. Essa mesma filosofia é adotada na plataforma InfoVis utilizada nesse trabalho. 


\section{Modelos de Coordenação}

No capítulo anterior, verificamos que um sistema de visualização flexível no tratamento de mecanismos de coordenação requer um modelo capaz de formalizar como as informações são trocadas entre as múltiplas visualizações, especificando o que pode ser coordenado e de que modo. Nesse capítulo faremos uma breve apresentação de três modelos de coordenação propostos na literatura. Analisaremos como cada um deles gerencia a coordenação, bem como os seus objetivos, características principais e restrições.

\subsection{O modelo proposto por North}

O primeiro sistema de visualização que adotou um modelo de coordenação para possibilitar que coordenações entre diferentes visualizações fossem criadas pelo usuário em tempo de execução foi o Snap Together Visualization. O desenvolvimento do Snap foi orientado para permitir que diferentes ferramentas de visualização criadas por diferentes desenvolvedores sejam integradas, facilitando a construção de ambientes de visualização extensíveis e personalisadas para uma exploração rápida dos dados e suas relações [Nor 2000].

O modelo conceitual do Snap é baseado no modelo relacional de dados e possibilita aos usuários definirem as coordenações com base no esquema relacional da base de dados cujo conteúdo será visualizado. Primeiramente, deve-se carregar os dados das relações (tabelas de dados) em visualizações e depois estabelecer as coordenações com base nas junções relacionais definidas no modelo de dados. Há uma correspondência direta entre os conceitos do modelo de dados relacional e os conceitos definidos no Snap, listadas a seguir:

- Componente de visualização = relação de dados. Toda Visualização representa os dados de uma tabela ou resultados de uma consulta. Poe exemplo, um gráfico de dispersão pode ser usado para visualizar uma relação binária ou uma projeção bidimensional de uma relação.

- Item da visualização = tupla de dados. Cada item (marcador gráfico) da visualização representa um registro da relação, como por exemplo, um marcador em um gráfico de dispersão. Cada item da visualização tem um identificador que é baseado na chave primária da relação de dados. 
- Propriedade visual $=$ atributo de dados. Cada atributo visual do marcador gráfico (cor, posição, tamanho, etc...) pode mapear os valores de um determinado atributo de dados.

- Coordenação visual = Junção de dados. As ações de interação realizadas pelo usuário sobre um item da visualização disparam outras ações nas tuplas associadas por junção exibidas em outra visualização.

A Figura 3.1 ilustra um exemplo da relação entre os conceitos do modelo de coordenação do Snap e os conceitos do modelo relacional. O banco de dados relacional possui, por exemplo, duas tabelas, Pastas e Arquivos, que dão origem a uma visualização de árvore e a uma visualização de tabela, respectivamente, como no Windows Explorer. É definida uma relação de junção 1-para-muitos entre ambas tabelas, que se reflete com uma coordenação entre as visualizações. Quando uma pasta é selecionada no Gráfico de Dispersão, seus arquivos são exibidos na Tabela.

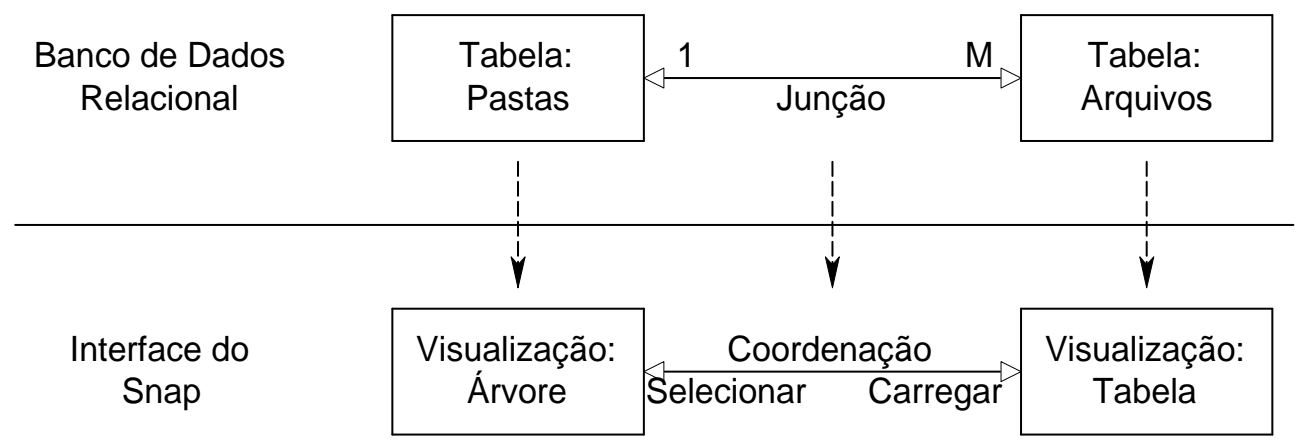

Figura 3.1 Modelo conceitual do Snap e analogia com o modelo relacional Adaptado de [Nor 2000a].

As visualizações normalmente permitem aos usuários selecionar, navegar, ou demonstrar algum tipo de interesse em determinados itens do conjunto de dados. Estas ações são chamadas de ações de chave primária, pois a chave é utilizada como identificador dos registros afetados pelas ações. O sistema pode responder à ação do usuário, por exemplo, destacando os objetos selecionados, e uma possível extensão dessa interação seria destacar os objetos com a mesma chave primária em outras visualizações. Para identificar em quais objetos esta ação deve ser executada são comparados os valores da chave primária.

Podem existir, também, ações envolvendo a chave estrangeira, em que um item de dado de uma relação pode estar relacionado a vários itens de outra relação. Neste caso, dada uma certa chave primária associada a um item de uma visualização, pode-se utilizá-la para destacar os itens de outras visualizações que tenham esse mesmo valor como chave estrangeira. 
A interface do usuário do Snap permite que o usuário defina o esquema de coordenação, o qual é representado como um grafo no qual os nós representam visualizações e as arestas representam as coordenações. No ícone associado a cada nó existem regiões coloridas com letras que sinalizam as ações visuais que podem ser associadas a esses nós e as visualizações a eles associados. Para estabelecer uma coordenação, o usuário precisa clicar num par dessas regiões, uma em cada nó, criando uma aresta que liga os dois nós, a qual representa a coordenação das respectivas ações nas respectivas visualizações.

A Figura 3.2 ilustra uma aplicação semelhante ao Windows Explorer, criada no Snap, para a exploração da estrutura de diretórios de um sistema de arquivos. No canto superior direito da tela temos uma visualização em árvore que representa os diretórios do sistema. Ao clicar em um dos diretórios as informações referentes aos seus arquivos são carregadas na tabela exibida no canto inferior. Há também um Treemap [Shn 1992] no canto superior esquerdo que exibe toda a estrutura de diretórios. Nessa representação o tamanho dos retângulos mapeia o espaço ocupado pelo arquivo no disco. A ação de selecionar um diretório no Treemap faz com que o mesmo seja destacado na visualização em árvore.

A Figura 3.3 apresenta o esquema de coordenação dessa aplicação, com as três visualizações representadas pelos respectivos ícones e as suas coordenações representadas pelas linhas ligando os ícones. Os quadrados identificados por letras representam as coordenações possíveis: S (verde) - Select (Seleção); S (amarelo) - Scroll; L - Load (Carregar); Z - Zoom. 


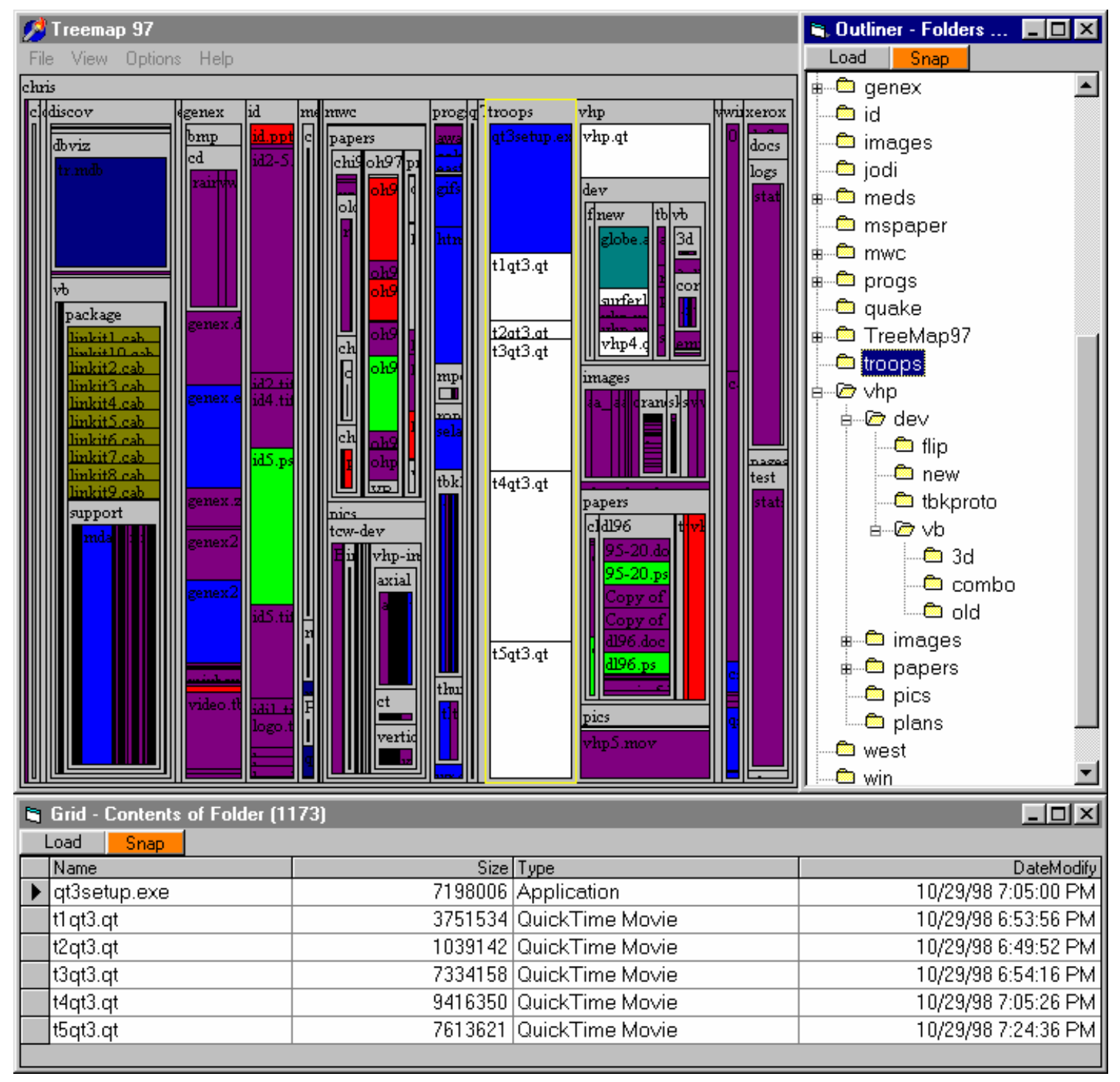

Figura 3.2 Exemplo de aplicação para exploração de estruturas de arquivos com três visualizações coordenadas, utilizando o Snap [Nor 1999].

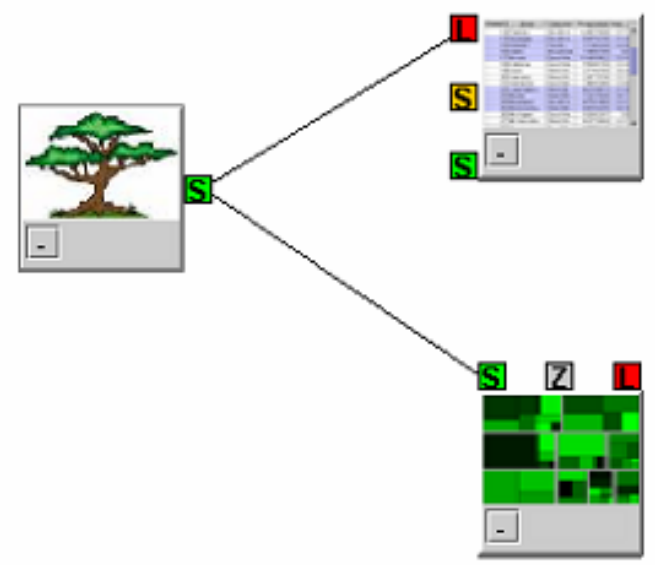

Figura 3.3 Esquema de coordenação referente à aplicação para exploração de arquivos. 
A versão inicial do sistema Snap [Nor 1999] foi aprimorada, e a ela foi acrescido o conceito de servidor de visualização [Nor 2002]. A nova arquitetura é composta por três camadas, as quais podem ser observadas no diagrama da Figura 3.4. $\mathrm{O}$ acesso à base de dados é via JDBC, além de ODBC, com possibilidade de conexão com bases de dados remotas (Figura 3.4(d)). A medida em que o usuário constrói o esquema de visualização é gerado um grafo de coordenação (Figura 3.4(c)), que permite gerência a coordenação entre as visualizações. Componentes de visualização, em conformidade com a padronização definida pela API do Snap, podem ser adicionados ao sistema e disponibilizados aos usuários, e se comunicam com o gerenciador de coordenações por meio de "Adapters" (Figura 3.4(b)), o que permite a incorporação de componentes implementados com diferentes tecnologias [Nor 2002].
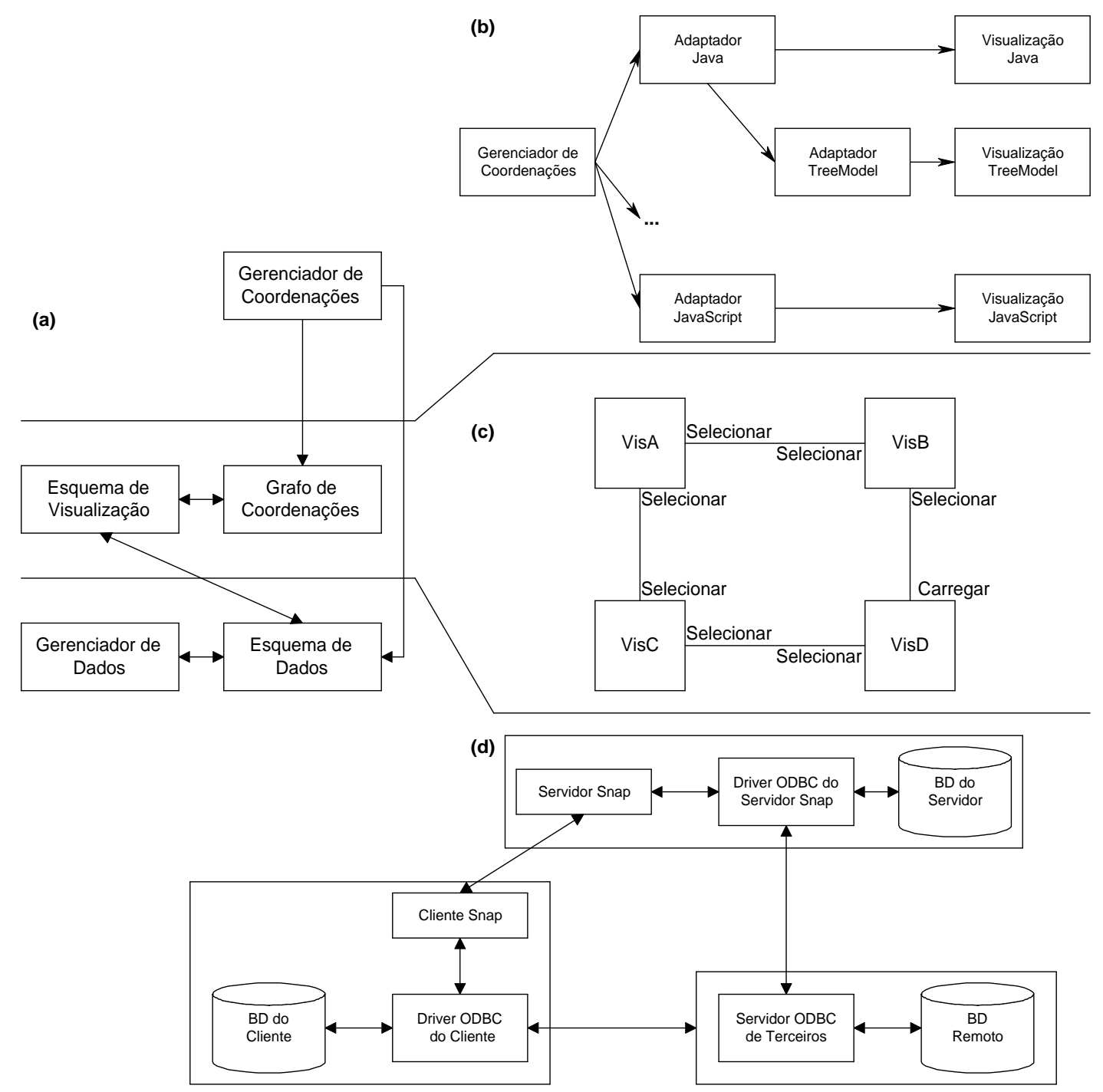

Figura 3.4 Camadas da arquitetura do Snap. Adaptado de [Nor 2002] 
O modelo do Snap é centrado nos dados e permite definir coordenações apenas sobre ações que atuam nos elementos de dados. A motivação para esta abordagem é o fato da maioria das coordenações normalmente utilizadas poderem ser implementadas dessa forma, sendo independentes da representação utilizada e, portanto, podem ser aplicadas a quaisquer duas visualizações, favorecendo a extensibilidade [Nor 2002]. Essa abordagem simplifica o projeto da interface do usuário utilizada para especificar as coordenações utilizadas, embora uma grande variedade de coordenações potencialmente úteis não possa ser implementada apenas com esse mecanismo [Pat 2001]. Um exemplo seria alterar os elementos gráficos que representam os elementos de dados ou realizar uma rotação simultânea sobre projeções diferentes de um mesmo conjunto de dados.

Nas Seções 3.2 e 3.3 são discutidos modelos mais genéricos que têm por objetivo permitir a coordenação entre elementos de dados e também entre propriedades das visualizações.

\subsection{O modelo proposto por Boukhelifa}

Nadia Boukhelifa [Bou 2003] apresenta um novo modelo de coordenação que potencialmente permite coordenar qualquer aspecto em diferentes etapas do processo de geração das visualizações, por exemplo, a preparação dos dados, o mapeamento dos dados e os movimentos de janelas. Seu estudo procurou analisar como outras disciplinas tratavam questões de interdependência da informação, multi-tarefas e interdependência e acoplamento de componentes. Tal estudo resultou em algumas idéias utilizadas no modelo de coordenação proposto, em que visualizações são modeladas em termos de entidades, objetos, eventos, processos, funções e agentes. Antes de definir um novo modelo de coordenação, Boukhelifa apresenta alguns elementos básicos que tal modelo deve considerar:

- Entidades de coordenação: Especifica o que está sendo coordenado: aspectos da janela atual, da visualização, dos dados, de um registro, de um atributo, de uma função, do tempo, etc...

- Tipo: Determina o método pelo qual as entidades de coordenação são ligadas e é influenciado por dois fatores: Tipo dos Parâmetros - coordenações podem ser implementadas por tipos de dados simples como inteiros e reais, ou por tipos estruturados mais complexos; e Direcionalidade: coordenação uni ou bidirecional. 
- Cronologia (tempo de vida e agendamento): Pode-se coordenar ações permanentemente ou para uma certa ação. Por exemplo, pode-se querer rotacionar uma visualização mais lentamente do que outra, o que ativaria a coordenação a cada $n$ ações realizadas.

- Escopo: Pode-se definir grupos de visualizações coordenadas, e sempre que uma nova visualização fosse adicionada ao grupo ela já estaria automaticamente coordenada às demais.

- Inicialização: Pode ser automática, especificado pelo usuário, ou especificada pelo grupo, como no caso acima.

- Atualização: Normalmente todas as visualizações são atualizadas em tempo real, mas pode-se possibilitar que algumas visualizações reflitam um estado anterior do processo.

- Controle do usuário: Como o usuário define as coordenações e como o esquema é apresentado.

Os elementos acima descritos devem ser abordados pelo modelo, que não deve impor nenhuma restrição quanto aos conjuntos de dados utilizados, viabilizando um ambiente flexível, adaptável e extensível, que permita especificar formalmente as coordenações. O modelo define "objetos de coordenação", que englobam combinações de entidades que controlam aspectos das visualizações. Cada objeto de coordenação é associado a uma coordenação no sistema e uma visualização é dita coordenada quando ela compartilha um objeto de coordenação com outra visualização. O conjunto de objetos de coordenação forma o espaço de coordenação. Objetos de coordenação contêm parâmetros que podem ser desde limites para certos atributos de uma consulta, coordenadas do clique do mouse, chaves dos registros selecionados, até informações mais complexas, como modificações na função de mapeamento das cores. Para facilitar a coordenação, esses parâmetros devem estar no formato utilizado pelo evento que os modifica, mesmo que tenham que ser traduzidos para se adequarem ao modo como as visualizações processam as alterações.

Os parâmetros de um objeto de coordenação são alterados via eventos que podem ser ativados por ações do usuário ou pelo próprio sistema, não precisando ter qualquer ligação com uma visualização específica. Todas as visualizações coordenadas devem ter funções de tradução que podem ser ignoradas, caso o objeto e a visualização utilizem a mesma representação dos parâmetros utilizada pelo objeto de coordenação. As visualizações também devem ser notificadas sempre que os parâmetros do objeto de coordenação forem alterados e, para isso, devem estar registradas no próprio objeto. Um fato importante é que cada visualização não tem acesso direto às demais, e nem sabe se existem outras visualizações coordenadas. A Figura 3.5 ilustra o modelo de coordenação com duas visualizações $\left(\mathrm{V}_{1}\right.$ e $\left.\mathrm{V}_{2}\right)$ 
e dois objetos de coordenação representando duas coordenações diferentes entre ambas as visualizações. Também pode-se observar na figura as funções de tradução $\left(f_{x, y}\right)$, os eventos de ativação, e os eventos de notificação (Notify $\left.{ }_{\mathrm{x}, \mathrm{y}}\right)$.

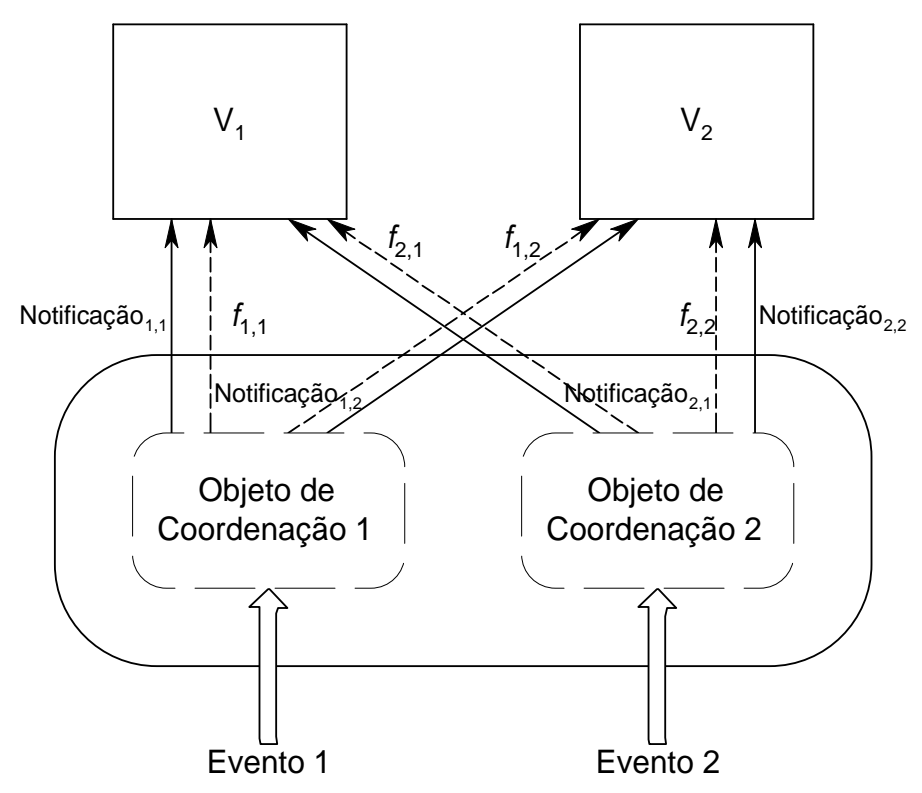

Figura 3.5 Modelo conceitual proposto por Boukhelifa. Adaptado de [Bou 2003].

A coordenação pode ocorrer em vários níveis do paradigma de fluxo de dados [Hab 1990]. Seguindo esse paradigma, em um processo de visualização, primeiramente os dados são realçados ou enriquecidos de alguma forma, após isso são mapeados em um objeto abstrato de visualização e logo após renderizados em uma imagem. Em resposta a ações efetuadas pelo usuário, algumas transformações podem ser realizadas na imagem. Múltiplas visualizações de um mesmo conjunto de dados é um caso em que o fluxo se divide em algum desses estágios.

Examinaremos agora um exemplo abstrato de uso do modelo em uma aplicação na visualização de mapas geográficos que contém quatro visualizações de um mapa de uma determinada região. $\mathrm{O}$ evento analisado será a seleção de uma região quadrangular do mapa em qualquer uma das visualizações. Na Visualização 1, o efeito será filtrar os dados para que a visualização apenas exiba o que está dentro do retângulo, enquanto na Visualização 2, o efeito desejado é destacar as junções de estradas contidas no retângulo selecionado. A Visualização 3 aumentará o nível de detalhe da área selecionada exibindo estradas secundárias e a Visualização 4 exibirá uma combinação de todos efeitos acima.

Podemos analisar também as funções de tradução. A função na primeira visualização apenas repassa os dados das coordenadas, dizendo qual área deve ser cortada, enquanto na segunda visualização, a função tem que informar como o mapeamento de cores deve mudar na área 
informada. A função na Visualização 3 somente deverá acrescentar as coordenadas do retângulo uma informação sobre o nível de detalhe requerido e, finalmente, a função referente à última visualização deverá combinar todos os parâmetros das outras funções. A Figura 3.6 ilustra o fluxo de dados nesse exemplo e como as funções de tradução podem alterá-lo em seus diversos estágios.

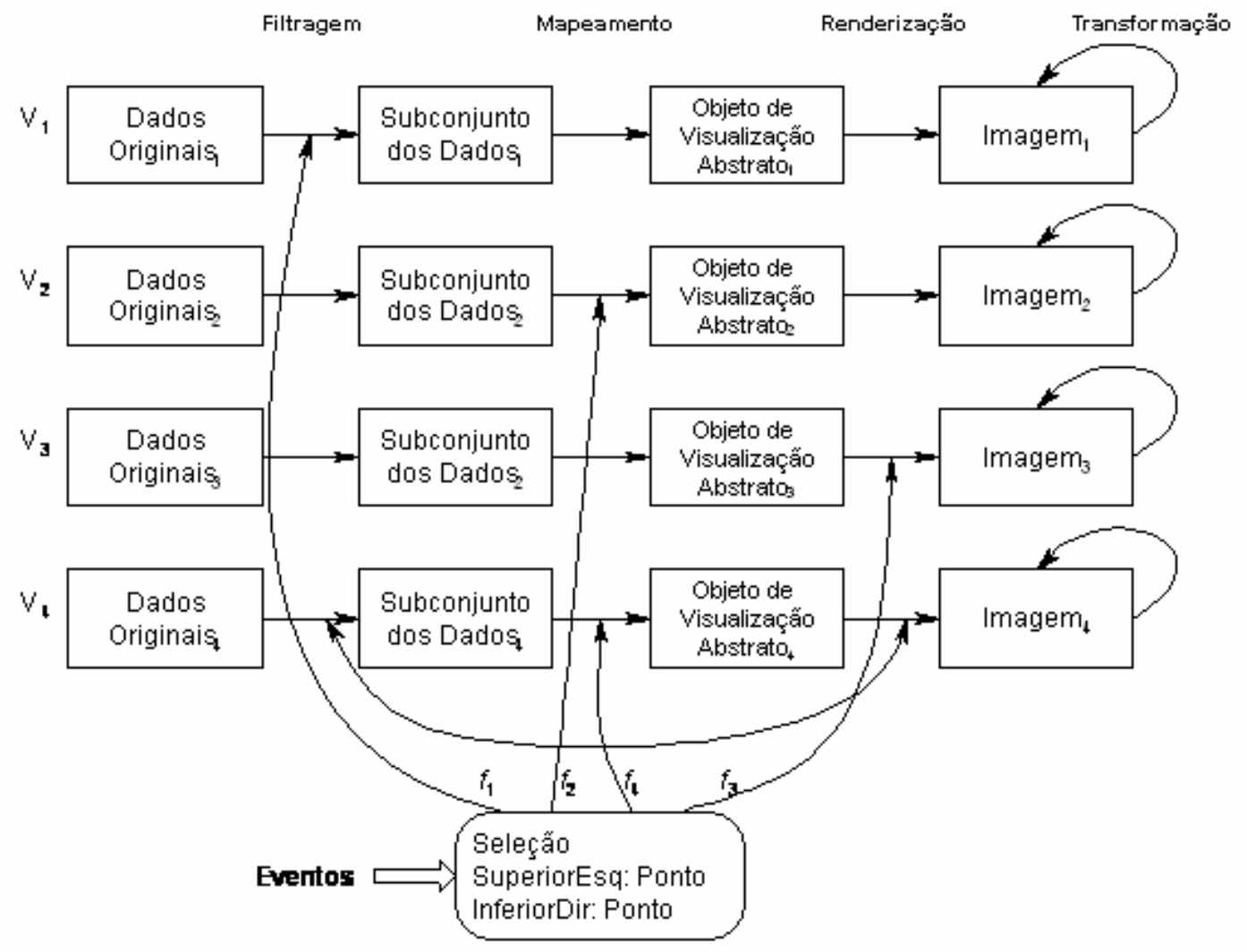

Figura 3.6 Fluxo de dados em uma aplicação com quatro visualizações coordenadas e suas respectivas funções de tradução.

\subsection{0 modelo proposto por Weaver}

Um dos modelos de coordenação mais recentes foi proposto por Weaver [Wea 2004], o qual também é baseado no modelo de dados relacional e permite aos usuários especificar suas próprias coordenações. Ele utiliza conceitos de vários sistemas e modelos já propostos, inclusive do modelo discutido na sub-seção anterior, e foi desenvolvido para aumentar a flexibilidade do sistema DEVise [Liv 1997], criando um novo sistema chamado Improvise [Wea 2004]. 
O DEVise é um sistema baseado no modelo relacional que utiliza apenas Gráficos de Dispersão para criar ambientes de múltiplas visualizações. Ele possui alguns mecanismos de coordenação básicos que permitem estabelecer coordenações elementares como: seleção ligada, navegação sincronizada e detalhes sob demanda.

Segundo Weaver, sistemas como o Snap Together Visualization e o DEVise empregam combinações simples de coordenações e visualizações bastante conhecidas. Embora a construção de pequenas aplicações de visualização nesses sistemas seja bastante simples, o número de visualizações e o grau de coordenação que podem ser incorporados são bastante limitados. O objetivo do modelo de Weaver é aumentar a flexibilidade das coordenações sem diminuir drasticamente sua facilidade de uso. O modelo combina um mecanismo de coordenação direta simples, denominado Live Properties, com um outro mecanismo mais poderoso de coordenação indireta, denominado Consultas Coordenadas.

A primeira característica importante do modelo de Weaver é a definição de Live Properties (LP), um mecanismo simples de coordenação que utiliza um objeto de coordenação compartilhado. As LPs definem uma interface para coordenar controles da visualização, como barras de rolagem, propriedades da visualização e outros. Cada controle define uma ou mais LPs, cada qual podendo estar associada a uma variável de coordenação, que por sua vez são utilizadas para compartilhar informações entre as visualizações coordenadas. Quando ocorrem mudanças nas variáveis, estas alterações são propagadas aos controles pelas suas LPs.

As LPs têm duas utilidades. Primeiro, definir valores que determinam a aparência e o comportamento dos controles. Por exemplo, um gráfico de dispersão cujas dimensões sejam maiores do que a área visível pode utilizar duas LPs de intervalo (x e y) para definir qual região exibir, e uma outra propriedade de cor para definir sua cor de fundo. Segundo, elas agem como portas pelas quais os controles comunicam-se entre si como resultado de uma interação do usuário. Tanto as LPs quanto as variáveis de coordenação são fortemente tipadas e sua ligação também.

Na Figura 3.7 temos um esquema que ilustra como funciona a coordenação direta entre dois controles. No primeiro passo um controle modifica o valor de uma de suas LPs devido à alguma interação (1). Em seguida, a LP repassa seu novo valor a uma variável de coordenação (2), que envia um sinal a todas as LPs relacionadas informando que seu valor foi alterado (3). Finalmente, as LPs avisam os seus controles para refletir visualmente as mudanças ocorridas (4). 


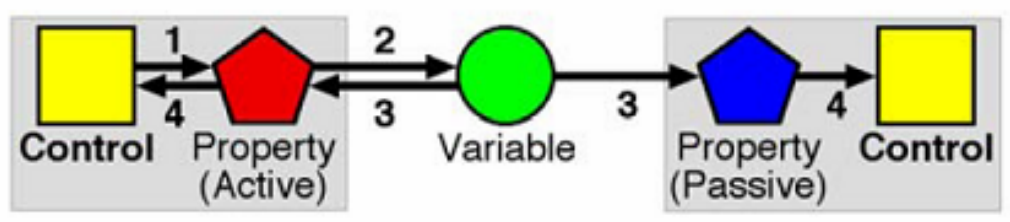

Figura 3.7 Modelo de coordenação direta por Weaver [Wea 2004].

A segunda definição característica do modelo diz respeito às consultas coordenadas (Coordinated Queries), uma linguagem de abstração visual baseada no modelo relacional. Uma expressão nessa linguagem tem o formato de uma árvore de operadores em que o valor de saída de um operador é calculado com base nos valores de entrada. As expressões são construídas em forma de árvore na qual a expressão é desenvolvida de cima para baixo (topdown) escolhendo um operador para cada parâmetro (nó da árvore). Outras expressões são adicionadas quando o operador escolhido requer outros parâmetros. Existem dois tipos de expressões:

- Filtros. Uma expressão simples é utilizada para calcular um valor booleano para cada registro de dados. Apenas os registros cuja expressão resulte em verdadeiro são processados pela visualização

- Projeções: Uma ou mais expressões são utilizadas pra calcular valores sucessivos de um registro de saída para cada entrada. As visualizações exibem os registros com base nas informações contidas nos valores desse registro como cor e posicionamento.

Quando um controle depende do valor de uma variável que resulta de uma expressão que contém uma projeção ou filtro, ele depende indiretamente das variáveis contidas dentro da expressão da projeção ou do filtro. A Figura 3.8 mostra um esquema de coordenação indireta por meio das consultas coordenadas. Toda vez que um objeto altera o valor de uma das variáveis (1), ela notifica os valores léxicos das expressões que são calculados com base naquela variável (2). Cada expressão alterada notifica as variáveis que estão relacionadas com seu valor final (3). Finalmente, a variável notifica os controles aos quais ela esta ligada pra refletirem as novas alterações.

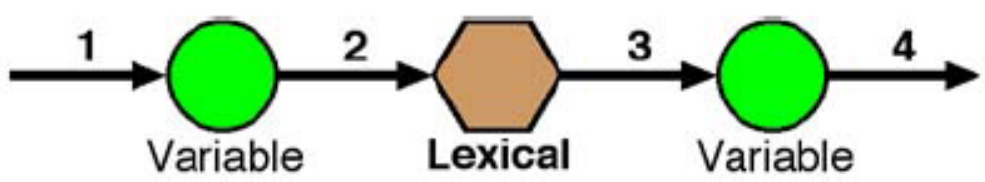

Figura 3.8 Modelo de coordenação indireta usando consultas coordenadas proposto por Weaver [Wea 2004]. 
A seguir, é exemplificado o uso do modelo. Na Figura 3.9 temos uma aplicação na qual são visualizadas trajetórias de íons. Nela podemos encontrar seis coordenações diferentes:

- A. Gráfico de Dispersão + Eixos: Os eixos e seus rótulos são independentes, mas podem ser coordenados com o Gráfico de Dispersão para refletirem em sua escala as alterações realizadas.

- B. Scrolling Sincronizado: O scrolling horizontal nos três gráficos de dispersão é sincronizado.

- C. Matriz de Gráficos de Dispersão: Cada um dos Gráficos de dispersão mostra uma projeção ortogonal diferente de um Gráfico de Dispersão 3D. Alterações na região visualizada em um deles são refletidas nos outros.

- D. Visão geral + Detalhe: Uma visualização de detalhe exibe com um maior nível de detalhe a região selecionada na visão geral.

- E: Perceptual Slider: Permite ao usuário selecionar um intervalo de interesse por meio de cores, ao invés de trabalhar apenas com valores numéricos.

- F: Nested Views: Os nomes de cada uma das trajetórias são acompanhados de ícones representando uma pequena visualização 3D (gerada em tempo de execução) da trajetória.

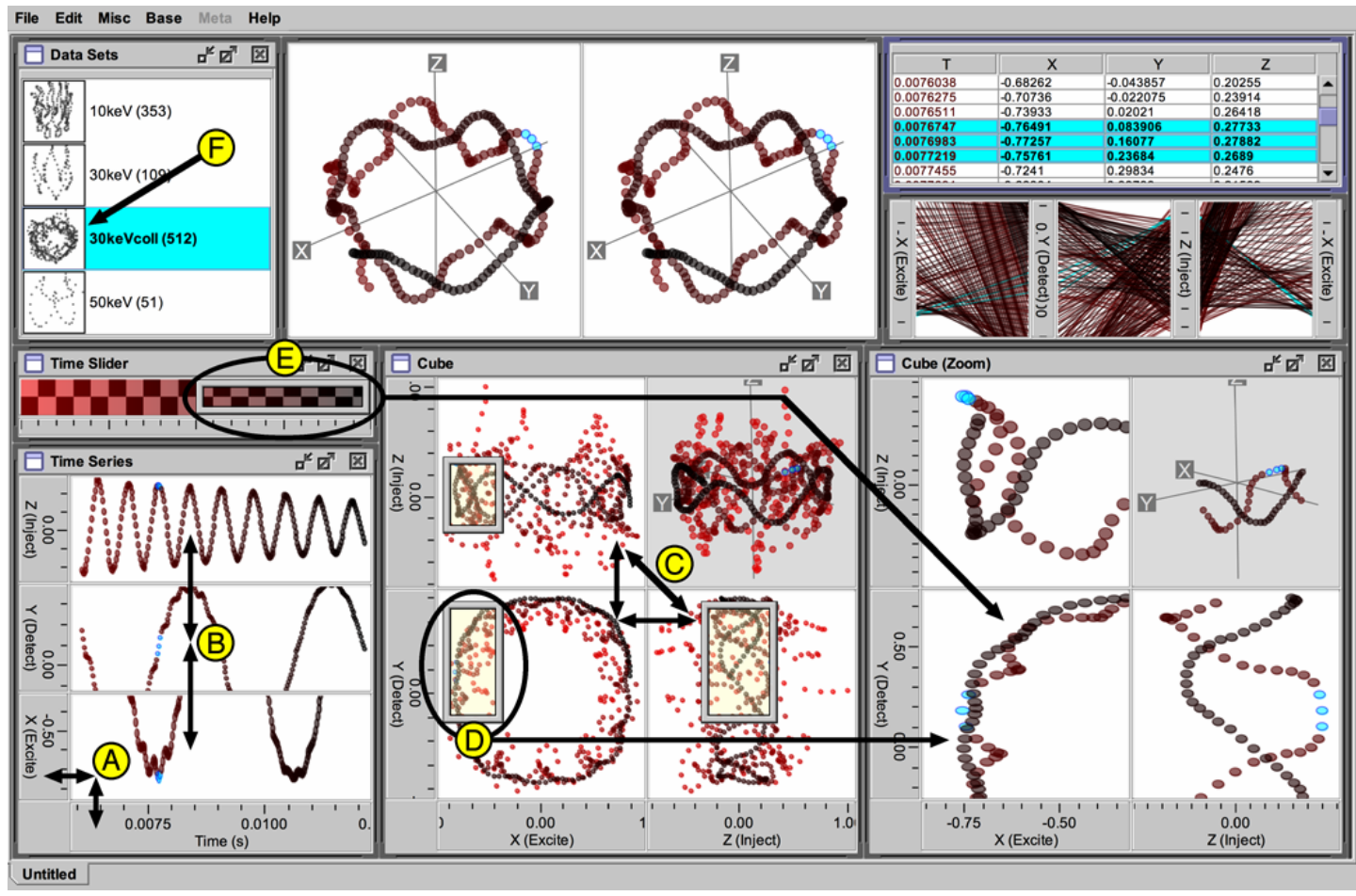

Figura 3.9 Aplicação desenvolvida no sistema Improvise, destacando os seis mecanismos de coordenação utilizados [Wea 2004]. 
O esquema de coordenação na Figura 3.10 ilustra a coordenação implementada no caso A do exemplo acima, em que propriedades de um controle são coordenadas. Qualquer deslocamento ou aproximação realizado em um dos eixos (no caso, $\mathrm{T}$ que representa o tempo), altera o valor da variável de intervalo respectiva, refletindo em uma alteração da região exibida no gráfico. Caso a alteração seja realizada diretamente no gráfico, o caminho inverso é realizado e as escalas dos eixos serão atualizadas.

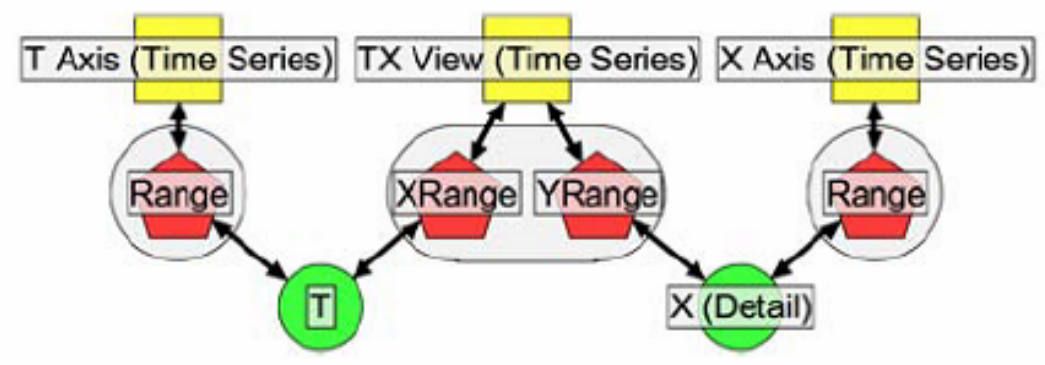

Figura 3.10 Esquema de coordenação envolvendo controles [Wea 2004].

Na Figura 3.11 temos o esquema de coordenação do caso B da aplicação acima. Os eixos $\mathrm{X}$ de cada um dos Gráficos de Dispersão representam o tempo $(\mathrm{T})$ e são coordenados para que o scrolling em qualquer um dos três seja refletido nos outros dois. Os eixos $\mathrm{Y}$ que representam as três variáveis em estudo continuam independentes.

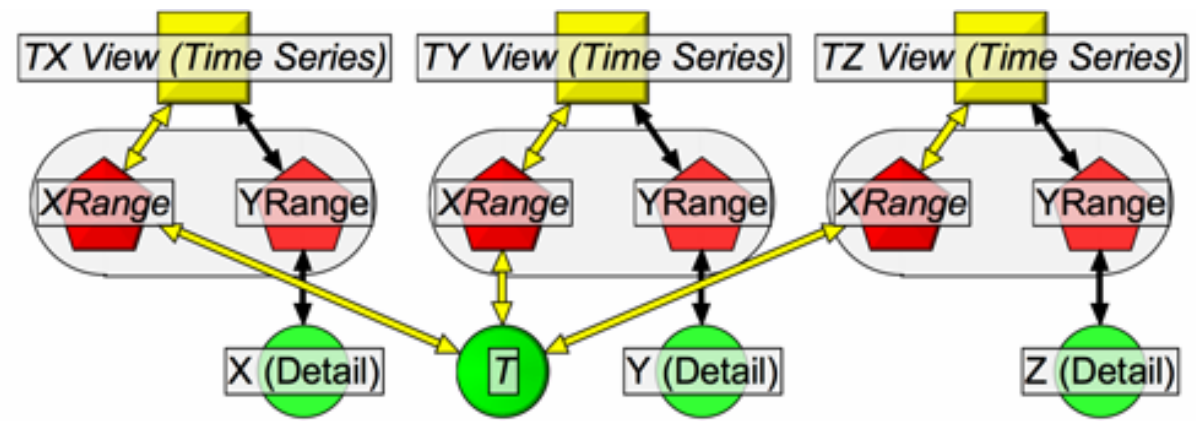

Figura 3.11 Esquema de coordenação de navegação (scrolling) sincronizada [Wea 2004]. 


\subsection{Considerações Sobre os Modelos}

Vários modelos de coordenação foram propostos para formalizar as coordenações entre múltiplas visualizações. Cada um deles tem alguns objetivos principais, como: facilitar o estabelecimento de coordenações, possibilitar a integração de novas técnicas de visualização ao ambiente mantendo as possibilidades de coordenações e generalizar as coordenações para que qualquer aspecto envolvido no processo de visualização possa ser coordenado.

Dos modelos revistos, o modelo do Snap se preocupa em fornecer um mecanismo de coordenação simples que permita ao usuário um rápido aprendizado e facilidade de inclusão de novas técnicas. O modelo de Boukhelifa é mais conceitual, e pretende estabelecer um modelo genérico que abrange todas possibilidades de coordenação sem estabelecer uma ligação muito forte com um sistema sem si, podendo ser utilizado como base para o desenvolvimento de um modelo mais específico. Weaver propõe um modelo que simplifica o modelo de Boukhelifa mantendo a possibilidade de definir coordenações avançadas e configurando um ambiente de fácil interação com o usuário, mas de difícil adaptação para inclusão de novas técnicas.

O modelo adotado por cada sistema leva em consideração as características desejadas para o sistema em questão. Não há um modelo ideal que atinja todos os objetivos com excelência, e sim modelos que abordam o problema da coordenação sob vários ângulos diferentes. O novo modelo de coordenação proposto é baseado no modelo de Boukelifa, utiliza o conceito de objeto de coordenação, permite o estabelecimento de diversas possibilidades de coordenação, mas com prioridade para a extensibilidade. Alguns conceitos do modelo do Snap também são aproveitados como o método de acesso aos dados, a utilização das relações presentes no modelo de dados, e a interdependência entre os componentes. 


\section{A Plataforma InfoVis}

Neste capítulo apresentamos brevemente o InfoVis, uma plataforma de software extensível que incorpora diversas técnicas de visualização, em desenvolvimento no ICMC. Como parte de um projeto de doutorado foi desenvolvida uma primeira implementação desta plataforma e, nesta primeira implementação, o estabelecimento de coordenações entre visualizações era bastante limitado. Buscando ampliar as possibilidades de coordenação da plataforma, procurou-se nesse projeto a concepção e implementação de um modelo de coordenação adequado às características desejadas para o sistema. Uma descrição geral da plataforma se encontra na Seção 4.1, e o mecanismo de coordenação presente na primeira versão é descrito na Seção 4.2.

Para possibilitar a inclusão do novo modelo de coordenação, algumas mudanças foram introduzidas na plataforma. A Seção 4.3 descreve o novo componente Gerenciador de Dados (GD) e a Seção 4.4 apresenta as mudanças introduzidas no conjunto de componentes funcionais, bem como no processo de inclusão de novos componentes na plataforma.

\subsection{Características - Versão Original}

Shimabukuro [Shi 2004], em sua tese de doutorado, propõe um modelo de arquitetura de software cuja finalidade é estabelecer um arcabouço para nortear o desenvolvimento e a implementação de uma plataforma computacional extensível, que permita a geração de ambientes personalizados de apoio ao processo de descoberta de conhecimento. A plataforma deve permitir que o usuário configure seu próprio ambiente de visualização a partir de módulos disponíveis pela plataforma, e estabelecer suas próprias coordenações entre visualizações de sua escolha. As principais características que uma implementação dessa plataforma deve possuir são:

- Extensibilidade. A plataforma disponibiliza técnicas de visualização implementadas em módulos independentes e auto-suficientes, responsáveis pelo controle de seus parâmetros e pela interação do usuário. Um usuário de visualização pode, a partir do conjunto de módulos disponíveis, configurar um ambiente integrado de visualização composto por um ou múltiplos módulos de interesse. Um requisito fundamental para garantir o uso integrado e coordenado de múltiplas visualizações é que cada módulo seja capaz de trocar 
mensagens e informações com outros módulos de visualização. Para isso, os módulos incorporados à plataforma devem aderir a um protocolo de comunicação, implementando um conjunto de comportamentos ou métodos predefinidos que garante a funcionalidade de coordenação;

- Configurabilidade. Diferentes tarefas, em uma mesma aplicação, podem ser realizadas por meio de seqüências diversificadas de ações coordenadas envolvendo diferentes representações visuais. Por isso, a coordenação de ações entre visualizações deve ser estabelecida pelo usuário em tempo de execução, durante o uso do ambiente, segundo suas necessidades, preferência e experiência. Em uma outra perspectiva, deve ser possível definir, a partir da plataforma, vários cenários de visualização distintos, cada qual disponibilizando as técnicas de visualização escolhidas para atender os requisitos de uma aplicação específica. Como cada técnica de visualização define as suas ações de interação possíveis, o conjunto de visualizações escolhidas define o conjunto de ações coordenadas que podem ser estabelecidas pelo usuário.

- Monitorabilidade. A facilidade de definir ambientes personalizados cria uma fonte de informação potencial para a documentação e avaliação de diferentes cenários de uso de múltiplas visualizações coordenadas e, também, do processo de descoberta de conhecimento. O registro de informações sobre as representações visuais utilizadas, sobre as ações coordenadas definidas, e sobre a sequiência de ações executadas e seus respectivos parâmetros é um instrumento estratégico em processos de extração de informação, e pode oferecer informações úteis para pesquisadores em visualização. Um usuário particular pode revisar e avaliar suas formas de atuação com base nesse registro, e refinar seu processo de análise caso julgue necessário. A plataforma deve oferecer mecanismos para capturar e armazenar essas informações e outras de interesse. No âmbito da operação de um ambiente, as informações capturadas podem ser utilizadas para desfazer ou repetir ações, e também para a criação de macro operações, isto é, uma seqüência de ações que definem uma tarefa ou sub-tarefa.

A partir desses requisitos foi desenvolvida a plataforma InfoVis, que integra múltiplas técnicas de visualização e cuja arquitetura é organizada em dois núcleos: um núcleo básico, que agrega as funcionalidades necessárias ao gerenciamento do ambiente, e um núcleo funcional, que agrega os componentes de visualização e de acesso aos dados. Uma visão geral da arquitetura da plataforma é apresentada na Figura 4.1. 


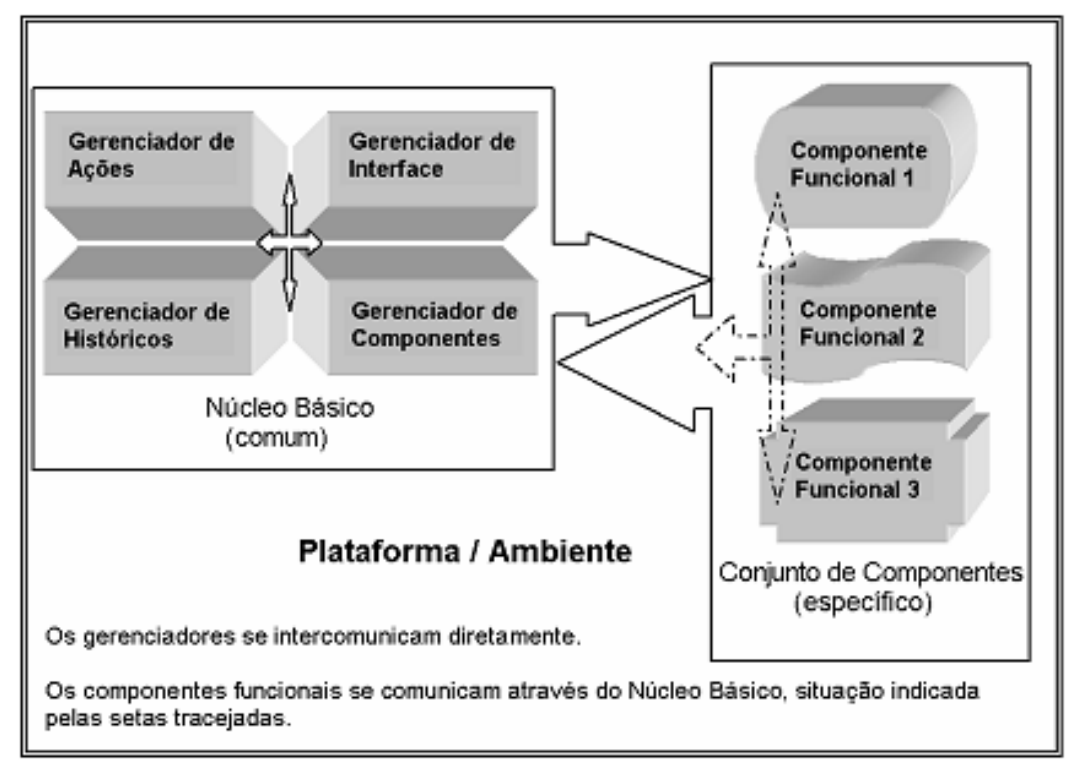

Figura 4.1 Visão geral da arquitetura do InfoVis [Shi 2004].

No InfoVis, os componentes dos Núcleos Básico e Funcional foram implementados como classes Java. Segundo o modelo subjacente à plataforma, os componentes do núcleo funcional comunicam-se com os do núcleo básico e entre si para ativar tarefas básicas de gerenciamento e de coordenação de ações. As funcionalidades de gerenciamento, pertinentes ao núcleo básico, são realizadas por quatro componentes:

- Gerenciador de Interface (Acesso). Responsável pela apresentação da interface de acesso à plataforma de visualização: dá ao usuário acesso aos recursos dos diferentes componentes dos núcleos básico e funcional, também é responsável pela inicialização dos demais componentes básicos. Solicita aos componentes funcionais a apresentação de suas interfaces;

- Gerenciador de Componentes (Integração). Controla a ativação dos componentes funcionais, e mantém a lista de referência daqueles que estão ativos. Quando um componente funcional é finalizado, este gerenciador procede à sua desativação;

- Gerenciador de Ações (Coordenação). Propaga a ação sobre uma representação visual para as demais representações visuais, para que essas realizem as ações coordenadas estabelecidas pelo usuário que configurou o ambiente. A coordenação entre as ações é feita dinamicamente de acordo com as necessidades de cada tarefa;

- Gerenciador de Históricos (Monitoramento). Registra as ocorrências dentro do ambiente, os componentes ativados, as ações coordenadas definidas e suas ativações com 
os respectivos parâmetros. Esses registros mantêm uma descrição dos vários cenários testados e das estratégias de atuação adotadas ao longo de um processo de exploração.

O Núcleo funcional é composto pelos componentes funcionais e podem variar dependendo da aplicação. Os componentes funcionais podem ser agrupados em diferentes categorias, de acordo com o tipo de funcionalidade oferecida. Essa categorização delimita o que cada componente deve implementar, preservando o caráter genérico dos componentes. Inicialmente, identificamos as seguintes categorias para os componentes funcionais:

- Fonte de Dados. Implementam recursos para acesso a arquivos de dados ou gerenciadores de bases de dados externos, bem como recursos para filtragem, amostragem, seleção, e pré-processamento dos dados;

- Visualização. Implementam técnicas de visualização e seus recursos de interação;

- Interação. Implementam estratégias de interação genéricas, aplicáveis a diferentes técnicas de visualização (como Consultas Dinâmicas [Ahl 1992], por exemplo);

- Recursos Analíticos. Implementam recursos complementares aos de visualização; por exemplo, algoritmos de mineração ou ferramentas estatísticas.

Os módulos integrantes da primeira versão do núcleo funcional implementam técnicas de visualização de dados com atributos espaciais e temporais concebidas para apoiar a exploração de uma base de dados pluviométricos. Todos os componentes do núcleo funcional devem aderir ao modelo AdaptaVis seguindo um protocolo de serviços que assegura o funcionamento integrado e coordenado do aplicativo, o qual define um conjunto de métodos de comunicação com os componentes do núcleo básico.

Um dos componentes funcionais, denominado Distribuição Espacial ou Mapa, implementa uma técnica interativa que exibe o posicionamento espacial dos elementos representados nos registros. Os outros dois (Variação Temporal Uni-escala e Variação Temporal Multi-escala, ou Calendário) implementam técnicas interativas para apresentar o comportamento temporal de um determinado atributo escalar, em diferentes escalas de tempo. As técnicas implementadas podem ser enquadradas primariamente na categoria 'pixel-based', segundo a classificação de Keim e Kriegel para técnicas de visualização [Kei 1996] - sendo que o último também se enquadraria na categoria das representações icônicas, pois o arranjo dos pixels segue um padrão fixo (simular ao usado em calendários) e pode ser interpretado como um ícone. Além desses componentes foi implementado um componente que lê dados de um arquivo e apresenta-os diretamente em formato tabular (Tabela de Dados), e um 
componente de interação que utiliza Consultas Dinâmicas [Shn 1994, Bra 2003]. Esses componentes são apresentados de forma detalhada por Shimabukuro [Shi 2004].

\subsection{O Mecanismo de Coordenação}

O mecanismo de coordenação de ações entre os diferentes componentes de visualização é bastante limitado na primeira implementação da plataforma InfoVis. A coordenação é implementada como parte do protocolo de comunicação entre componentes do Gerenciador de Ações (GA), o qual é responsável pelo gerenciamento das ações envolvendo múltiplos componentes nos ambientes configurados a partir da plataforma. Esse protocolo assume que a coordenação sempre afeta os registros do arquivo de dados e opera sobre os mesmos registros em ambas as visualizações. Por exemplo, uma ação do usuário de 'selecionar' um conjunto de registros em uma visualização pode ser coordenada com a ação de 'destacar' os registros correspondentes (com os mesmos identificadores) em outra.

Todo componente, quando ativado, informa ao Gerenciador de Componentes quais ações coordenadas ele pode realizar. O usuário, ao definir uma coordenação, informa qual componente será coordenado, e escolhe uma das ações disponíveis do componente escolhido, registrando assim no GA os componentes envolvidos na coordenação. A coordenação é operacionalizada por meio da troca de mensagens entre ambos os componentes e o componente Gerenciador de Ações do Núcleo Básico, passando como parâmetros os identificadores dos registros envolvidos na coordenação. O componente no qual a ação é iniciada, passa para o GA uma mensagem informando o tipo de ação e os índices das tuplas afetadas. O GA verifica nos seus registros quais componentes funcionais devem refletir a ação e envia a eles uma mensagem contendo a ação a ser realizada e os índices dos registros afetados.

A Figura 4.2 ilustra a interface de um ambiente de visualização no qual são apresentadas duas visualizações coordenadas: Distribuição Espacial e Tabela de Dados. Os registros selecionados pelo usuário na Distribuição Espacial (mapa) são destacados na Tabela. Não é possível coordenar nesse mecanismo uma ação de selecionar um elemento na visualização de Distribuição Espacial com a ação de carregar dados detalhados sobre este registro, que se encontram em outro arquivo. A Figura mostra ainda, a interface principal da plataforma e o registro dos componentes ativados, as coordenações estabelecidas e as ações realizadas pelo usuário nessa seção. 


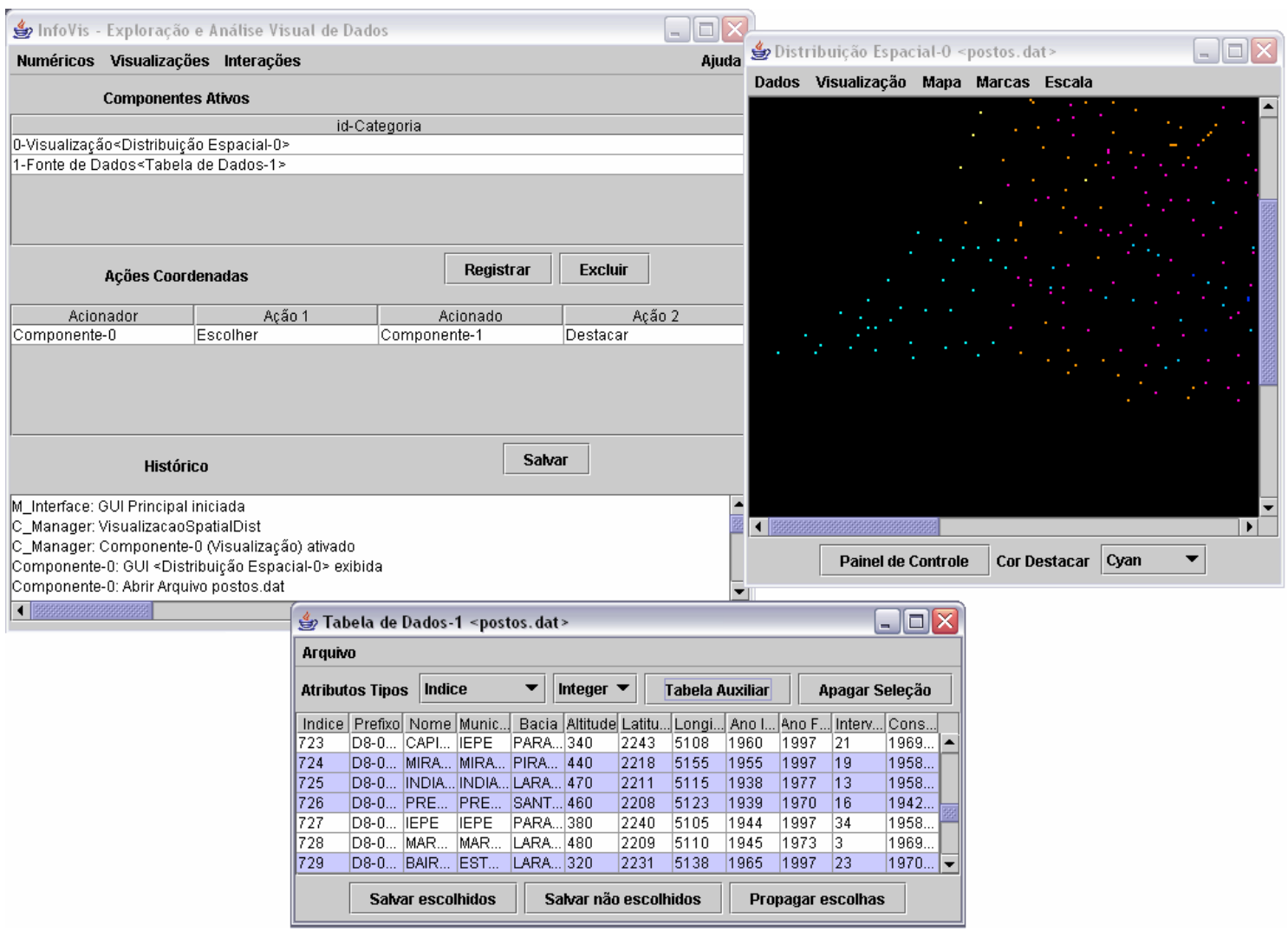

Figura 4.2 Exemplo de uso da plataforma InfoVis apresentado sua interface principal e duas visualizações coordenadas

Além da implementação do modelo de coordenação, a plataforma sofreu outras alterações nos mecanismos de acesso aos dados, e de desenvolvimento de novos componentes. Essas alterações são discutidas nas próximas seções.

\subsection{Componente Gerenciador de Dados}

Muitas estratégias de coordenação atuam sobre os elementos de dados (registros) sendo visualizados. Esses registros normalmente sofrem diversas ações de interação do usuário, por exemplo, elementos gráficos associados a alguns registros podem ser destacados na visualização, enquanto outros podem ser removidos para diminuir a quantidade de informação na tela, em um processo de filtragem. Para que as visualizações "saibam" a quais elementos uma certa ação deve ser aplicada, todo registro de dados deve ter uma identificação única. A alternativa mais frequentemente utilizada pelos sistemas de visualização, e também pelos mecanismos de coordenação, consiste em utilizar a chave primária do registro como o seu identificador. 
O uso da chave primária traz como vantagem principal o fato de ser uma informação a qual toda visualização pode ter acesso, e cujos valores são únicos. O uso da chave primária em conjunto com chaves estrangeiras permite que as coordenações utilizem relações estabelecidas entre dois conjuntos de dados (ou duas tabelas de dados em um SGBD). Um exemplo seria uma tarefa que envolve a análise de visualizações com informações relativas aos estados de um país, e às cidades em cada estado. A seleção de um estado em particular em uma das visualizações ativaria uma coordenação, e resultaria no carregamento dos dados referentes às cidades deste estado em outra visualização.

$\mathrm{Na}$ versão anterior do InfoVis não foi implementado nenhum mecanismo de gerenciamento de acesso aos dados, de modo que cada visualização acessava os seus arquivos dados diretamente e à sua maneira. Isso dificulta o processo de coordenação, pois não existe padronização no formato dos dados a serem acessados, na forma em que são carregados e tampouco na definição de como identificar unicamente um registro. Para contornar essas deficiências e facilitar o desenvolvimento dos componentes foi incorporado à plataforma InfoVis um componente Gerenciador de Dados que gerencia o acesso aos dados via JDBC, permitindo o acesso aos dados armazenados em diferentes formatos (via drivers ODBC) e o uso de consultas SQL. Outras formas de acesso direto poderão ser utilizadas, mas o desenvolvedor do componente deve prover a compatibilidade com os demais componentes.

O Gerenciador de Dados (GD) necessita que o usuário da plataforma possua um driver ODBC configurado para o acesso ao banco de dados a ser visualizado. Na inicialização do sistema, o usuário deve definir o nome de sistema do driver (DSN) e, caso necessário, o seu nome de usuário com a respectiva senha. O GD analisa o banco de dados e apresenta, em sua interface (Figura 4.3), um painel com o nome de todas as tabelas presentes. Caso o driver utilizado permita, o GD também procura pelas chaves primárias e estrangeiras pertencentes a cada tabela exibida, caso contrário a definição dessas chaves pode ser feita pelo usuário utilizando a interface da Figura 4.4.

\begin{tabular}{|c|c|c|c|c|c|}
\hline \multicolumn{2}{|c|}{ Tabelas de Dados } & Abrir Tabela & Abrir Consulta & Def. Chaves & \\
\hline $\begin{array}{l}\text { Tabela } \\
\text { pucmusus }\end{array}$ & $\begin{array}{l}\text { Ch. Primária } \\
\text { roct chermu }\end{array}$ & Ch. Estrangeira & Tab. Relacionada & Campo Relac. & \\
\hline postos & idPostos & & & & $\Delta$ \\
\hline profile & nia & & & & \\
\hline report & nia & & & & - \\
\hline states & STATE_ESRI & & & & $\equiv$ \\
\hline vacinas & Codvacina & & & & $\nabla$ \\
\hline
\end{tabular}

Figura 4.3 Interface do Gerenciador de Dados exibindo as tabelas presentes no Banco de Dados e suas chaves. 


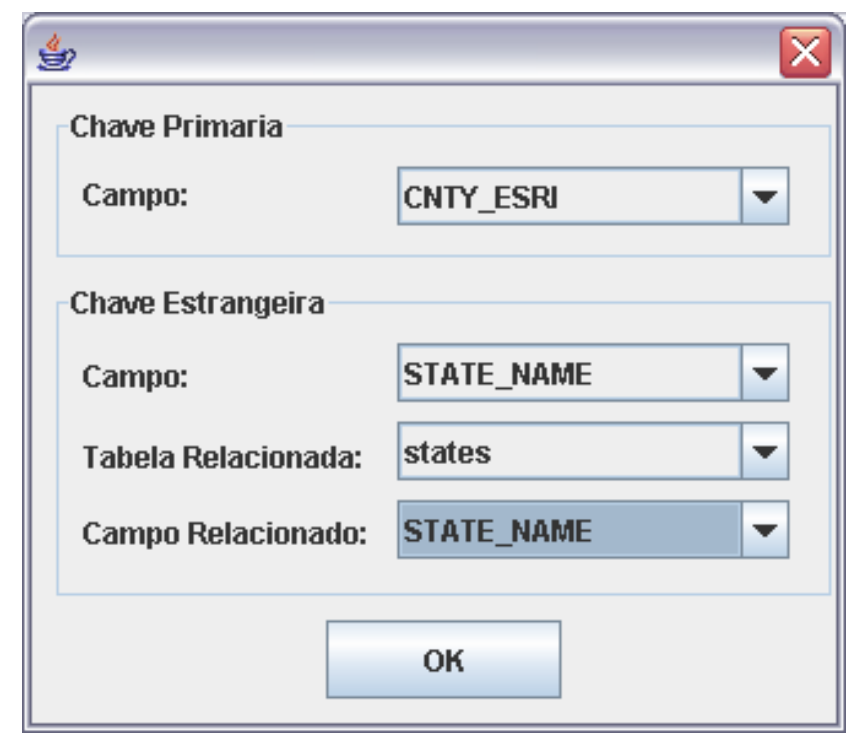

Figura 4.4 Interface para definição manual das chaves primária e estrangeira.

Para utilizar uma visualização, primeiramente escolhe-se a tabela de dados a ser visualizada e, em seguida, o Componente Funcional (CF) a ser utilizado. O GD fornece ao componente um objeto contendo os dados propriamente ditos no formato utilizado pelo JDBC, e possui métodos para recuperação de informações sobre as chaves da tabela. É possível utilizar como dados para a visualização o resultado de uma consulta SQL, mas nesse caso a definição das chaves deve ser feita no momento da abertura da consulta.

\subsection{Componentes Funcionais}

A versão inicial do InfoVis possuía poucos componentes, os quais foram criados para facilitar a exploração da base de dados pluviométricos que foi objeto de estudo de Shimabukuro em sua tese de doutorado [Shi 2003]. Esses componentes necessitavam de alterações para que pudessem manipular conjuntos de dados genéricos e ficar em conformidade com o novo modelo de coordenação. Apenas o componente Variação Temporal Uni-Escala, que era de uso específico aos dados pluviométricos, não foi atualizado e, por conseqüência, foi removido da plataforma.

Alem dos componentes atualizados da versão original (Tabela de Dados e Variação Temporal Multi-Escala), outros componentes criados por pesquisadores do grupo foram incorporados à plataforma InfoVis. Um destes é um componente de interação que implementa a técnica de Consultas Dinâmicas, e outro componente de visualização que implementa a 
técnica Coordenadas Paralelas. Para ampliar o número de técnicas disponíveis e possibilitar testes mais elaborados, também foram incorporados alguns componentes adaptados da plataforma Snap, que implementam as seguintes técnicas: TreeMap, Gráficos de Dispersão e outra implementação de Coordenadas Paralelas.

O processo de adaptação de componentes para inclusão na plataforma também foi alterado. A versão inicial do InfoVis especificava um protocolo com diversos métodos que deveriam ser implementados em cada componente. Verificou-se que uma grande parte desses métodos realiza tarefas que independem da função do componente, como setar gerenciadores, devolver o tipo ou o nome do componente, etc. Estes métodos foram encapsulados em uma classe base, evitando que o desenvolvedor necessite copiá-los para a sua classe. Outra vantagem de uma classe base abstrata é que toda classe derivada deve implementar os métodos abstratos presentes na classe base, o que permite que o desenvolvedor saiba claramente quais são esses métodos, sendo que mensagens de erro são geradas enquanto estes métodos não forem especificados. Esta nova abordagem tornou o processo de adaptação mais simples e menos confuso. Informações mais detalhadas sobre o modelo, sua implementação e o desenvolvimento de novos componentes são apresentadas no Capítulo 5. 


\section{O Modelo de Coordenação}

Dentre os modelos de coordenação estudados no Capítulo 3, o modelo proposto por Boukhelifa foi escolhido para nortear o desenvolvimento do modelo a ser utilizado na plataforma InfoVis, devido à sua característica de possibilitar a criação de vários tipos de coordenação, oferecendo uma solução simples e flexível capaz de acomodar futuras extensões e adaptações da plataforma. Nos moldes do modelo de Boukhelifa, o modelo proposto para a

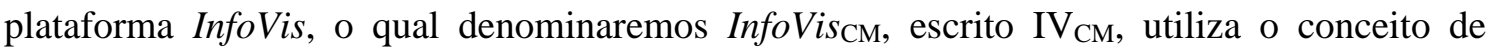
Objeto de Coordenação (OC), o qual oferece a base para uma estrutura extensível para a troca de informações entre as visualizações coordenadas.

$\mathrm{Na}$ Seção 5.1 é apresentado o modelo $\mathrm{IV}_{\mathrm{CM}}$ com suas características principais e funcionamento básico. Na Seção 5.2 são apresentados os detalhes de implementação de vários aspectos da solução incorporada na plataforma InfoVis, como diferenças em relação ao modelo de Boukhelifa, o novo Gerenciador de Ações, as mensagens XML utilizadas na comunicação entre os componentes. Também são descritos os processo de incorporação de novos Componentes Funcionais e de novas coordenações, segundo o modelo implementado.

\subsection{Modelo Conceitual}

Como discutido anteriormente, duas ou mais visualizações podem ser utilizadas em conjunto a fim de proporcionar mais recursos para a exploração dos dados. Os mecanismos de coordenação têm como função tornar aparentes as relações entre as visualizações, permitindo que as mesmas troquem informações sem que isso demande esforço adicional do usuário. A função do modelo de coordenação é definir como ocorre esta comunicação entre diferentes visualizações na plataforma. A seguir, serão revistos ou apresentados alguns termos do InfoVis que serão utilizados na apresentação do modelo:

- Componentes Funcionais (CFs). Implementam técnicas de visualização ou estratégias de interação aplicáveis a diferentes técnicas de visualização, de forma independente. Todo CF deve possuir uma lista das ações de coordenação que suporta.

- Gerenciador de Ações (GA). Componente responsável por gerenciar o estabelecimento das coordenações e a comunicação entre os CFs. Na versão anterior o GA basicamente registrava os pares de ações coordenadas, descritas na forma de duplas <ação 
acionadora, ação acionada>, e cuidava do repasse das mensagens entre as ações de um par.

- Parâmetros de Coordenação. Valores de alguma informação associada às visualizações, os quais podem variar desde informações sobre os dados, como identificadores ou valores de certo atributo, até informações sobre a exibição dos dados, como mapeamentos de cores ou posicionamento da câmera.

- Ação Acionadora. Uma ação iniciada pelo usuário e que pode ativar uma ou mais coordenações. É especificada por meio de uma dupla contendo o índice do CF que a originou e a descrição da ação. Exemplos de ações acionadoras seriam: selecionar um grupo de elementos, apontar um elemento de dados (mouse over), rotacionar a visualização, alterar a tabela de cores.

- Ação Acionada. Uma ação ativada em decorrência da ativação de uma coordenação. Também é identificada por uma dupla contendo o índice do CF alvo e a descrição da ação. Por exemplo: destacar elementos de dados, carregar os dados na visualização, rotacionar a visualização, alterar a tabela de cores. Note que algumas ações podem ser utilizadas como acionadoras e acionadas, sendo diferenciadas pelo modo como são ativadas: por interação do usuário ou pela ativação da coordenação.

Como discutido na Seção 4.2, o mecanismo de coordenação utilizado na versão da plataforma InfoVis disponibilizada em julho de 2004 era bastante limitado, admitindo apenas coordenações relacionais, nas quais os parâmetros de coordenação envolvem unicamente elementos de dados. No InfoVis elementos de dados do arquivo de entrada são identificados por um identificador seqüencial especificado pelo próprio sistema, esse identificador é utilizado na passagem de parâmetros entre coordenações para indicar os elementos afetados pela ação. Essa solução é limitada e dificulta a inclusão de novos componentes, a coordenação entre eles, e a coordenação entre componentes que manipulam tabelas de dados diferentes. Além disso, o mecanismo não possibilita o uso de qualquer outro tipo de informação como parâmetro de coordenação além dos identificadores de registros e, portanto, não suporta a inclusão de outros tipos de coordenação que não a relacional.

O novo modelo de coordenação para o InfoVis proposto no âmbito deste trabalho buscou tratar as limitações acima, e incluir mecanismos capazes de facilitar a inclusão de novos Componentes Funcionais, bem como a utilização de diferentes tipos de coordenação, além do tipo relacional. O modelo proposto apresenta as seguintes características principais: 
- Flexibilidade: O modelo pode utilizar como parâmetros de coordenação quaisquer tipos de dados, simples ou complexos, possibilitando a criação e o uso de diferentes tipos de coordenações. A utilização de tipos diferentes de dados resulta em tipos diferentes de OC que podem coordenar um conjunto diferente de ações. A Seção 6.3 apresenta vários exemplos de possibilidades de coordenação.

- Extensibilidade: A introdução de um tipo de coordenação ou de novos CFs não interfere no funcionamento do sistema. Para introduzir um novo tipo de coordenação, o desenvolvedor necessita apenas criar um novo padrão de mensagem trocada entre os CFs e garantir que os CFs que venham a utilizar o novo tipo de coordenação estejam aptos a gerar e tratar as mensagens nesse novo formato. Os outros CFs não necessitam ser alterados. Para que um novo CF seja introduzido e utilize os recursos de coordenação da plataforma basta que defina as suas ações coordenadas possíveis e implemente rotinas para a criação e recepção de mensagens específicas para um ou mais determinados tipos de coordenação. A Seção 5.4 apresenta mais informações sobre a inclusão de novos componentes e estratégias de coordenação.

- Multi-coordenação: No mecanismo anterior do InfoVis a coordenação era unidirecional e sempre envolvia dois componentes, sendo um componente acionador e um acionado. Coordenações entre múltiplos componentes ou coordenações bidirecionais somente poderiam ser definidas por meio da definição de várias coordenações entre pares, um processo demorado e confuso. O novo modelo permite estabelecer coordenações entre vários CFs. Uma coordenação no $\mathrm{IV}_{\mathrm{CM}}$ pode ser acionada por uma ação pertencente ao conjunto de ações acionadoras e, como resultado ativa todas ações acionadas registradas, como ilustra a Figura 5.1 Como exemplo, podemos citar a seleção compartilhada entre dois ou mais CFs, que no mecanismo anterior somente poderia ser obtida por meio do estabelecimento de $n^{2}$ coordenações, duas para cada par de CFs, e que no modelo atual pode ser definida por um único OC. 


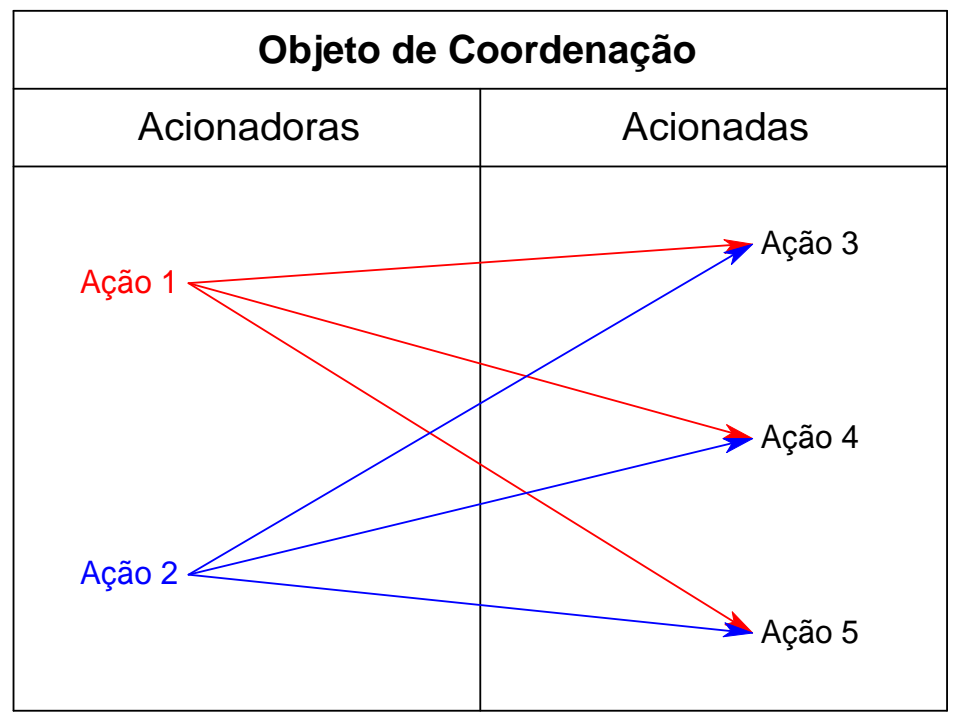

Figura 5.1 Esquema de ativação das ações em um OC

Para participar de uma coordenação, todo CF precisa definir suas ações suportadas (acionadoras e acionadas) e nessa definição encontramos, além da descrição da ação propriamente dita, uma definição de seu tipo. O tipo da coordenação não está relacionado ao comportamento da ação, mas sim com o tipo dos parâmetros de coordenação utilizados pela ação. Por exemplo, uma ação de centralizar pode ser considerada uma ação relacional se for aplicada a um conjunto de elementos do arquivo de entrada. Nesse caso, a informação utilizada como critério para definir como a ação será executada seria o conjunto de índices dos elementos de dados que irão sofrer a ação e, portanto, a ação de centralizar utilizaria como parâmetro esses conjunto de índices. Em outro caso, esta mesma ação pode se referir a um ajuste na exibição da cena, e seria tratada por um OC que utiliza como parâmetros as coordenadas cartesianas da projeção da cena, as quais podem especificar diretamente a posição a ser centralizada.

Uma coordenação no $\mathrm{IV}_{\mathrm{CM}}$ é representada por um Objeto de Coordenação (OC) que é responsável por gerenciar a coordenação verificando as ações acionadoras e a ativação das ações acionadas. Para isso o OC contém as seguintes informações sobre a coordenação: componentes funcionais (visualizações) e respectivas ações acionadoras, componentes funcionais e respectivas ações acionadas, e o tipo da coordenação. Os OCs são instanciados e armazenados pelo GA, que também provê uma interface para que o usuário crie e modifique os OCs.

A definição do tipo do OC ocorre no momento em que o usuário define a primeira ação, fazendo com que o OC receba, como tipo associado, o tipo da primeira ação adicionada. 
Desse ponto em diante, apenas ações que possuam o tipo requerido pelo OC podem ser adicionadas, o que garante a compatibilidade entre as mensagens trocadas pelos diferentes CFs. A lista de ações acionadas é utilizada pelo OC para determinar quais ações ativam a coordenação, e uma vez ativada, todas as ações presentes na lista de ações acionadas são ativadas. Caso o usuário deseje ter um maior controle sobre quais ações ativam outras ações, é necessário criar um OC para cada coordenação.

A Figura 5.2 ilustra o funcionamento da coordenação segundo o novo modelo. Ao ter uma de suas ações acionadoras inclusas em um OC, o CF incrementa uma variável que indica o numero de OCs em que a ação está registrada. Após a instanciação e o registro das demais ações coordenadas, o usuário pode realizar uma interação em um CF. Nesse momento a variável descrita acima é consultada e, caso seu valor seja superior à zero, o CF envia ao GA uma mensagem contendo a descrição da ação acionadora realizada (dupla contendo o índice do CF no qual a ação foi realizada e a descrição da ação) e os valores dos parâmetros de coordenação envolvidos.

A mensagem é repassada a todos OCs instanciados, e cada um deles verifica se a ação está registrada como ativadora da coordenação. Uma vez ativada a coordenação, o OC monta uma nova mensagem para cada ação acionada registrada inserindo o índice do componente a ser acionado, a ação a ser executada e os parâmetros de coordenação com seus valores (copiados da mensagem acionadora), e pede ao GA que envie a mensagem aos respectivos CFs. Finalmente, os CFs recebem as mensagens e executam as ações requisitadas, com base nos parâmetros repassados, realizando as traduções necessárias.

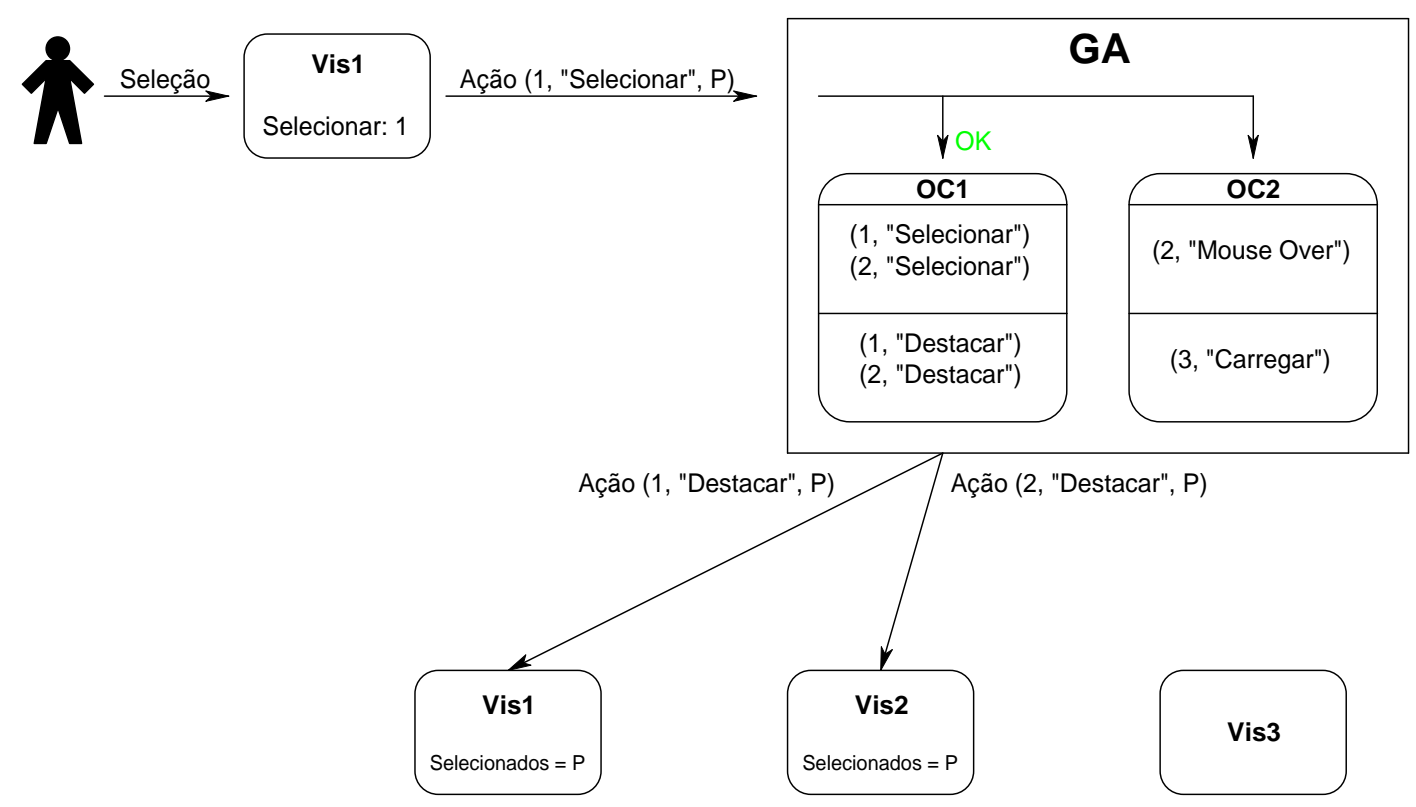

Figura 5.2 Esquema de funcionamento das coordenações no modelo $\mathrm{IV}_{\mathrm{CM}}$. 


\subsection{Implementação}

Essa Seção apresenta em maiores detalhes, alguns aspectos da implementação do modelo de coordenação que merecem uma atenção especial.

\subsubsection{Sobre o Modelo de Boukhelifa}

O modelo de Boukhelifa é bastante genérico e abstrato, de maneira que, no âmbito deste trabalho, optou-se por introduzir algumas modificações, especificações e simplificações:

- No modelo de Boukhelifa, em resposta a uma ação executada pelo usuário os OCs apenas notificam as visualizações coordenadas (Componentes Funcionais (CFs) no InfoVis) de que os valores de seus parâmetros foram alterados, cabendo às próprias visualizações a verificação das alterações realizadas nos valores dos parâmetros e a ativação das funções de tradução, responsáveis por transformar os dados contidos no parâmetro em um formato compreensível para a respectiva visualização. No modelo $\mathrm{IV}_{\mathrm{CM}} \mathrm{O}$ OC é responsável por notificar a ocorrência de uma ação por meio do envio de uma mensagem XML contendo, além da descrição da ação a ser realizada, os novos valores dos parâmetros alterados envolvidos, sem que haja necessidade de uma requisição por parte do $\mathrm{CF}$.

- No modelo $\mathrm{IV}_{\mathrm{CM}}$ todo OC armazena, além dos valores de seus parâmetros de coordenação, duas listas contendo as ações envolvidas na coordenação, sendo cada ação especificada pelo par $<C F$ acionador, descrição da ação realizada $>$. A primeira lista armazena as ações acionadoras da coordenação, e a segunda lista armazena as ações acionadas. Qualquer ação acionadora realizada ativa o conjunto de ações acionadas.

- O modelo de Boukhelifa não especifica onde e como ocorre a verificação de um evento, i.e., se o evento ativa (ou não) um determinado objeto de coordenação. No modelo $\mathrm{IV}_{\mathrm{CM}}$ esta tarefa fica a cargo de cada $\mathrm{OC}$, que recebe todos os eventos gerados pelo sistema com os valores dos parâmetros (mensagem XML) e verifica se a ação realizada se encontra na sua lista interna de ações acionadoras da coordenação. Apenas ações registradas em um ou mais OCs geram eventos, diminuindo o número de verificações necessárias. 
- No IV $\mathrm{IM}_{\mathrm{CM}}$ toda ação coordenada está associada a um tipo, que especifica a natureza da informação contida nos parâmetros de coordenação. Essa classificação permite maior controle sobre as ações que podem ser utilizadas em associação a cada tipo de OC.

$\mathrm{Na}$ incorporação do novo modelo de coordenação, algumas questões relativas à extensibilidade da plataforma foram levantadas. Em uma primeira implementação, cada tipo de OC foi implementado como uma classe derivada de uma classe básica de OCs. Nessa abordagem, uma nova classe deveria ser implementada para cada novo tipo de OC a ser incorporado, prejudicando a extensibilidade do modelo de coordenação e da plataforma. Em contrapartida, características específicas de cada tipo de OC, como as funções de tradução, passariam a ser introduzidas diretamente em cada CF que a necessitasse.

Como a característica marcante de plataforma InfoVis é a extensibilidade, procurou-se adotar uma nova abordagem de implementação que eliminasse a necessidade de desenvolver uma nova classe para cada tipo de OC a ser incorporado. Primeiramente, foi eliminado o armazenamento dos valores dos parâmetros pelo OC. Essa função tornou-se desnecessária quando esses valores foram incorporados às mensagens de notificação, que são assim repassados diretamente a todas as visualizações.

A generalização dos objetos de coordenação implica em sua simplificação, pois os OCs, passam a ser responsáveis apenas pelo registro das ações envolvidas em uma determinada coordenação, pela verificação de ativação de uma ação coordenada, e pelo repasse das mensagens aos CFs registrados. A implementação de funções de tradução das mensagens (se necessária) fica a cargo de cada $\mathrm{CF}$, bem como a implementação de outros elementos básicos do modelo de Boukhelifa, como controle de escopo e atualização (descritos na Seção 3.2).

Com as modificações descritas acima os OCs podem utilizar qualquer tipo de dado, sendo que o tipo de OC não é mais definido pela classe, mas pelo formato da mensagem XML. A definição do formato da mensagem será utilizada como definição dos tipos dos parâmetros trocados na coordenação, caracterizando o tipo de OC. O tipo do OC é uma propriedade textual do mesmo, e é utilizada para verificar quais ações podem ser utilizadas em conjunto com aquela instância de OC pra que não ocorra incompatibilidade na troca de mensagens.

Caso seja necessário criar um novo tipo de OC que necessite salvar informações ou implementar funções de tradução mais complexas ainda existe a possibilidade de se extender a classe básica de OCs, incorporando novas propriedades e/ou reimplementando a função de transferência de parâmetros de coordenação. Na Seção 6.2 ilustramos um exemplo de coordenação que faz uso da definição de uma nova classe de OCs. 


\subsubsection{Sobre o Gerenciador de Ações (GA)}

O GA é o responsável por instanciar e gerenciar os Objetos de Coordenação (OCs), os quais são armazenados em um vetor. O GA também cuida da troca de informações entre os OCs e os outros componentes da plataforma. Quando um Componente Funcional (CF) deseja repassar um evento aos OCs, ele envia sua requisição ao GA que, por sua vez, a repassa a todos OCs. Do mesmo modo, um OC que deseja enviar uma requisição de ação a um CF envia a sua requisição contendo o índice do $\mathrm{CF}$ ao GA, e este se encarrega de repassar ao CF correspondente. Deste modo, os CFs não precisam saber em quais OCs estão registrados, possibilitando que seu funcionamento seja independente. Os OCs, por sua vez, apenas necessitam do índice do CF, e não precisam saber como repassar as informações aos CFs e nem com qual tipo de componente estão interagindo.

A interface com o usuário do GA (Figura 5.3) apresenta uma tabela com a descrição dos OCs ativos, contendo o nome do OC (definido pelo usuário), a descrição de seu tipo e a quantidade de ações acionadoras e acionadas registradas. Possui, também, controles que permitem criar, editar e destruir objetos de coordenação.

\begin{tabular}{|l|l|l|l|l|}
\hline \multicolumn{2}{|c|}{ Objetos de Coordenação } & Nowo & Editar & \multicolumn{1}{c|}{ Excluir } \\
\hline \multicolumn{1}{|c|}{ Nome } & \multicolumn{2}{|c|}{ Tipo } & \# Acionadores & \# Acionados \\
\hline \# Obj. & Filtro CP & Relacional & 1 & 1 \\
\hline 1 & Selecao Compartilhada & Relacional & 2 & 2 \\
\hline 2 & Tabela de Cores & Color Table & 1 & 1 \\
\hline & & & \\
\hline
\end{tabular}

Figura 5.3 Área de interface do GA indicando três OCs ativados.

\subsubsection{Sobre as mensagens $\mathrm{XML}$}

A troca de informações entre os CFs e os OCs se dá por meio de mensagens XML. A Figura 5.4 apresenta o esquema XML dessas mensagens. 


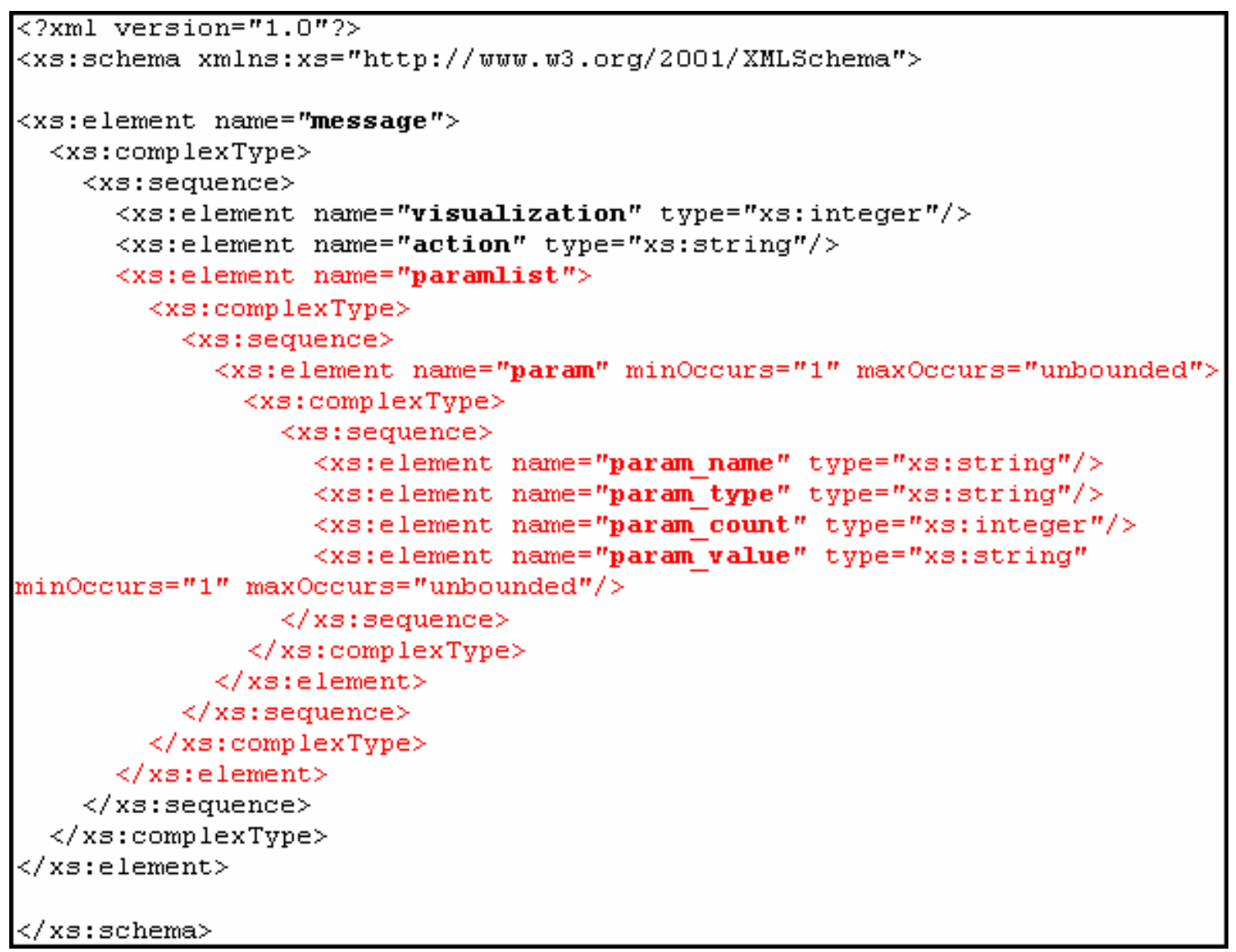

Figura 5.4 XML Schema das mensagens trocadas pelos componentes

No caso de uma ação acionadora a mensagem XML é criada pelo CF e enviada ao OC. O elemento visualization contém o índice do CF que realizou a ação, e o elemento action armazena a descrição textual da ação realizada (ex.: Selecionar). Já no caso de uma ação acionada, o OC envia uma mensagem diferente para cada $\mathrm{CF}$ acionado. $\mathrm{O}$ elemento visualization armazena o identificador do CF acionado (um índice) e a descrição da ação a ser realizada é fornecida no elemento action.

O elemento paramlist (em destaque) engloba todas as informações relativas aos parâmetros utilizados na coordenação. O OC não analisa seu conteúdo, apenas copia o elemento trazido pela mensagem da ação acionadora para todas as mensagens das ações acionadas. Cada tipo de OC requer certa formatação para os sub-elementos contidos neste elemento, mas todos eles podem ser verificados pelo esquema acima. O esquema é composto por uma lista de elementos param, em que cada elemento contém a descrição do parâmetro <param_name>, o seu tipo de dado <param_type>, a quantidade de valores <param_count $>$ e um ou mais valores <param_value>, possibilitando o uso de vetores como parâmetros. Outras formatações podem ser utilizadas, pois como mencionado o OC não realiza nenhum tipo de verificação dessas informações. 
A Figura 5.5 ilustra dois exemplos de mensagens XML. A primeira delas é uma mensagem referente a um OC do tipo relacional, e contém no elemento <param> os valores das chaves que identificam os elementos envolvidos na coordenação, organizados em único parâmetro, um vetor com os valores das chaves. O segundo exemplo apresenta uma mensagem que especifica uma tabela de mapeamento de cores, descrita por meio de três vetores: um indica os valores mínimos que definem cada intervalo de cor, outro indica os valores máximos, e o último indica os respectivos valores das cores associadas a cada intervalo.

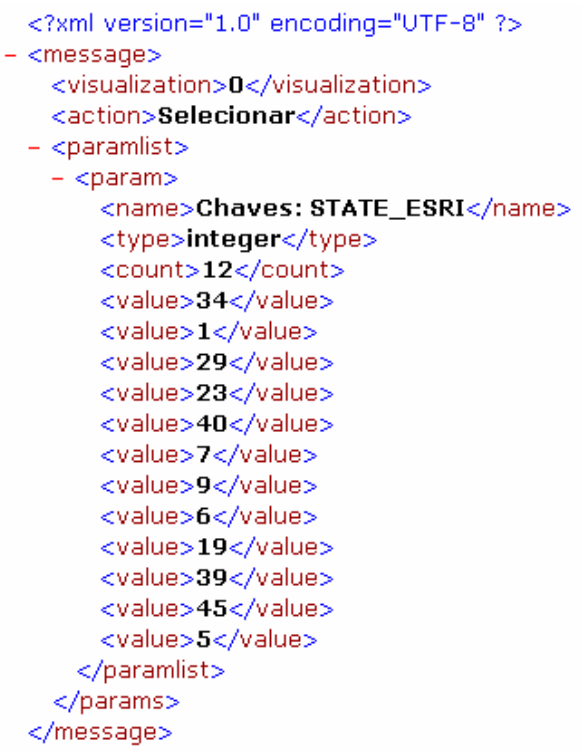

(a)

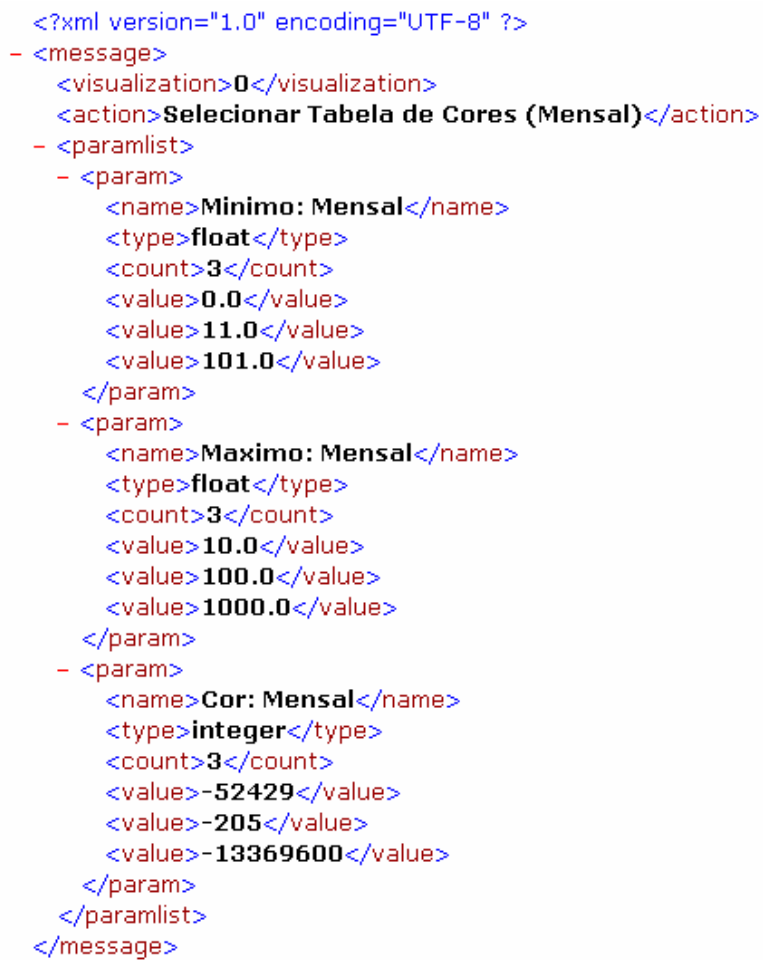

(b)

Figura 5.5 Exemplos de mensagens XML utilizando como parâmetros chaves de identificação (a) e atributos de uma tabela de cores (b).

\subsubsection{Sobre a definição dos Componentes Funcionais}

Um CF no InfoVis precisa definir uma interface que estende a classe base InfoVisComponent, a qual agrega todos os métodos e propriedades necessários para o gerenciamento dos componentes. A classe base, por sua vez, é derivada da classe Jframe, nativa da linguagem Java. No Anexo A é apresentado o código de um exemplo completo de inclusão de um componente e algumas observações sobre a implementação. 
Todo componente deve implementar o método setTableData, cuja função é repassar ao CF o conjunto de dados fornecido pelo GD e realizar todos os procedimentos necessários para inicializar esses dados na visualização implementada pelo CF. Os dados são repassados no formato ResultSet, utilizado pela linguagem Java para encapsular todas as informações referentes a uma tabela de dados. O GD também fornece, junto com os dados, um conjunto de meta informações referentes às chaves da tabela carregada. O novo componente também precisa definir o método showGUI utilizado para ativar a visualização e exibir sua interface na tela.

Um CF precisa definir quais ações coordenadas suporta. Um vetor presente na classe base armazena objetos do tipo CoordAction, os quais são utilizados para definir uma ação coordenada. Essa definição requer o nome da ação - esse nome será utilizado para apresentação na interface e como identificador da ação -, o tipo de OC que pode registrar essa ação, e se a respectiva ação é acionadora da coordenação ou se é acionada por ela.

O desenvolvedor do componente deve avisar ao GA toda vez que uma interação do usuário resultar em um evento que pode disparar uma ação coordenada, embora seja possível checar se a respectiva ação encontra-se registrada em algum OC antes da criação e envio da mensagem. O CF deve criar uma mensagem XML contendo o índice identificador do componente, a identificação da ação realizada e os valores dos parâmetros a serem modificados. Existe uma rotina do GA para automatizar o processo de criação de mensagens em que os parâmetros da coordenação são os valores de chaves que identificam os elementos afetados (utilizados nas coordenações em que o OC é do tipo relacional). Quando uma coordenação é ativada o GA repassa a mensagem aos CFs com ações acionadas registradas, chamando o método DoAction. Esse método deve incluir instruções para a recuperação das informações contidas na mensagem XML e a execução da respectiva ação.

O desenvolvedor deve se certificar de que seu componente esteja enviando e recebendo mensagens no formato exigido pelo tipo de OC no qual se enquadra a sua ação coordenada. Com a finalidade de facilitar essa tarefa foram implementadas no GA funções para a criação e recuperação de elementos específicos da mensagem. Para a criação de mensagens, existe a classe de objetos CoordMsg, cujo construtor requer como parâmetros o índice do componente e a ação correspondente.

A classe CoordParam encapsula as informações sobre um parâmetro de coordenação. Seu construtor necessita da descrição do parâmetro, a descrição do tipo (inteiro, real, etc.) e um vetor contendo os parâmetros no formato string. Os parâmetros podem, então, ser adicionados à classe CoordMsg por meio do método $A d d$. Após a inclusão de todos parâmetros de 
coordenação, a chamada ao método generateDoc realiza todas as operações necessárias ao documento XML passado como parâmetro, para que o mesmo possa ser enviado ao GA.

Para facilitar a recuperação de dados específicos contidos na mensagem, o GA possui os seguintes métodos, todos utilizando a mensagem XML como parâmetro:

- public int getIndex(Document Doc): retorna o índice do componente que criou a mensagem (ação acionadora) ou o índice do componente para o qual a mensagem é destinada (ação acionada).

- public String getActionName(Document Doc): retorna a descrição da ação realizada (ação acionadora) ou a descrição da ação a ser realizada (ação acionada)

- public String getParamName(Document Doc, int n): retorna a descrição do parâmetro $n$ (sendo $n=1$ o primeiro parâmetro).

- public String getParamType(Document Doc, int $n$ ): retorna o tipo associado ao parâmetro $n$.

- public Vector getParamValues(Document Doc, int $n$ ): retorna um vetor contendo objetos com os valores do parâmetro $n$. Utiliza o método acima para definir o tipo de objeto a ser retornado.

- public Vector getStringParamValues(Document Doc, int n) retorna um vetor contendo os valores do parâmetro $n$ no formato de string de texto.

Resumindo, para incluir um novo CF o desenvolvedor deve:

- Fornecer um método para carregar no CF os dados enviados pelo GD quando ocorre a ativação do componente;

- Definir as ações coordenadas que seu componente pode realizar;

- Gerenciar a interação do usuário, gerando um evento para cada ação passível de coordenação;

- Responder ao envio de mensagens do GA quando da ativação da coordenação, efetuando as ações requisitadas.

Após a adequação do componente, ele estará pronto para uso, podendo ser selecionado na janela de seleção de visualização As suas ações coordenadas poderão ser incluídas nos OCs, desde que o tipo da ação seja idêntico ao tipo do OC. No Capítulo 6 são apresentados alguns resultados de processos de inclusão de componentes na plataforma InfoVis, após a implementação do novo modelo. 


\subsubsection{Sobre a definição de novos tipos de coordenação}

Pode ocorrer uma situação em que o desenvolvedor deseje definir novas formas de coordenação, utilizando outros tipos de informações como parâmetros da coordenação. Nesse caso, o desenvolvedor ficaria encarregado de criar um nome para o novo tipo de OC e um novo formato de mensagem XML para tratar da passagem dos dados, mas sempre obedecendo ao padrão do XML Schema apresentado anteriormente. O único elemento que necessita de modificações é o elemento <params> e seus sub elementos.

Como exemplo, a versão atual do InfoVis não incorpora nenhuma técnica de visualização em três dimensões, mas futuramente CFs que implementem técnicas 3D podem vir a ser incorporados à plataforma. Um usuário poderia desejar coordenar as transformações 3D (escala, rotação, translação) que estas visualizações viessem a sofrer. Para permitir esse novo tipo de coordenação, o desenvolvedor poderia criar um novo tipo de OC e implementar rotinas para a geração e o tratamento das mensagens nos CFs que utilizarão esse tipo de coordenação. No Capítulo 6 são apresentados este e outros exemplos que ilustram a definição de novas estratégias de coordenação, e os respectivos padrões de mensagens utilizados. 


\section{Cenários de Uso}

Nesse capítulo apresentamos alguns cenários de uso que abrangem desde o uso do sistema por usuários finais, até o seu uso por desenvolvedores que desejam incluir novos componentes ou introduzir diferentes estratégias de coordenação na plataforma.

Exemplos que apresentam a interface da nova versão do InfoVis e ilustram o seu uso por usuários são apresentados na Seção 6.1. A Seção 6.2 apresenta vários exemplos de estratégias de coordenação que podem ser estabelecidas utilizando o modelo IV ${ }^{\mathrm{CM}}$. A Seção 6.3 ilustra alguns exemplos de inclusão à plataforma de novos CFs e coordenações associadas, realizadas pelo desenvolvedor do modelo e por terceiros.

\subsection{Interface com o Usuário e Definição de Coordenações}

A interface com o usuário do InfoVis foi alterada em relação à original. Essa alteração se deve, basicamente, à inclusão do Gerenciador de Dados (Seção 4.4), o que altera a forma em que os dados a serem visualizados são carregados. Na versão anterior, o usuário iniciava uma sessão escolhendo, a partir de um menu com as opções disponíveis, os Componentes Funcionais (CF) a serem utilizados. Cada CF ficava responsável por abrir o conjunto de dados a ser visualizado. Na versão disponibilizada como resultado deste trabalho, o usuário define primeiramente a tabela de dados a ser visualizada e, na seqüência, os CFs a serem utilizados para visualizar esses dados.

A interface principal do InfoVis com o usuário, apresentada na Figura 6.1, contém uma área associada a cada um dos quatro componentes gerenciadores da plataforma (Gerenciador de Dados - GD, Gerenciador de Componentes - GC, Gerenciador de Ações - GA e Gerenciador de Históricos - GH). A área do GD apresenta todas as tabelas presentes no Banco de Dados com informações sobre as suas chaves. Como exemplo, usamos essa interface para instanciarmos dois CFs: Coordenadas Paralelas e Treemap. Para instanciar os CFs, selecionamos a tabela a ser utilizada, no caso a tabela States (contendo dados sobre os estados norte-americanos), e pressionamos o botão "Abrir Tabela", o qual apresenta a lista dos CFs possíveis onde escolhemos a técnica a ser utilizada.

$\mathrm{Na}$ área do GC é apresentada a lista dos CFs ativos (no momento, temos dois CFs ativados (Coordenadas Paralelas e Treemap), e na área do GA é apresentada a lista de Objetos de Coordenação Ativos, definidos durante a sessão de uso. Para criar um novo objeto de 
coordenação, basta clicar no botão Novo na área de interface do GA e uma interface para a escolha da primeira ação a ser coordenada será exibida (Figura 6.2). Uma vez selecionado o $\mathrm{CF}$, o GA requisita ao mesmo a lista de suas ações suportadas, a qual é apresentada ao usuário para que ele defina a ação coordenada associada. Após a definição da primeira ação, um novo objeto de coordenação é instanciado e seu tipo é definido com base no tipo da ação. Como exemplo, selecionamos um CF que implementa a técnica Coordenadas Paralelas e a ação de "Selecionar". O tipo da ação, nesse caso, é relacional e, portanto, o tipo do novo Objeto de Coordenação (OC) instanciado também é relacional.

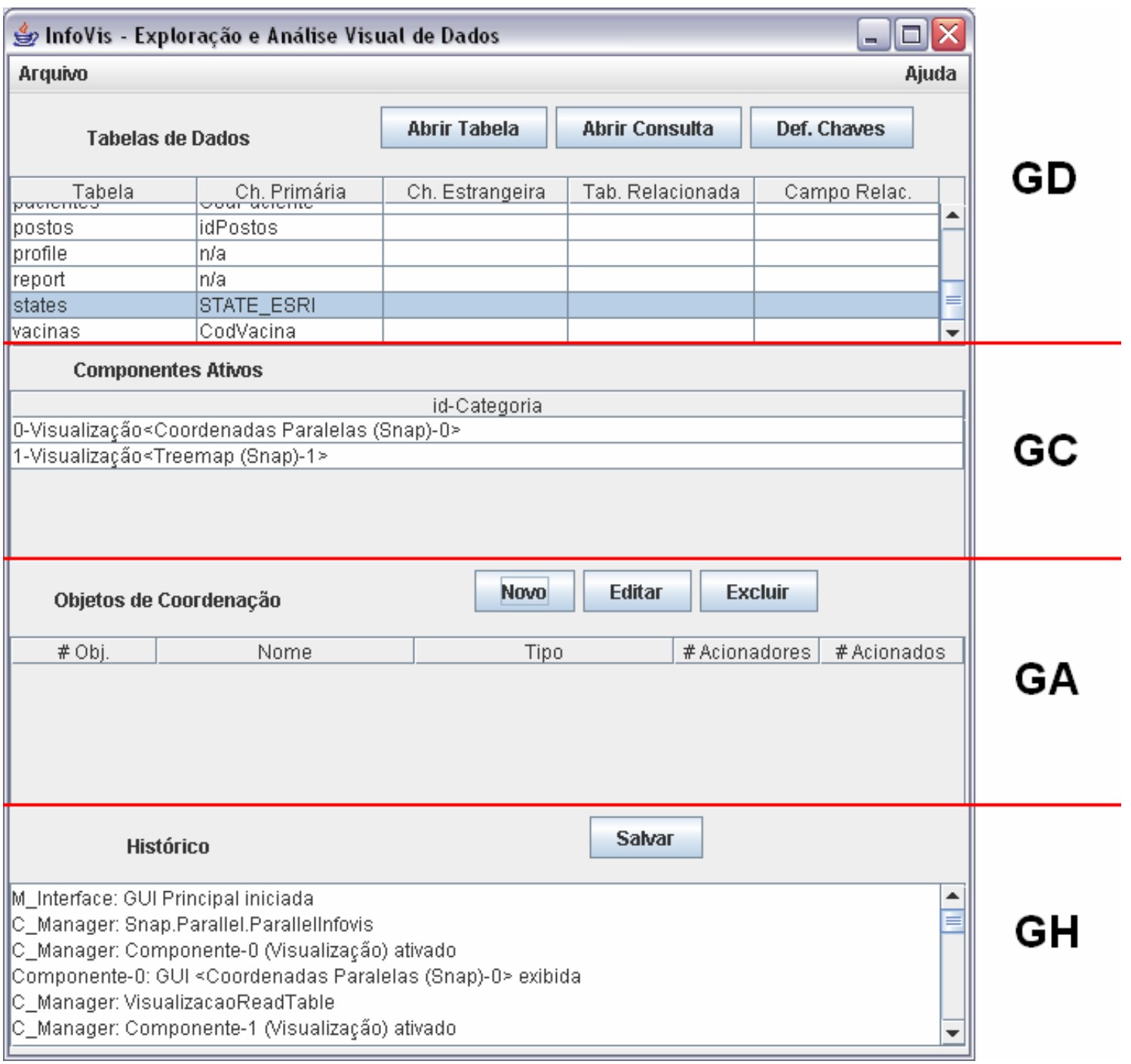

Figura 6.1 Interface principal do InfoVis ilustrando os componentes gerenciadores (GD: Gerenciador de Dados, GC: Gerenciador de Componentes, GA: Gerenciador de Ações e GH: Gerenciador de Históricos. 


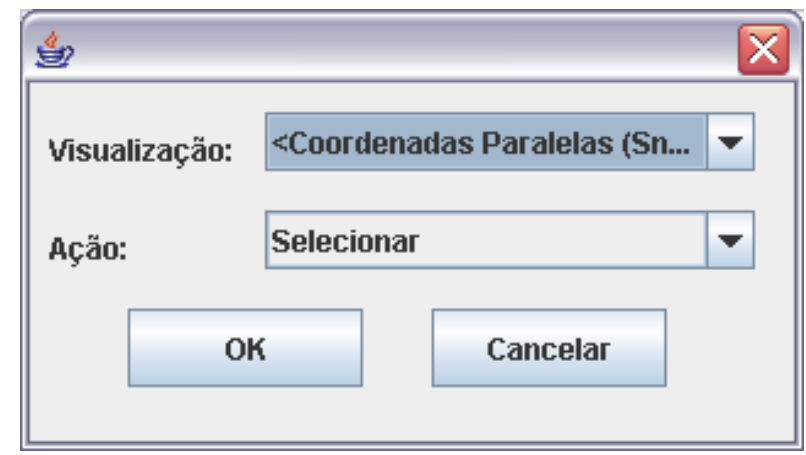

Figura 6.2 Interface para escolha das ações coordenadas

Novas ações podem ser incluídas em um OC já instanciado por meio da interface da Figura 6.3, que apresenta as informações sobre um OC específico. Essa janela é apresentada após a criação de um novo OC, ou pode ser acessada pelo botão Editar na interface principal (área do GA). Assim que o usuário escolhe um $\mathrm{CF}$ o OC faz um cruzamento entre o seu tipo (definido pela primeira ação) e o tipo das ações suportadas pelo CF escolhido, para definir quais ações serão exibidas para escolha do usuário. O OC restringe a inclusão de novas ações, impossibilitando que ações não compatíveis com o seu tipo sejam incluídas. Não faz sentido, por exemplo, incluir uma ação "Destacar" que utiliza como parâmetro as chaves de cada registro em um OC que coordena tabelas de cores. Continuando o exemplo, adicionamos agora novas ações coordenadas ao objeto de coordenação já instanciado, definindo a ação acionadora "Selecionar" para o Treemap, e duas ações acionadas "Destacar" para os outros dois componentes funcionais, resultando em uma seleção compartilhada entre as três visualizações, i. e., toda vez que ocorre uma seleção em qualquer uma das visualizações, as demais refletem essa seleção, destacando os elementos selecionados. 


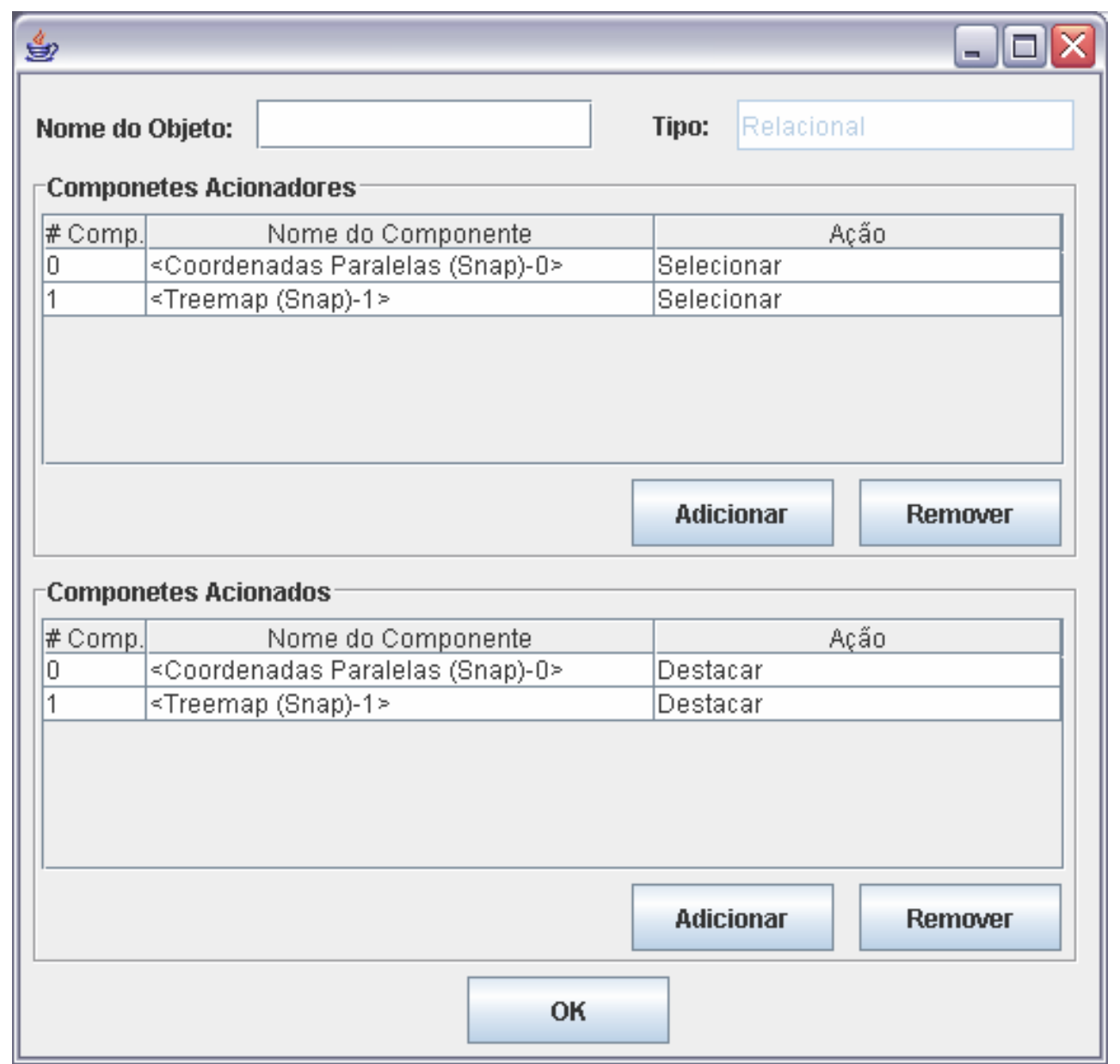

Figura 6.3 Interface de um OC contendo duas ações acionadoras e duas ações acionadas

Para acrescentar uma nova coordenação que explore relacionamentos entre diferentes tabelas de dados relacionadas entre si por meio de chaves estrangeiras e chaves primárias, devemos, primeiramente, nos certificar de que a chave estrangeira esteja definida na interface do Gerenciador de Dados. Caso não esteja, o usuário pode utilizar a interface do GD para definir das chaves, como ilustrado na Figura 6.4. Continuando o exemplo anterior, suponha que estamos utilizando duas tabelas de dados: States (carregada nas visualizações Coordenadas Paralelas e Treemap) e Counties (contendo dados sobre os condados, e relacionada com a tabela anterior por uma variável que informa o nome do estado ao qual o condado pertence). Definimos uma chave estrangeira na tabela Counties, a ser relacionada com a tabela States, e utilizamos as novas definições de chaves para instanciar um novo componente CF do tipo Tabela de Dados, e adicionamos ao nosso OC uma nova ação de “Carregar” para este CF, utilizando a chave estrangeira. Agora, qualquer seleção efetuada em uma das outras visualizações resulta no carregamento dos elementos de dados relacionados no CF Tabela de Dados. Caso o usuário deseje ativar o carregamento dos dados apenas quando a 
seleção é realizada no componente Coordenadas Paralelas (desvinculando a coordenação do Treemap e da outra Tabela) seria necessário criar um novo OC que incluísse apenas a ação acionadora requisitada. Isso porque a realização de qualquer ação acionadora registrada no objeto ativa a coordenação e, por conseqüência, ativa todas as ações acionadas - todas elas são vinculadas à ação acionadora 'Selecionar'. A Figura 6.5 ilustra o esquema de coordenação e a relação entre as tabelas.

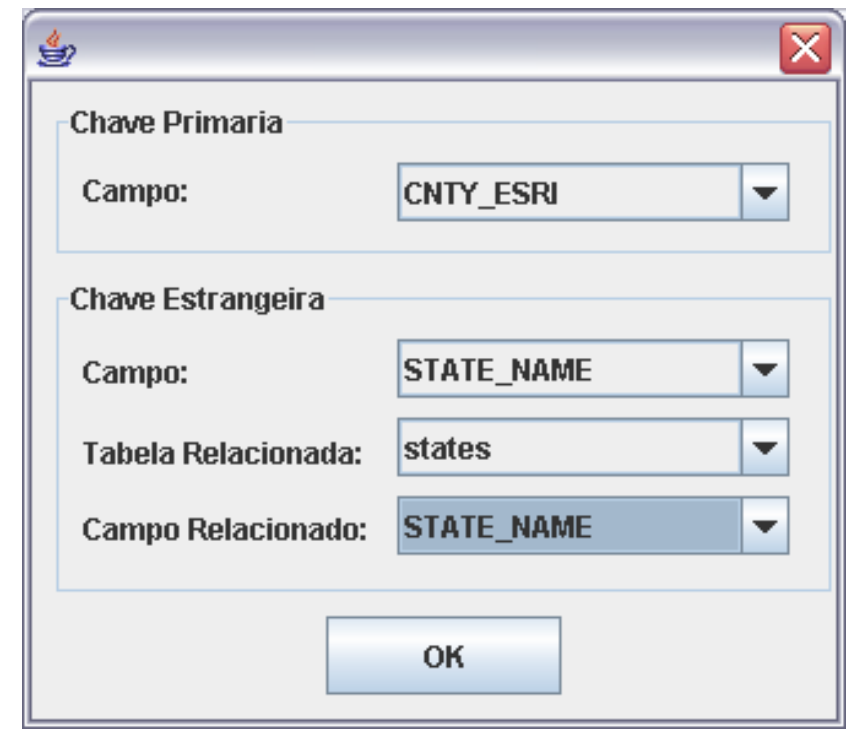

Figura 6.4 Interface para definição de chaves primárias e estrangeiras.

Durante os testes, a interface para o estabelecimento de coordenações se mostrou um pouco trabalhosa, pois a definição de cada ação coordenada precisa ser feita individualmente, e sem o apoio de recursos gráficos. Para facilitar a interação do usuário é oferecida uma opção no menu principal para salvar e restaurar o estado do sistema, que registra o estado da sessão com os CFs ativados e seus respectivos conjuntos de dados, e os OCs instanciados e as suas respectivas ações coordenadas definidas. A interface com o usuário não foi o foco deste trabalho, e pode ser melhorada em futuras versões da plataforma. 


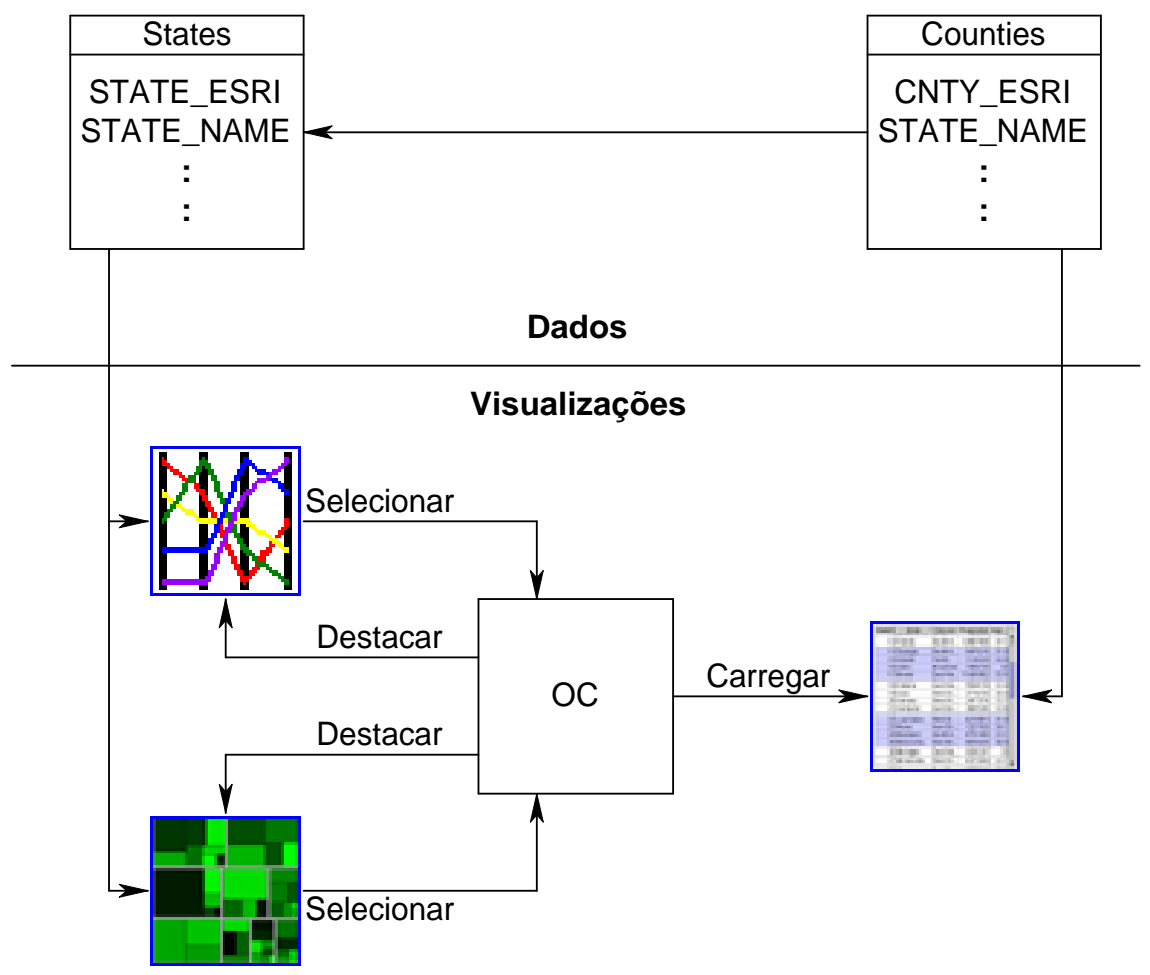

Figura 6.5 Esquema de coordenação utilizando chaves estrangeiras, apresentando também a relação entre as tabelas.

\subsection{Inclusão de Novos Tipos de Coordenação}

$\mathrm{O}$ modelo $\mathrm{IV}^{\mathrm{CM}}$ permite definir e utilizar diferentes estratégias de coordenação na plataforma InfoVis. O objetivo desta seção é ilustrar como várias coordenações possíveis poderiam ser definidas na plataforma, com base no modelo. As duas primeiras coordenações aqui descritas estão implementadas na plataforma e seus exemplos já foram ilustrados anteriormente. As outras soluções ilustradas nessa seção ainda não foram implementadas na plataforma, mas o objetivo é discutir como isso poderia ser feito, exemplificando o formato da mensagem XML que poderia ser utilizado para estabelecer a comunicação entre os componentes e citando um exemplo da mesma.

\subsubsection{Coordenações Relacionais}

As coordenações relacionais utilizam como parâmetros identificadores de elementos de dados, os quais, na implementação atual, são representados por valores das chaves primária ou 
estrangeira de uma tabela. Esse é um tipo freqüente de coordenação que engloba uma grande variedade de ações possíveis, como seleção, destaque e filtragem de elementos, carregamento de elementos específicos, centralização de um ou mais elementos, entre outras.

A mensagem XML utilizada em um OC do tipo relacional tem o seguinte formato (o esquema de uma mensagem desse tipo foi ilustrado na Figura 5.5(a)):

- Tipo do Objeto: Relacional

- Parâmetros:

○ Nome: Chaves: <NomedoAtributoChave >

○ Descrição: Valores das chaves afetadas pela ação.

○ Tipo: Vetor (o tipo dos objetos contidos no vetor depende do tipo do atributo utilizado como chave e deve ser especificado pelo elemento XML param.type)

\subsubsection{Tabelas de Cores}

Duas ou mais visualizações podem compartilhar o mapeamento de cores utilizado, de modo que alterações introduzidas no mapeamento sejam refletidas simultaneamente nas múltiplas visualizações. Neste caso, o parâmetro de coordenação seria a especificação do mapeamento de cores a ser utilizado. Essa especificação pode ser feita, por exemplo, informando a tabela de cores, por exemplo listando os limites inferior e superior de cada intervalo de valores e sua respectiva cor associada. A mensagem XML poderia utilizar o seguinte padrão, no qual o três parâmetros consistem, respectivamente, em um vetor com os limites inferiores de cada intervalo de cor, um vetor com os respectivos limites superiores desses intervalos, e um com os valores de cor propriamente ditos (o esquema de uma mensagem desse tipo foi ilustrado na Figura 5.5(b)):

- Tipo do Objeto: Tabela de Cores

- Parâmetro 1:

○ Nome: Mínimo <NomeDaTabela $>$

○ Descrição: Valores dos limites inferiores dos intervalos

○ Tipo: Vetor de reais

- Parâmetro 2:

○ Nome: Máximo <NomeDaTabela $>$

○ Descrição: Valores dos limites superiores dos intervalos 
○ Tipo: Vetor de reais

- Parâmetro 3:

○ Nome: Cor <NomeDaTabela>

- Descrição: Valores primários que definem as cores associadas, respectivamente, a cada intervalo

○ Tipo: Vetor de triplas de inteiros (formato RGB)

\subsubsection{Transformações 3D}

Duas ou mais visualizações 3D podem compartilhar transformações como rotação, translação e escala. Os parâmetros de coordenação, nesse caso, devem incluir um identificador da transformação (string) e os seus respectivos parâmetros para cada eixo cartesiano (x, y, z). O padrão da mensagem XML poderia ser o seguinte:

- Tipo do Objeto: Transform3D

- Parâmetros:

○ Nome: Coordenadas

- Descrição: Valores da transformação para cada coordenada cartesiana

○ Tipo: Vetor de três reais $(\mathrm{x}, \mathrm{y}, \mathrm{z})$

Utilizando esse padrão uma rotação de noventa graus $\left(90^{\circ}\right)$ em torno do eixo $\mathrm{X}$ seria descrita como 'Rotação' com parâmetros $(90,0,0)$ como ilustra a Figura 6.6.a

Esse tipo coordenação pode ser utilizado para demonstrar como definir algumas estratégias de coordenação envolvendo tempo e taxa de atualização, descritas por Boukhelifa [Bou 2003]. Como exemplo, desejamos criar uma coordenação que, a cada segundo, rotacione automaticamente a visualização em cinco graus em relação a um eixo qualquer. Para possibilitar essa coordenação, o desenvolvedor poderia criar um componente de interação com um temporizador, no qual o usuário poderia definir o intervalo entre a realização de cada ação e o tipo de transformação a ser aplicada. Esse componente definiria uma ação acionadora que seria disparada automaticamente pelo temporizador e que pode ser utilizada para ativar um OC, que por sua vez dispararia a ação de efetuar a transformação escolhida na respectiva visualização coordenada. 


\subsubsection{Posicionamento de Janelas}

Um usuário poderia desejar coordenar o posicionamento relativo de duas ou mais janelas de exibição referentes a técnicas de visualização, de modo que, uma vez que uma destas janelas fosse movida, as demais acompanhem seu movimento. Outra restrição de posicionamento seria impor que as janelas devem ser reorganizadas de modo que todas continuem em primeiro plano no caso de um reposicionamento, ou que as janelas se mantenham em um arranjo pré-estabelecido. A coordenação do posicionamento de janelas pode ser útil, por exemplo, quando o usuário quer impor a restrição que as janelas não se sobreponham umas as outras. Nesse caso, a movimentação de uma das janelas ativaria a coordenação, e o OC verificaria se ocorre sobreposição de janelas no novo posicionamento. Caso seja necessário, o OC enviaria mensagens informando as novas coordenadas de posição para as janelas que precisam ser reposicionadas.

Esse tipo de coordenação necessita armazenar informações referentes à posição de cada uma das janelas antes da ocorrência do evento que ativa a coordenação. Também precisa redefinir a função de transferência dos parâmetros, que normalmente apenas copia os valores, para que esta calcule a nova posição de cada janela, levando em conta a posição onde cada uma delas estava anteriormente.

Para que esse procedimento seja implementado no modelo $\mathrm{IV}_{\mathrm{CM}}$ é necessário que o desenvolvedor implemente um novo tipo de OC, que armazene uma propriedade extra para cada ação coordenada acionada, correspondente às coordenadas dos cantos superior esquerdo e inferior direito da janela. O novo tipo de OC também deve reimplementar a função de registro de ações para que esta inicialize essa propriedade extra com as coordenadas da posição inicial de cada janela. Finalmente, a função de transferência dos parâmetros deve ser reescrita para realizar os cálculos específicos para o reposicionamento, operando somente com o padrão de mensagem XML, o qual poderia ser descrito da maneira abaixo e que está exemplificado na Figura 6.6.b

- Tipo do Objeto: Janelas

- Parâmetros:

○ Nome: Posicao (xi, yi, xf, yf)

- Descrição: Novas Coordenadas da Janela

○ Tipo: Vetor de quatro inteiros (x_inicial, y_inicial, $\left.x \_f i n a l, y \_i n i c i a l\right)$ 


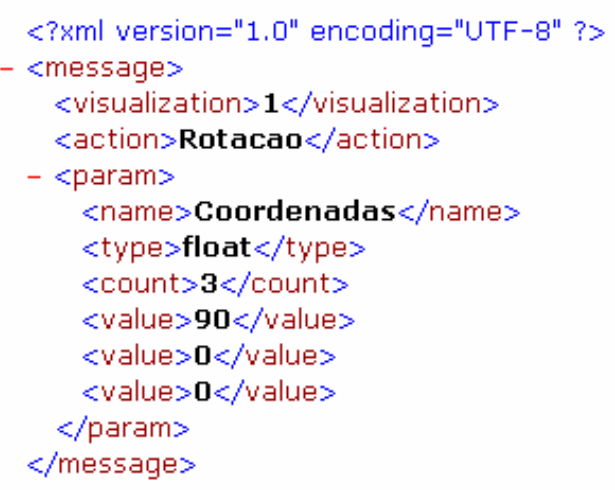

(a)

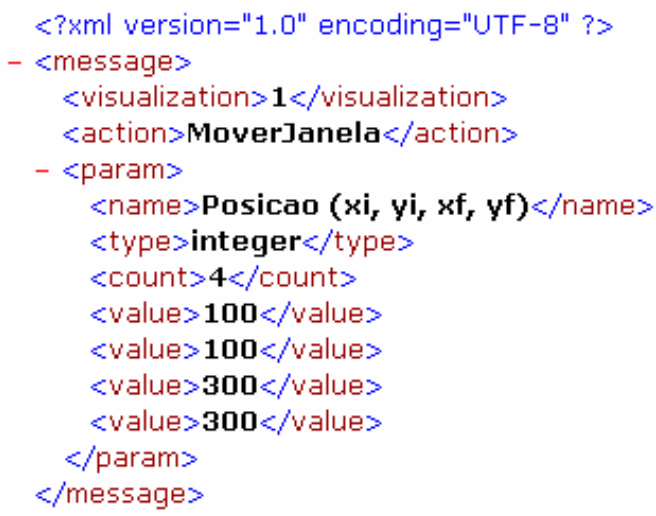

(b)

Figura 6.6 Exemplo de mensagens XML para coordenações de transformações 3D entre múltiplas visualizações (a) e para coordenações envolvendo reposicionamento de janelas (b).

\subsection{Inclusão de Componentes}

Nesta seção descrevemos como alguns componentes funcionais foram incorporados à plataforma InfoVis, de modo a validar as alterações introduzidas e verificar os aspectos de extensibilidade na nova versão da plataforma. Foram incorporados, inicialmente, três módulos que implementam as técnicas Coordenadas Paralelas, Gráficos de Dispersão (Scatterplots) e TreeMaps [Shn 1992], e integram a plataforma Snap [Nor 2002]. A decisão de incluir estes módulos foi motivada pela semelhança entre as propostas de ambas as plataformas e nos mecanismos similares de tratar dados. Os componentes do Snap foram desenvolvidos para funcionar como componentes independentes entre si, e possuem uma classe que trata da comunicação do componente com o núcleo da plataforma. Para realizar o acoplamento desses novos componentes foi necessário apenas reimplementar essa classe de comunicação, de modo a torná-la compatível com o InfoVis.

A inclusão dos novos componentes foi feita implementando-se todos os métodos exigidos, conforme a descrição de Shimabukuro [Shi 2004] e se mostrou bastante simples, embora um pouco trabalhosa devido ao número elevado de funções requisitadas. A coordenação entre os novos CFs e aqueles já implementados na plataforma foi testada com sucesso por meio de coordenações relacionais utilizando várias ações já definidas nos componentes do Snap, sendo que nos exemplos de uso são utilizados alguns desses componentes. 
Também decidiu-se solicitar a outros pesquisadores do grupo de CG\&PI do ICMC incorporassem módulos desenvolvidos à plataforma, como forma de validar informalmente o processo de inclusão de novos CFs. Ao longo da interação com outros pesquisadores, surgiram sugestões para simplificar esse processo, o que resultou em uma nova abordagem para o desenvolvimento dos CFs baseada em uma classe ancestral, a qual possui propriedades e métodos comuns a todo $\mathrm{CF}$, resultando em implementações mais simples e enxutas.

O processo de inclusão de componentes por outros desenvolvedores teve início com a distribuição da última versão da plataforma, juntamente com um exemplo simples de componente, e algumas observações relativas aos procedimentos mais importantes, os quais se encontram descritos no Anexo A. Um pesquisador do grupo que desenvolveu, como trabalho de mestrado na Universidade de Salvador, uma aplicação de visualização utilizando a técnica TreeMap, denominada TreeMiner [Alm 2003], executou a tarefa de adaptar o seu ambiente de modo a transformá-lo em um componente funcional integrado à plataforma InfoVis.

As principais etapas realizadas para o processo de adaptação seguem os passos descritos na Seção 5.2, envolvendo a inclusão de métodos para: carregar os dados, definir as ações, avisar o GA da ocorrência de uma ação acionadora e responder às requisições de ações acionadas do GA. Inicialmente, as maiores dificuldades encontradas diziam respeito a aspectos de interface da plataforma. A transformação entre o conjunto de dados fornecido pela plataforma para um formato que possa ser utilizado pelo componente foi imediata, pois ambos utilizavam o mesmo formato para os dados. Foram definidas duas ações relacionais básicas: "Selecionar" (acionadora) e "Destacar" (acionada) e implementados os procedimentos para o tratamento das mesmas. Devido a uma restrição do Treeminer, na versão atual a seleção só pode ser feita em um elemento de cada vez e o destaque apenas afeta o primeiro elemento da lista de destacados. Mesmo com essa restrição, pode-se dizer que a coordenação funcionou da maneira esperada, pois a comunicação entre os componentes ocorre sem problemas. A Figura 6.7 apresenta um exemplo de uso do componente Treeminer em coordenação com outro componente da plataforma. 


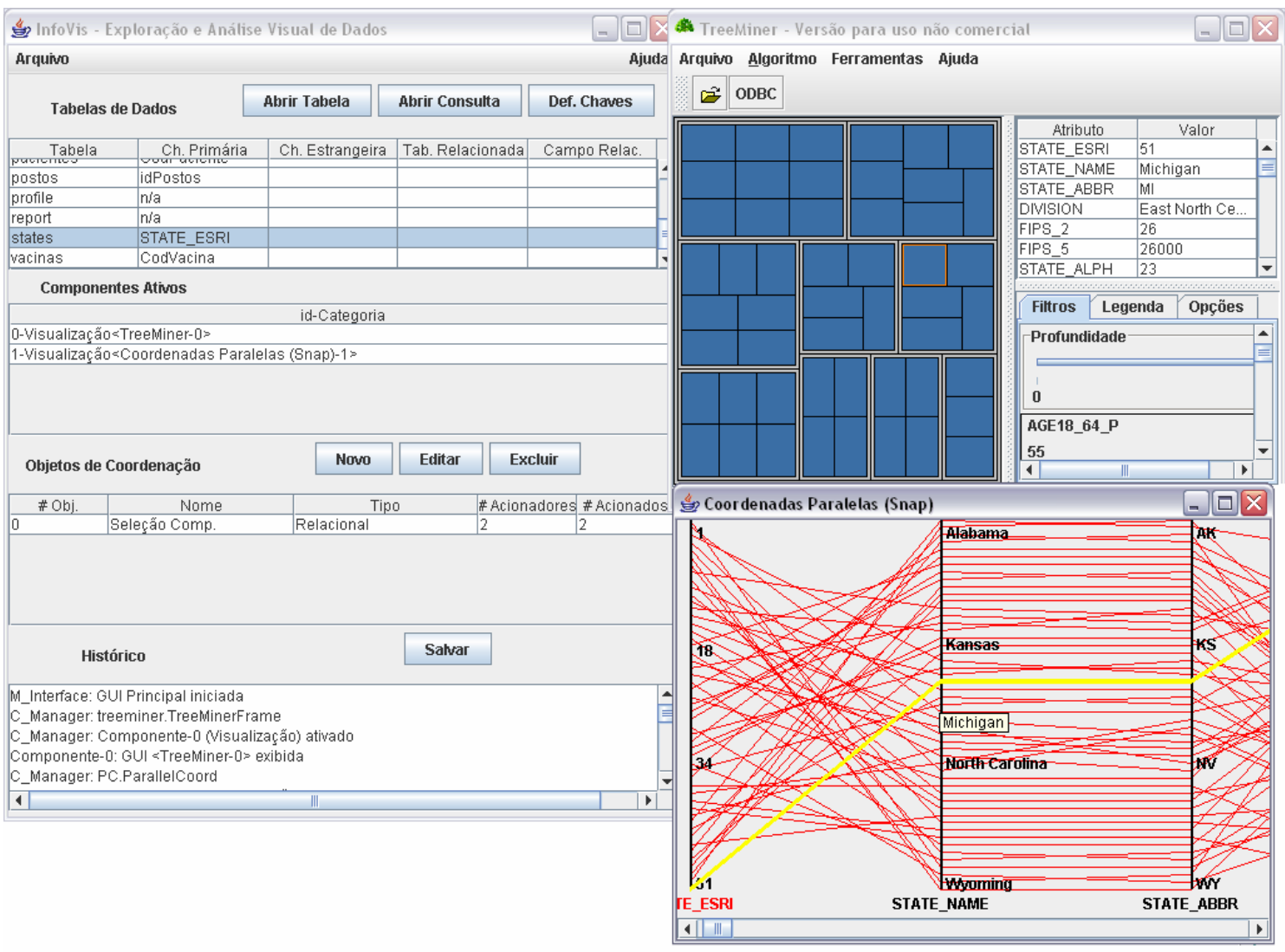

Figura 6.7 Exemplo de uso da plataforma InfoVis: sessão tem como componentes funcionais ativos, operando de maneira coordenada, o Treeminer e o módulo Coordenadas Paralelas do ambiente Snap. O mesmo elemento está selecionado em ambas as visualizações (indicado em amarelo no Coordenadas Paralelas, e em laranja no TreeMiner) 


\section{Conclusões}

Sistemas de visualização de propósito geral, que incorporam diferentes técnicas, oferecem uma abordagem bastante interessante para manipular, interpretar e extrair informações de conjuntos de dados, pois apresentam ao usuário a possibilidade de analisar os seus dados visualmente, sob diferentes perspectivas. Entretanto, é importante tornar aparentes as relações entre múltiplas visualizações e manter a sua consistência. A coordenação entre múltiplas visualizações pode ser utilizada com o propósito de propagar as interações realizadas pelo usuário para todas as visualizações relacionadas. Pode-se coordenar o conteúdo apresentado, a forma de apresentação e o comportamento das visualizações. Sem mecanismos de coordenação a interação do usuário é dificultada pela necessidade de acompanhar as ocorrências e alterações nas múltiplas janelas.

A plataforma InfoVis é um projeto cujo desenvolvimento envolve vários pesquisadores do grupo de Computação Gráfica e Processamento de Imagens do ICMC. Trata-se de uma plataforma de Visualização de uso geral cuja principal característica é a extensibilidade, por permitir aos usuários incluírem novos componentes de visualização de maneira simples e eficiente, permitindo a definição de novas estratégias de coordenação utilizando esses novos componentes. A plataforma é integrada por um Núcleo Básico e um Núcleo Funcional. O Núcleo Básico é estável, e oferece as funcionalidades necessárias para o gerenciamento da plataforma. O Núcleo Funcional é extensível, e seus componentes consistem de módulos que implementam técnicas de visualização ou estratégias genéricas de interação. Como discutido no texto, a versão anterior da plataforma possuía algumas limitações, algumas das quais foram objeto de estudo dessa dissertação, cujo enfoque foi na proposta e implementação de um modelo de coordenação pelo qual os CFs que integram o Núcleo Funcional possam ter ações de interação coordenadas.

Nesse contexto, o modelo de coordenação proposto e implementado neste trabalho manteve a extensibilidade característica da plataforma, sem restringir as coordenações possíveis, fornecendo um conjunto de regras e protocolos para a descrição de ações coordenadas que permite que os diferentes componentes de visualização compartilhem ações coordenadas entre si. São contribuições desse trabalho para a plataforma InfoVis:

- Implementação de um modelo de coordenação genérico que possibilita o estabelecimento de diversas estratégias de coordenação de forma simples, mantendo a característica de fácil extensibilidade da plataforma; 
- Inclusão de um módulo gerenciador de dados via JDBC a fim de padronizar o método de acesso a dados e seus respectivos meta dados na plataforma, e permitir a conectividade a diversas bases de dados, com suporte ao uso de relações presentes no Banco de Dados;

- Inclusão de novos CFs que implementam algumas técnicas de visualização de uso geral bastante conhecidas e utilizadas, a saber: Coordenadas Paralelas, Gráficos de Dispersão e Treemap.

- Adequação do processo de incorporação de novos componentes à plataforma, visando maior simplicidade e compatibilidade com o modelo de coordenação;

- Implementação de um método para armazenamento e recuperação do cenário atual do sistema (dados da sessão), incluindo componentes funcionais ativos e coordenações estabelecidas entre eles.

Entre as limitações deste trabalho pode-se citar a falta de um número maior de ações definidas para cada $\mathrm{CF}$, a incompatibilidade de alguns drivers $\mathrm{ODBC}$, que resulta na falha da definição automática das chaves de cada tabela e a interface com o usuário, a qual ainda gera alguma confusão para executar algumas tarefas simples como a abertura de uma conexão ODBC que necessita da configuração externa do driver e a definição manual das chaves das tabelas

Como este é um projeto de longa duração, a ser continuado por outros pesquisadores, pode-se citar algumas sugestões de melhorias para as próximas versões:

- Criação de uma interface gráfica para a inicialização das visualizações e estabelecimento das coordenações;

- Incorporação de novos componentes de visualização que implementam técnicas de visualização ainda não presentes na plataforma;

- Adição de novas ações coordenadas aos CFs já presentes, a fim de ampliar as possibilidades de coordenações entre os mesmos, como por exemplo ações para filtragem de dados ou ações que possibilitem o uso de duas cores para o destaque dos elementos. 


\section{Referências Bibliográficas}

[Ahl 1992] Ahlberg, C.; Williamson, C.; Shneiderman, B. - Dynamic Queries for Information Exploration: An Implementation and Evaluation, Proceedings ACM Conference on Human Factors in Computer Systems, pp. 619-626, 1992

[Ahl 1995] Ahlberg, C.; Wistrand, E. - IVEE: An environment for automatic creation of dynamic queries applications, Proceedings of CHI '95, pp 15-16, Maio/1995.

[Alm 2003] Almeida M. Uma ferramenta para mineração visual de dados usando mapas em árvore e suas aplicações, Universidade Salvador, Dissertação de Mestrado, Salvador, 2003

[Bal 2000] Baldonado, M.Q.W.; Woodruff, A.; Kuchinsky, A. - Guidelines for Using Multiple Views in Information Visualization, Proceedings of the Advanced Visual Interfaces, pp. 110-119, 2000

[Bou 2003] Boukhelifa, N.; Roberts, J.C.; Rodgers, P.J. - A coordination model for exploratory multi-view visualization, IEEE Proceedings of the International Conference on Coordinated and Multiple Views in Exploratory Visualization CMV2003, pp. 76-85, 2003

[Bra 2003] Branco, V.M.A. - Visualização como Suporte à Exploração de Dados Pluviométricos, Dissertação de Mestrado, ICMC/USP, São Carlos-SP, Abril/2003

[Car 1999] Card, S.K.; Mackinlay, J.D. Shneiderman, B. (eds.) - Readings in Information Visualization - Using Vision to Think, Morgan Kaufmann, San Francisco, CA, 1999.

[Hab 1990] Haber, R.; McNabb, D. - Visualization idioms: a conceptual model for scientific visualization systems, In: G. M. Nielson, B. Shriver, L.J. Rosenblum (Editores). Visualization in Scientific Computing, pp. 74-93, 1990

[Ins 1992] Inselberg, A.; Dimsdale, B. - Parallel Coordinates: A Tool for Visualizing Multi-Dimensional Geometry, Proceedings of Visualization '90, pp. 361370,1990

[Kei 1996] Keim, D.A; Kriegel, H.-P. - Visualization Techniques for Mining Large Databases: A Comparison, IEEE Transacations on Knowledge and Data Engineering, v. 8(6), pp. 923-938, Dezembro/1996.

[Kei 2002] Keim, D. - Information Visualization and Visual Data Mining, IEEE Transactions on Visualization and Computer Graphics, v. 7(1), JaneiroMarço/2002 
[Liv 1997] Livny, M.; Ramakrishnan, R.; Beyer, K.; Chen, G.; Donjerkovic, D.; Lawande, S.; Myllymaki, J.; Wenger, K. - DEVise: Integrated querying and visualization of large datasets, Proceedings of SIGMOD '97, pp 301-312, 1997.

[McC 1987] McCormick, B.; DeFanti,T.; Brown, R. - Visualization in scientific computing, Computer Graphics, v.21(6), Novembro/1987

[Nor 1999] North, C.; Shneiderman, B. - Snap-Together Visualization: Coordinating Multiple Views to Explore Information, Technical Report CS-TR-4020, 1999

[Nor 2000] North, C.; Shneiderman, B. - Snap-Together Visualization: A User Interface for Coordinating Visualizations via Relational Schemata, Proceedings of the ACM Advanced Visual Interfaces 2000, pp. 128-135, Maio/2000

[Nor 2000a] North, C.; Shneiderman, B. - Snap-Together Visualization: Can Users Construct and Operate Coordinated Views?, International Journal of Human-Computer Studies, Academic Press, 53(5), pp. 715-739, Novembro/2000

[Nor 2002] North, C.; Conklin, N.; Idukuri, K.; Saini, V. - Visualization Schemas and a Web-based Architecture for Custom Multiple-View Visualization of Multiple-Table Databases, Information Visualization, Palgrave-Macmillan, Dezembro/2002

[Oli 2003] Oliveira, M.C.F.; Levkowitz, H. - From Visualization to Visual Data Mining: A Survey, IEEE Transactions on Visualization \& Computer Graphics, pp. 378-394, v. 9(3), Julho-Setembro/2003

[Pat 2001] Pattison T., Phillips M. - View coordination architecture for information visualization, Australian Symposium on Information Visualisation, vol. 9, pp. 165-171, 2001

[Shi 2004] Shimabukuro M.H. - Modelo para um Ambiente Adaptável de Visualização Interativa Aplicado a Dados Espaço-Temporais, ICMCUSP, Tese de Doutorado, São Carlos, 2004

[Shn 1992] Shneiderman, B. - Tree visualization with treemaps: a 2-D space-filling approach, ACM Transactions on Graphics, vol. 11(1), pp. 92-99, Janeiro/1992.

[Shn 1994] Shneiderman, B. - Dynamic Queries for Visual Information Seeking. Technical Report UMCP-CSD CS-TR-3022, 1994

[Shn 1996] Shneiderman, B. - The Eyes Have It: A Task by Data Type Taxonomy for Information Visualizations, Proceedings of the 1996 IEEE Symposium on Visual Languages, IEEE Computer Society, pp. 336-343, Boulder, CO, Setembro/1996 
[War 1994] Ward, M.O. - XmdvTool: Integrating Multiple Methods for Visualizing Multivariate Data. Proceedings of Visualization '94, pp. 326-33, 1994

[Wea 2004] Weaver, C. E. - Building Highly-Coordinated Visualizations in Improvise, Proceedings of Information Visualization 2004, Outubro/2004. 


\section{Anexo A - Código Exemplo de Componente Funcional}

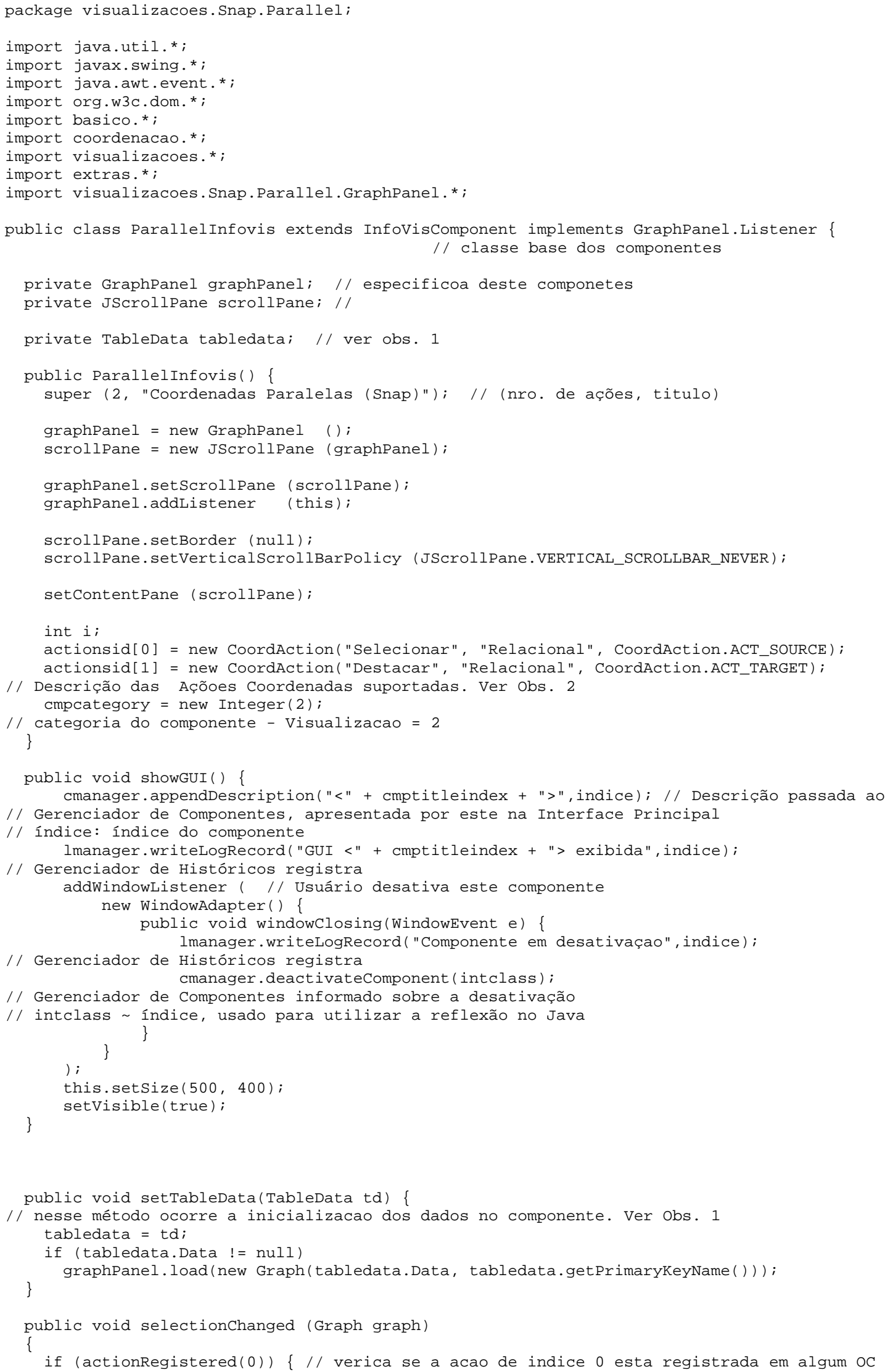




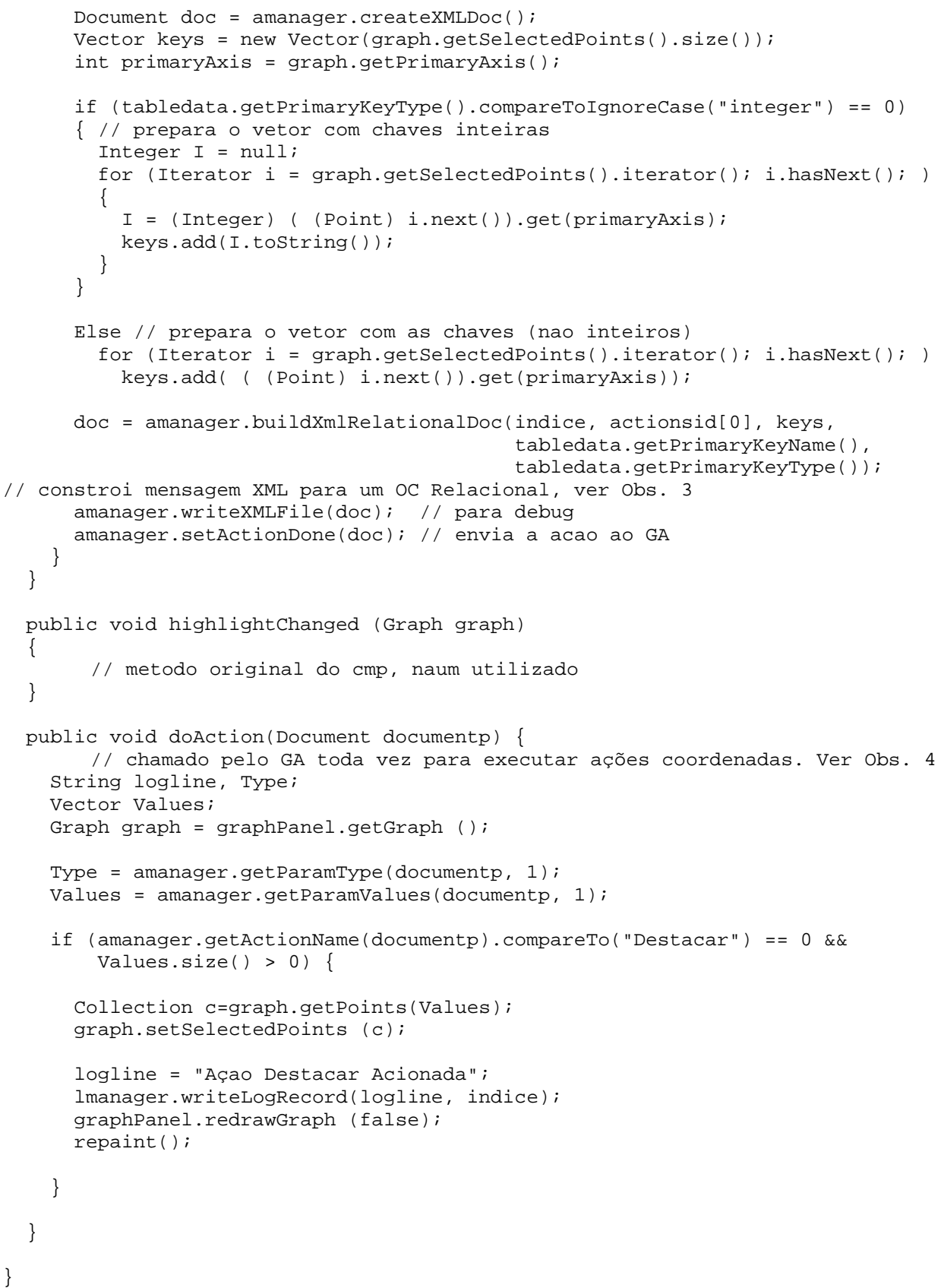

\section{Observações}

1. A classe TableData contém informações sobre os dados contidos em uma tabela e suas chaves. É passado pelo Gerenciador de Dados aos componentes pelo método setTableData. Nesse método o desenvolvedor do componente deve inicializar os dados. A classe TableData possui as seguintes propriedades e métodos: 
- ResultSet Data: Propriedade que contém os dados propriamente ditos no formato utilizado pela linguagem.

- String getPrimaryKeyName(): retorna o nome do campo utilizado como chave principal.

- $\quad$ int getPrimaryKeyPos(): retorna a posição do campo utilizado como chave principal.

- String getPrimaryKeyType(): retorna o tipo do campo utilizado como chave principal.

- String getForeignKeyName(), int getPrimaryKeyPos(), String getPrimaryKeyType(): idem aos métodos acima, mas com o campo utilizado como chave estrangeira.

- String getForeignTable(): retorna o nome da tabela relacionada pela chave estrangeira.

- String getForeignTableField(): retorna o nome do campo relacionado com a chave estrangeira na tabela relacionada.

- String getForeignTablePKey(): retorna o nome do campo chave primária da tabela relacionada pela chave estrangeira.

2. As ações coordenadas que um componente pode realizar são registradas no vetor actionsid. Cada elemento do vetor é um objeto da classe CoordAction, cujo construtor tem o formato:

CoordAction(String name, string objtype, int type)

em que name é o nome da ação que aparecerá na interface, objtype é o nome do tipo de objeto que suporta essa ação (por exemplo, "Relacional”, utilizado para coordenações envolvendo chaves de registros) e type pode receber os valores: CoordAction.ACT_SOURCE para ações acionadoras da coordenação e CoordAction.ACT_TARGET para ações acionadas pela coordenação

3. Sobre a ativação da coordenação.

Para ativar a coordenação é necessário primeiramente construir a mensagem XML e depois enviá-la para o Gerenciador de Ações (GA). Existem métodos que criam automaticamente as mensagens para coordenações específicas para determinados tipos de objetos de coordenação. Nos caso do OC Relacional, o método utilizado é:

public Document buildXmlRelationalDoc(int index, CoordAction action, Vector items, String KeyName, string Keytype) 
em que index é o índice do componente atribuído pelo Gerenciador de Componentes, action é um objeto do tipo CoordAction que define a ação, items é o vetor com os valores das chaves dos registros afetados, KeyName é o nome da chave principal, KeyType é o tipo da chave primaria.

Para enviar as mensagens, utiliza-se o método setActionDone, passando como parâmetro a mensagem XML. O método writeXMLFile pode ser utilizado para produzir um arquivo XML a fim de possibilitar a observação do conteúdo da mensagem.

\section{Efetuando ações.}

Quando o GA deseja que um componente efetue uma ação coordenada em razão da ativação de uma coordenação, ele chama o método doAction do componente e passa como parâmetro a mensagem XML. Para facilitar a recuperação de dados específicos contidos na mensagem, o GA possui os seguintes métodos, todos eles utilizando a mensagem XML como parâmetro.

- int getIndex(Document Doc): retorna o índice do componente que criou a mensagem ou o índice do componente o qual a mensagem é destinada.

- public String getActionName(Document Doc): retorna a descrição da ação realizada ou a descrição da ação a ser realizada

- public String getParamName(Document Doc, int $n$ ): retorna a descrição do parâmetro $n$ (sendo $n=1$ o primeiro parâmetro).

- public String getParamType(Document Doc, int $n$ ): retorna o tipo associado ao parâmetro $n$.

- Vector getParamValues(Document Doc, int $n$ ): retorna um vetor contendo objetos com os valores do parâmetro $n$. Utiliza o método acima para definição do tipo de objeto a ser retornado.

- Vector getStringParamValues(Document Doc, int $n$ ): retorna um vetor contendo os valores do parâmetro $n$ no formato de cadeias de caracteres (strings) . 